\title{
AVALIAÇÃO DE DOSÍMETROS TERMOLUMINESCENTES EMPREGANDO OBJETOS SIMULADORES EQUIVALENTES À ÁGUA PARA APLICAÇÃO NA DOSIMETRIA DE FEIXES CLÍNICOS DE ELÉTRONS
}

Amanda Bravim

Dissertação apresentada como parte dos requisitos para obtenção do Grau de Mestre em Ciências na Área de Tecnologia Nuclear - Aplicações.

Orientadora:

Profa. Dra. Letícia L. C. Rodrigues

São Paulo 
A Deus, pois sem Ele nada seria possível. Aos meus pais e avós, minha base, onde busquei forças para mais esta conquista. 
"A ciência humana de maneira nenhuma nega a existência de Deus. Quando considero quantas e quão maravilhosas coisas o homem compreende, pesquisa e consegue realizar, então reconheço claramente que o espírito humano é obra de Deus, e a mais notável." (Galileu Galilei) 


\section{AGRADECIMENTOS}

À minha orientadora, Dra. Letícia L. C. Rodrigues, pelo incentivo, confiança, paciência, amizade e por todo conhecimento a mim repassado durante esses anos. Grande parte do meu amadurecimento e crescimento deve-se à oportunidade por ela concedida.

Ao IPEN, na pessoa do Sr. Superintendente Dr. Nilson Dias Vieira Júnior, pela oportunidade de executar este trabalho.

Ao Conselho Nacional de Desenvolvimento Científico e Tecnológico (CNPq), pela bolsa de mestrado que permitiu a dedicação exclusiva a esse trabalho de pesquisa.

À Dra. Linda V. E. Caldas, pela amizade, disponibilidade, preocupação e apoio durante toda a realização desse trabalho.

Ao Dr. José Carlos da Cruz, físico chefe do Setor de Radioterapia do Hospital Israelita Albert Einstein, por autorizar as irradiações e ao físico Roberto Sakuraba pelas orientações e auxílio nas irradiações dos dosímetros. Sua ajuda foi de extrema importância.

Aos meus pais, Ademir e Sueli, pelo amor, carinho, pelas palavras de incentivo e por sempre acreditarem na minha capacidade. É sempre por eles que eu sigo. São exemplos para mim de fé, força, companheirismo, humildade, coragem e principalmente de amor sincero.

Ao meu irmão Guilherme, amor sem tamanho, inexplicável. Distantes fisicamente, mas com pensamentos sempre interligados. Senti sua falta a cada segundo longe. 
Aos meus avós, Benedito e Eurides, por toda a preocupação, atenção e mimo. A vontade de estar perto fez as semanas parecerem intermináveis, mas a admiração e orgulho que eu via em seus olhos me motivaram a seguir em frente para mais essa vitória.

A toda a minha família, por estar presente e por colaborar, cada um da sua maneira, para o término desse trabalho. Em especial aos meus primos Daniel Carvalho e Gustavo Carvalho, que me receberam de braços abertos em sua casa e podem não saber, mas foram importantíssimos no início da minha jornada.

Aos amigos de Botucatu, Fernanda Teles, Letícia Vieira e Luana Fazzio, pela amizade sempre verdadeira e por estarem ao meu lado em todos os momentos.

Aos amigos de São Paulo, Andréia Barreto Brito, Cristina Lau Chu, Elaine Wirney Martins, Fernanda Beatrice Nonato, Kátia Suemi Tanimoto, Roberto Hazenfratz Marks e Tassiane Matsubara, pela amizade, companheirismo e por todos os ótimos momentos de descontração. Com vocês por perto tudo pareceu mais fácil. Também ao Cléber Feijó Silva, Luciana Cardoso Matsushima, Maíra Góes Nunes e Thyago Mangueira e pelo apoio, pelos esclarecimentos às minhas eternas dúvidas e por terem me acolhido de braços abertos.

A todos do GMR-IPEN que direta ou indiretamente contribuíram para a realização deste trabalho. 


\title{
AVALIAÇÃO DE DOSÍMETROS TERMOLUMINESCENTES EMPREGANDO OBJETOS SIMULADORES EQUIVALENTES À ÁGUA PARA APLICAÇÃO NA DOSIMETRIA DE FEIXES CLÍNICOS DE ELÉTRONS
}

\author{
Amanda Bravim
}

\begin{abstract}
RESUMO
A dosimetria em Radioterapia prevê a calibração do feixe de radiação e a dosimetria de rotina para controle de qualidade, pois o seu principal objetivo é determinar, com maior precisão, a dose absorvida pelo tumor. Este trabalho tem como objetivo avaliar o comportamento de três dosímetros termoluminescentes na dosimetria de feixes clínicos de elétrons. 0 desempenho de detectores de sulfato de cálcio dopado com disprósio ( $\mathrm{CaSO}_{4}$ :Dy) produzidos pelo IPEN foi comparado com o de dois dosímetros comercialmente disponíveis pela Harshaw, ambos denominados TLD-100, porém com dimensões distintas. Os dosímetros foram caracterizados com a utilização de objetos simuladores de água, água sólida RMI-457 e PMMA em campos de radiação de elétrons de 4, 6, 9, 12 e 16 MeV. Também foram realizadas medidas em feixes de fótons de 6 e $15 \mathrm{MV}$ (2 e $5 \mathrm{MeV}$ ) apenas para comparação de resultados. As curvas de dose-resposta foram obtidas para a radiação gama do ${ }^{60}$ Co no ar e em condições de equilíbrio eletrônico e para feixes clínicos de fótons e elétrons nas profundidades de máxima dose. A sensibilidade, a reprodutibilidade, a eficiência intrínseca e a dependência energética dos dosímetros termoluminescentes foram estudadas. $0 \mathrm{CaSO}_{4}$ :Dy apresentou comportamento semelhante ao dos TLD-100 com uma vantagem em relação à sensibilidade para os feixes e doses de radiação estudados. Sendo assim, o dosímetro produzido pelo IPEN pode ser considerado uma nova alternativa para a dosimetria nos departamentos de Radioterapia.
\end{abstract}




\title{
EVALUATION OF THERMOLUMINESCENT DOSIMETERS USING WATER EQUIVALENT PHANTOMS FOR APPLICATION IN CLINICAL ELECTRONS BEAMS DOSIMETRY
}

\author{
Amanda Bravim
}

\begin{abstract}
The dosimetry in Radiotherapy provides the calibration of the radiation beam as well as the quality control of the dose in the clinical routine. Its main objective is to determine with greater accuracy the dose absorbed by the tumor. This study aimed to evaluate the behavior of three thermoluminescent dosimeters for the clinical electron beam dosimetry. The performance of the calcium sulfate detector doped with dysprosium ( $\mathrm{CaSO}_{4}$ : Dy) produced by IPEN was compared with two dosimeters commercially available by Harshaw. Both are named TLD-100, however they differ in their dimensions. The dosimeters were evaluated using water, solid water (RMI-457) and PMMA phantoms in different exposure fields for 4, 6, 9, 12 and $16 \mathrm{MeV}$ electron beam energies. It was also performed measurements in photon beams of 6 and $15 \mathrm{MV}$ ( 2 and $5 \mathrm{MeV}$ ) only for comparison. The dose-response curves were obtained for the ${ }^{60} \mathrm{Co}$ gamma radiation in air and under conditions of electronic equilibrium, both for clinical beam of photons and electrons in maximum dose depths. The sensitivity, reproducibility, intrinsic efficiency and energy dependence response of dosimeters were studied. The $\mathrm{CaSO}_{4}$ : Dy showed the same behavior of TLD-100, demonstrating only an advantage in the sensitivity to the beams and radiation doses studied. Thus, the dosimeter produced by IPEN can be considered a new alternative for dosimetry in Radiotherapy departments.
\end{abstract}




\section{SUMÁRIO}

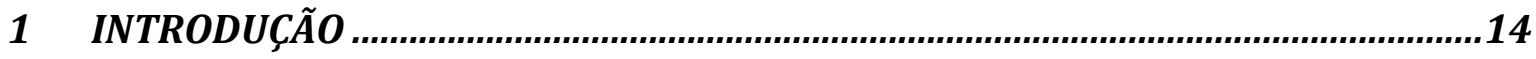

2 OBJETIVOS

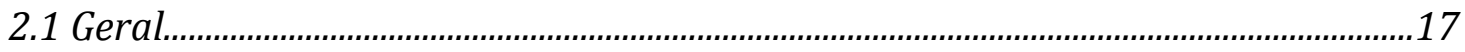

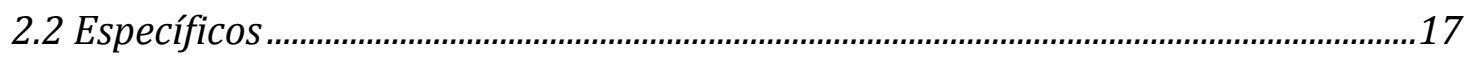

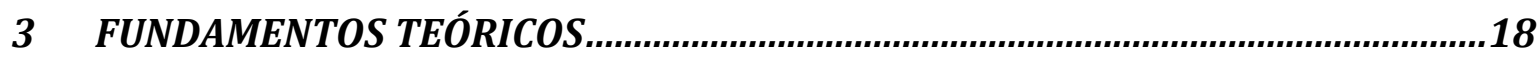

3.1 Interação da Radiação com a Matéria ……………………..........................................18

3.1.1 Fótons ...........................................................................................................18

3.1.1.1 Espalhamento Coerente .....................................................................19

3.1.1.2 Efeito Fotoelétrico ...............................................................................20

3.1.1.3 Efeito Compton …..............................................................................21

3.1.1.4 Produção de Pares ....................................................................................22

3.1.2 Elétrons .........................................................................................................23

3.1.2.1 Interações com elétrons orbitais...........................................................24

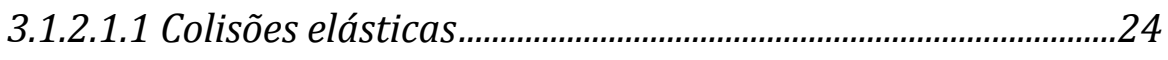

3.1.2.1.2 Colisões inelásticas..................................................................24

3.1.2.2 Interações com núcleos atômicos.............................................................24

3.2 Radiação Ionizante na Medicina....................................................................................25

3.3 Radioterapia …...........................................................................................................26

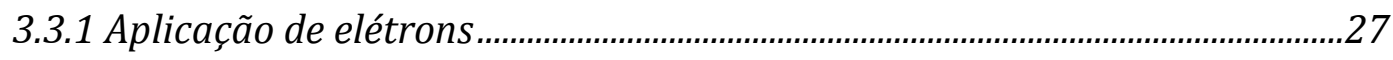

3.4.2 Aceleradores Lineares ..........................................................................................28

3.3.3 Dosimetria em Radioterapia ................................................................................29

3.4 Dosimetria Termoluminescente....................................................................................30

3.4.1Termoluminescência (TL)......................................................................................30

3.4.2 História da Dosimetria Termoluminescente......................................................31

3.4.3 Aplicações Clínicas da Dosimetria Termoluminescente .....................................32

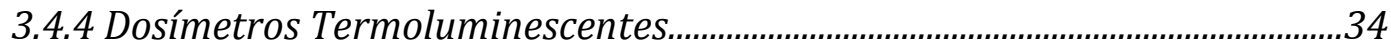

3.4.4.1 Propriedades Dosimétricas....................................................................34

3.4.4.1.1 Curva de Emissão ......................................................................37

3.4.4.1.2 Variação da Resposta TL com a Dose..................................37 
3.4.4.1.3 Sensibilidade .........................................................................38

3.4.4.1.4 Limite Inferior de Detecção (LID)....................................40

3.4.4.1.5 Estabilidade e Reprodutibilidade.......................................40

3.4.4.1.6 Decaimento Térmico do Sinal TL......................................41

3.4.4.1.7 Eficiência Intrínseca ............................................................41

3.4.4.2 Tratamento Térmico ..........................................................................42

3.4.4.3 Armazenamento e manuseio................................................................42

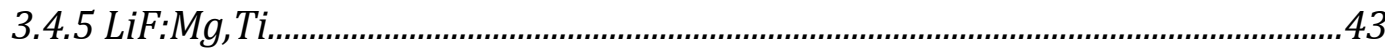

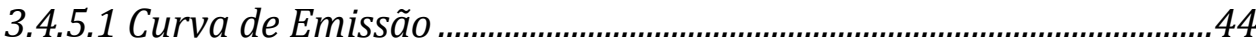

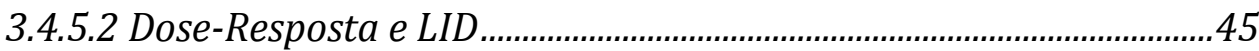

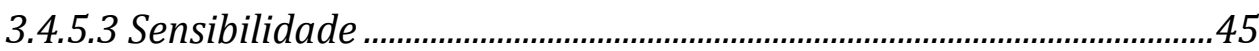

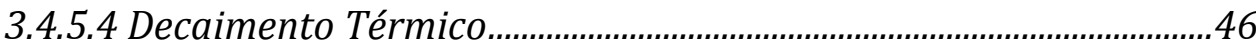

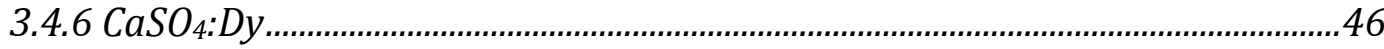

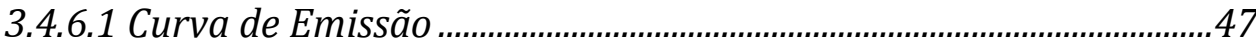

3.4.6.2 Dose-Resposta e LID ..............................................................................47

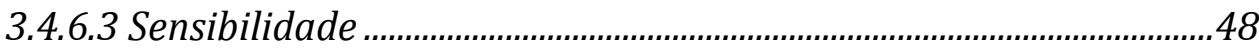

3.4.6.4 Decaimento Térmico..............................................................................48

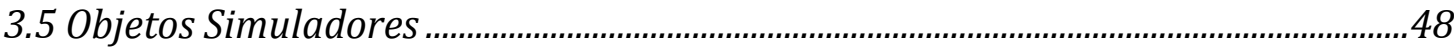

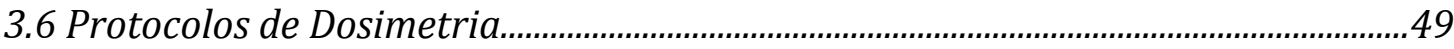

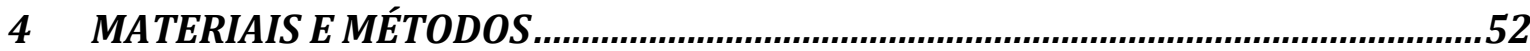

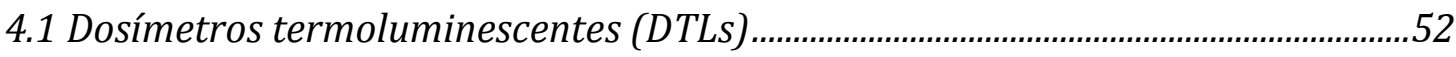

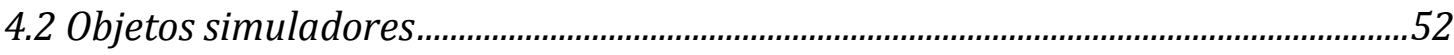

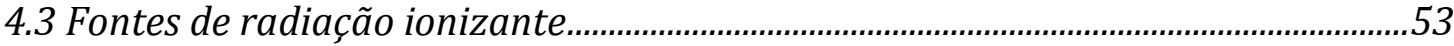

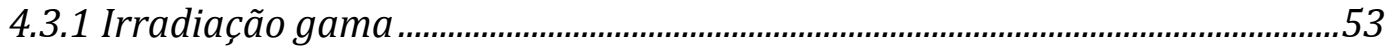

4.3.2 Irradiação com feixe de elétrons e fótons .........................................................54

4.4 Tratamento térmico dos dosímetros ...........................................................................55

4.5 Acondicionamento dos dosímetros.................................................................................56

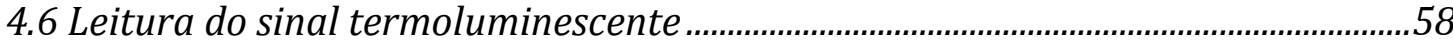

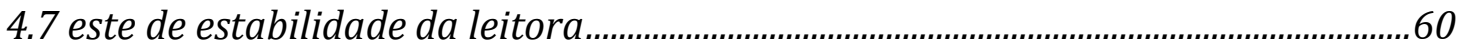

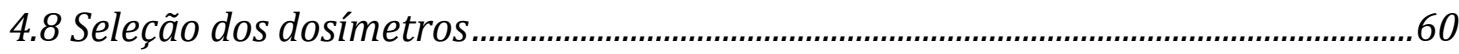

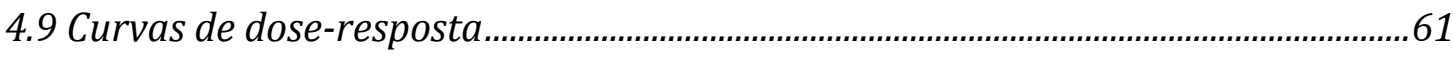

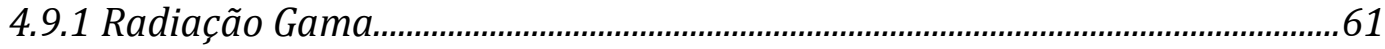

4.9.2 Feixe de Elétrons e Fótons..................................................................................61 


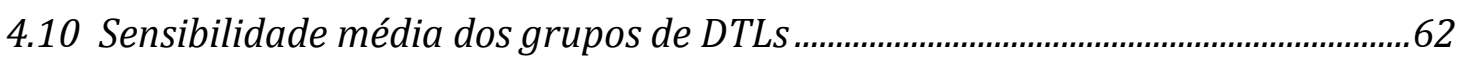

4.11 Reprodutibilidade da resposta TL aos feixes de elétrons e fótons..........................62

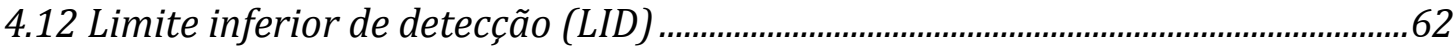

4.13 Eficiência intrínseca dos DTLs .............................................................................63

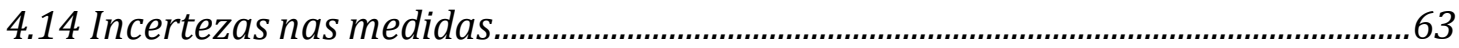

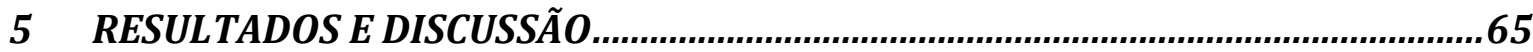

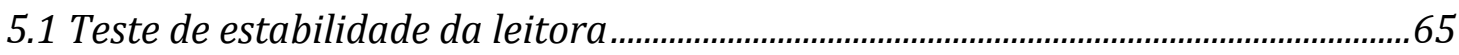

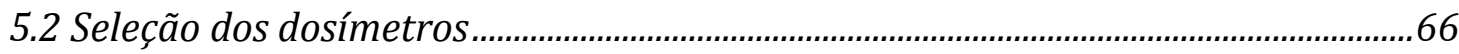

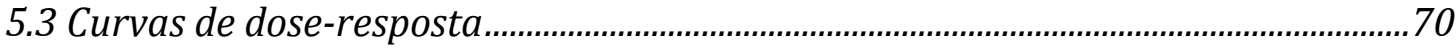

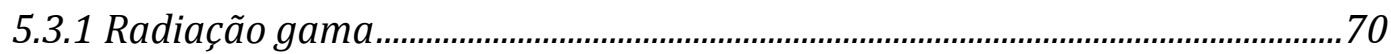

5.3.2 Feixes de Elétrons e Fótons................................................................................71

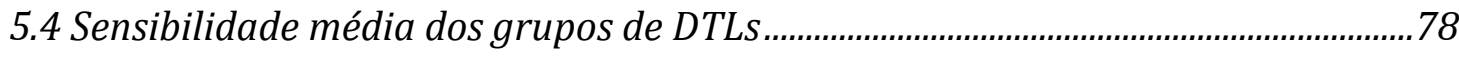

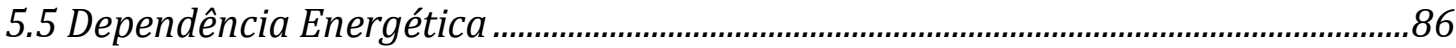

5.6. Reprodutibilidade da resposta TL aos feixes clínicos de fótons e elétrons ........ 87

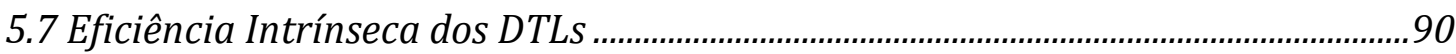

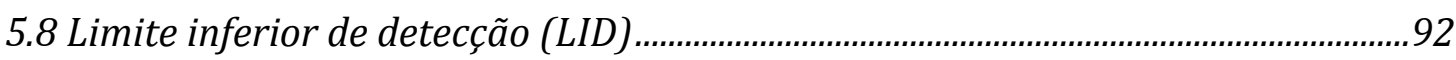

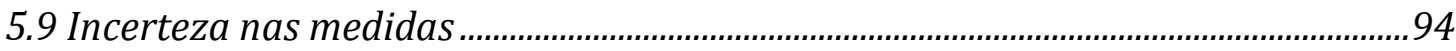

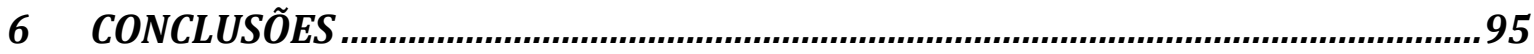




\section{LISTA DE FIGURAS}

FIGURA 1 - Predominância das interações de fótons com a matéria ...................................................19

FIGURA 2 - Processo de Espalhamento Rayleigh.................................................................................20

FIGURA 3 - Processo de Efeito Fotoelétrico............................................................................................21

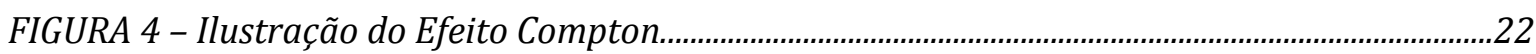

FIGURA 5 - Processo de Produção de Pares..................................................................................................23

FIGURA 6 - Interação de um elétron com um átomo do meio...............................................................24

FIGURA 7 - Acelerador Linear da marca Varian, modelo Clinac 2100C.............................................29

FIGURA 8 - Excitação e estimulação térmica em um cristal TL ...............................................................30

FIGURA 9 - Curva de dose-resposta de um material TL em função da exposição................................38

FIGURA 10 - Curva de emissão TL do LiF:Mg,Ti.................................................................................44

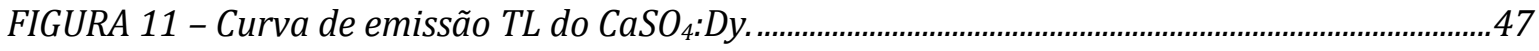

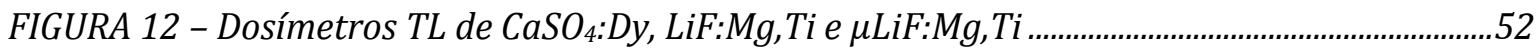

FIGURA 13 - Arranjo experimental da fonte de ${ }^{60}$ Co do LMD/IPEN …….............................................53

FIGURA 14 - Arranjo experimental do sistema de irradiação dos dosímetros em objeto

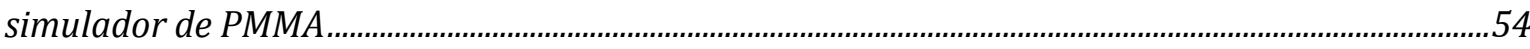

FIGURA 15 - Objeto simulador de águae arranjo experimental da irradiação dos DTLs em objeto simulador de água......................................................................................................................5

FIGURA 16 - (a) Forno tipo mufla marca VULCAN; (b) Estufa cirúrgica marca FANEM;

(c) Dosímetros de CaSO 4 :Dy acomodados na bandeja de alumínio. .56

FIGURA 17 - Posicionamento dos DTLs de CaSO4:Dy, em placas de PMMA, para irradiação no ar em fonte de ${ }^{60} \mathrm{Co}$.

FIGURA 18 - Irradiação dos DTLs na fonte de ${ }^{60}$ Co do LMD/IPEN.

FIGURA 19 - Dosímetros embalados em plástico resistente para irradiação no acelerador linear.

FIGURA 20 - (a) Sistema de leitura TL; (b) Prancheta metálica da leitora TL . .59

FIGURA 21 - Média das leituras de luz padrão de cada dia, médias de todos os dias de leitura e limite máximo de aceitação.

FIGURA 22 - Média das leituras de razão sinal/ruído de cada dia, médias de todos os dias de leitura e limite máximo de aceitação.

FIGURA 23 - Histogramas da sensibilidade da resposta TL das pastilhas de CaSO $4:$ Dy....................67

FIGURA 24 - Histogramas da sensibilidade da resposta TL das pastilhas de LiF:Mg,Ti...................68

FIGURA 25 - Histogramas da sensibilidade da resposta TL das pastilhas de $\mu$ LiF:Mg,Ti.................69 
FIGURA 26 - Curva de dose-resposta dos dosímetros de LiF:Mg,Ti, $\mu$ LiF:Mg,Ti e CaSO 4 :Dy à radiação de fótons do ${ }^{60}$ Co para irradiações no ar.

FIGURA 27 - Curvas de dose-resposta do CaSO 4 :Dy, LiF:Mg,Ti e $\mu$ LiF:Mg,Ti a fótons de $6 M V$

FIGURA 28 - Curvas de dose-resposta do CaSO 4 :Dy, LiF:Mg,Ti e $\mu$ LiF:Mg,Ti a fótons de $15 M V$.

FIGURA 29 - Curvas de dose-resposta do CaSO $4: D y$, LiF:Mg,Ti e $\mu$ LiF:Mg,Ti a elétrons de $4 \mathrm{MeV}$

FIGURA 30 - Curvas de dose-resposta do CaSO $4: D y$, LiF:Mg,Ti e $\mu$ LiF:Mg,Ti a elétrons de $6 \mathrm{MeV}$.

FIGURA 31 - Curvas de dose-resposta do CaSO 4 :Dy, LiF:Mg,Ti e $\mu$ LiF:Mg,Ti a elétrons de $9 \mathrm{MeV}$. 75

FIGURA 32 - Curvas de dose-resposta do CaSO $4: D y$, LiF:Mg,Ti e $\mu$ LiF:Mg,Ti a elétrons de $12 \mathrm{MeV}$..

FIGURA 33 - Curvas de dose-resposta do CaSO 4 :Dy, LiF:Mg,Ti e $\mu$ LiF:Mg,Ti a elétrons de $16 \mathrm{MeV}$

FIGURA 34 - Sensibilidade TL do $\mathrm{CaSO}_{4}: \mathrm{Dy}$, LiF: Mg,Ti e $\mu$ LiF:Mg,Ti à radiação de fótons do ${ }^{60}$ Co para irradiações no ar.

FIGURA 35 - Sensibilidade TL do CaSO 4 :Dy, LiF: Mg,Ti e $\mu$ LiF:Mg,Ti à radiação de fótons de $6 M V$...

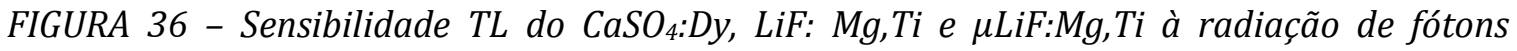
de $15 \mathrm{MV}$. .80

FIGURA 37 - Sensibilidade TL do CaSO 4 :Dy, LiF: Mg,Ti e $\mu$ LiF:Mg,Ti à radiação de elétrons de $4 \mathrm{MeV}$.

FIGURA 38 - Sensibilidade TL do CaSO 4 :Dy, LiF: Mg,Ti e $\mu$ LiF:Mg,Ti à radiação de elétrons de $6 \mathrm{MeV}$.

FIGURA 39 - Sensibilidade TL do CaSO 4 :Dy, LiF: Mg,Ti e $\mu$ LiF:Mg,Ti à radiação de elétrons de $9 \mathrm{MeV}$.

FIGURA 40 - Sensibilidade TL do $\mathrm{CaSO}_{4}$ :Dy, LiF: Mg,Ti e $\mu \mathrm{LiF}: M g$,Ti à radiação de elétrons de $12 \mathrm{MeV}$..

FIGURA 41 - Sensibilidade TL do CaSO 4:Dy, LiF: Mg,Ti e $\mu$ LiF:Mg,Ti à radiação de elétrons de $16 \mathrm{MeV}$.. 


\section{LISTA DE TABELAS}

TABELA 1 - Características dos dosímetros termoluminescentes. . .36

TABELA 2 - Propriedades do TLD-100 .44

TABELA 3 - Características dos picos de emissão do LiF:Mg,Ti. .45

TABELA 4 - Propriedades dosimétricas e físico-químicas do CaSO ${ }_{4}: D y$ 46

TABELA 5 - Características físico-químicas e fator de escalonamento de profundidades para o PMMA, água sólida RMI-457 e água .49

TABELA 6 - Profundidades de máxima dose utilizadas para a irradiação dos DTLs. . .55

TABELA 7 - Controle de qualidade dos DTLs utilizados na dosimetria do feixe de radiação.........60

TABELA 8 - Valores de energia e doses utilizados para irradiação dos DTLs no HIAE.. .61 TABELA 9 - Sensibilidade relativa ao ${ }^{60} \mathrm{Co}\left(S_{D T L, E}{ }^{60} C o\right)$ para os três tipos de DTLs irradiados com feixe de fótons. 87

TATABELA 10 - Sensibilidade relativa ao ${ }^{60} \mathrm{Co}\left(S_{D T L, E}{ }^{60}{ }^{C o}\right)$ para os três tipos de DTLs irradiados com feixe de elétrons. .88

TABELA 11 - Reprodutibilidade do CaSO 4 :Dy, LiF:Mg,Ti e $\mu$ LiF:Mg,Ti para cada energia dos feixes de fótons e elétrons. .89

TABELA 12 - Coeficientes angulares das curvas de calibração e eficiência intrínseca do $\mathrm{CaSO}_{4}$ :Dy para cada energia dos feixes de fótons e elétrons. 90

TABELA 13 - Coeficientes angulares das curvas de calibração e eficiência intrínseca do LiF:Mg,Ti para cada energia dos feixes de fótons e elétrons

TABELA 14 - Coeficientes angulares das curvas de calibração e eficiência intrínseca do $\mu$ LiF:Mg,Ti para cada energia dos feixes de fótons e elétrons.

TABELA 15 - Valores de leituras TL médias dos dosímetros não-irradiados. .92 TABELA 16 - Limite inferior de detecção (LID) do CaSO 4 :Dy para radiação gama do ${ }^{60} \mathrm{Co}$, feixe de elétrons e fótons. 92 TABELA 17 - Limite inferior de detecção (LID) do LiF:Mg,Ti para radiação gama do ${ }^{\circ} \mathrm{Co}$, feixe de elétrons e fótons. .93 TABELA 18 - Limite inferior de detecção (LID) do $\mu$ LiF:Mg,Ti para radiação gama do ${ }^{60} \mathrm{Co}$, feixe de elétrons e fótons.. 


\section{INTRODUÇÃo}

Em 1895, com as descobertas dos raios-X por Wilhelm Conrad Roentgen, e em 1896, da radioatividade por Becquerel e o casal Curie, teve inicio o uso da radiação ionizante para tratamentos com finalidades terapêuticas e diagnósticas na Medicina possibilitando, assim, um avanço tecnológico e científico na evolução dos métodos de tratamento existentes (Sprawls, 1993).

Com os avanços do uso da tecnologia nuclear para finalidade médica, surgiu uma grande preocupação relacionada à detecção da radiação e avaliação da dose para o controle ambiental e avaliação pessoal (Oberhofer e Scharmann, 1979). De acordo com a Portaria 453 de $1^{\text {o }}$ de junho de 1998 do Ministério da Saúde, as exposições radiológicas para fins de saúde constituem a principal fonte de exposição da população a fontes artificiais de radiação ionizante.

Os principais objetivos da dosimetria clínica são promover a proteção radiológica dos indivíduos (pacientes e trabalhadores) e estabelecer um controle de qualidade do feixe de radiação (Oberhofer e Scharmann, 1979). A verificação da dose no paciente tem sido recomendada para a melhoria da qualidade no tratamento radioterápico por várias organizações como a American Association of Physicists in Medicine (AAPM) (Kutcher et al, 1993) e a European Society of Therapeutic Radiology and Oncology (ESTRO) (Van Dam e Marinello, 1994; Huyskens et al, 2001). A Comissão Internacional de Unidades e Medidas de Radiação (ICRU) estabeleceu em 1976 que "todos os procedimentos envolvidos no planejamento e na execução da radioterapia podem contribuir para uma incerteza significativa na dose administrada no paciente". Os valores máximos recomendados para a incerteza na dose variam de $\pm 5 \%$ (ICRU, 1976).

Os feixes de elétrons de energias altas ( $\mathrm{E}>5 \mathrm{MeV}$ ) tem largo emprego na área médica, principalmente no tratamento de diversos tipos de câncer. A aplicação de elétrons em terapia exige grande exatidão na dose absorvida pelo tumor, pois uma pequena variação é altamente determinante no risco de recidiva ou seqüelas (ICRU, 1976). Este fato exige medidas e controle rigorosos das doses absorvidas pelos pacientes em tratamento por meio de dosímetros que apresentem grande exatidão e precisão nas medidas fornecidas. 
Vários tipos de dosímetros vêm sendo empregados em feixes de elétrons de energias altas. Na área médica os mais utilizados são as câmaras de ionização (Berger et al, 1976; Albuquerque e Caldas, 1990; Tessier e Kawrakow, 2009; Fraser et al, 2009; Pszona et al, 2010), dosímetros Fricke (Boudou et al, 2005; Bartesaghi et al, 2009) e dosímetros termoluminescentes (Rudén, 1976; Hufton, 1984; Derreumaux et al, 1994; Kalmykov, 1994; Robar et al, 1996; Metcalfe et al, 2007; Chatterjee et al, 2009).

Os dosímetros termoluminescentes (DTL) possuem um longo histórico na dosimetria da radiação ionizante em radioterapia. Nessa área, a maioria das medidas têm sido feitas com fluoreto de lítio ( $\mathrm{LiF}$ ) devido à sua equivalência ao tecido e ao fato da dependência da resposta com a energia, a taxa de dose e as temperaturas de utilização serem pequenas no intervalo de doses utilizadas em radioterapia (Eggermont et al, 1971; Gooden e Brickner, 1972; Rúden, 1976; Hufton, 1984, Kalmykov, 1994; Robar et al, 1996). Mais recentemente, tem sido caracterizados e utilizados os microdosímetros de LiF que, devido a suas mínimas dimensões, podem ser utilizados na dosimetria in vivo.

Outro material termoluninescente, o $\mathrm{CaSO}_{4}: \mathrm{Dy}$, já é intensamente empregado em medidas de dose em radioproteção devido à sua alta sensibilidade (Campos e Lima, 1987; Lakshmanan et al, 1991). Embora esse material apresente ótima linearidade de resposta a radiações beta e à feixe de fótons para uma ampla faixa de doses e estudos preliminares mostarem a viabilidade de sua aplicação em feixes de elétrons, ele não foi ainda suficientemente explorado em radioterapia (Campos e Lima, 1987; Campos e Souza, 1990, Nunes, 2008; Matsushima, 2010). 0 $\mathrm{CaSO}_{4}$ :Dy é fabricado e comercializado pelo Laboratório de Materiais Dosimétricos da Gerência de Metrologia das Radiações/IPEN (Nunes, 2008).

A alta sensibilidade dos materiais termoluminescentes permite a construção de detectores resistentes e em várias formas e tamanhos, o que os fazem uma ferramenta útil, em particular, para medidas de regiões de gradientes agudos de dose (Duch et al, 1998; Venables et al, 2004). Os diferentes materiais que compõem os objetos simuladores também alteram a resposta dos DTLs à radiação de fótons e elétrons, por isso, esses fatores devem ser considerados na dosimetria. É fundamental assegurar o princípio da otimização de doses de radiação aplicadas à 
pacientes em tratamentos, a fim de se controlar os riscos associados à exposição (Kron, 1999).

A dosimetria in vivo tem se tornado uma parte importante no Programa de Garantia de Qualidade (PGQ) nos Departamentos de Radioterapia e tem provado ser muito útil na determinação da dose aplicada a um determinado paciente, bem como na detecção de vários tipos de erros no processo de aplicação de dose (Leunens et al, 1990; Essers e Mijnheer, 1999). Pesquisas realizadas nos Estados Unidos estudaram os planejamentos de tratamentos que utilizam a radiação ionizante e apontaram que cerca de 50\% dos hospitais e 90\% das instituições acadêmicas utilizavam o método da termoluminescência para dosimetria in vivo (Kron, 1999).

Há um grande interesse no uso do $\mathrm{CaSO}_{4}$ :Dy na dosimetria em radioterapia não somente pelas suas características de sensibilidade e linearidade de resposta com a radiação, incluindo fótons e elétrons mas também devido a facilidade de aquisição dos dosímetros pelo IPEN (Nunes, 2008).

A fim de se considerar a viabilidade da aplicação do dosímetro de $\mathrm{CaSO}_{4}$ :Dy em radioterapia, avaliou-se o desempenho desse detectore TL na dosimetria de feixes clínicos de fótons e elétrons, empregando três tipos de objetos simuladores: polimetilmetacrilato (PMMA), água sólida RMI-457 e água. Seu desempenho foi comparado ao dos dosímetros de fluoreto de lítio dopado com magnésio e titânio (LiF:Mg,Ti) - detector mais utilizado em dosimetria clínica - e dos microdosímetros de fluoreto de lítio dopado com magnésio e titânio ( $\mu \mathrm{LiF}: \mathrm{Mg}, \mathrm{Ti}$ ). 


\section{OBJETIVOS}

\section{$2.1 \quad$ Geral}

Avaliar o desempenho de dosímetros de sulfato de cálcio dopado com disprósio ( $\mathrm{CaSO}_{4}$ :Dy), fluoreto de lítio dopado com impurezas compostas por magnésio e titânio (LiF:Mg,Ti) e de micro detectores termoluminescentes de fluoreto de lítio dopado com impurezas compostas por magnésio e titânio ( $\mu \mathrm{LiF}: \mathrm{Mg}, \mathrm{Ti}$ ) na dosimetria de feixes clínicos de elétrons de altas energias utilizando diferentes simuladores equivalentes à água.

\subsection{Específicos}

$\checkmark$ Comparar o desempenho dos detectores de $\mathrm{CaSO}_{4}$ :Dy produzidos pelo IPEN com os detectores de LiF TLD-100 comercialmente disponíveis.

$\checkmark$ Comparar o desempenho dos detectores empregando diferentes objetos simuladores tais como: PMMA, Água e Água Sólida.

$\checkmark$ Estabelecer uma nova metodologia para a avaliação de feixes clínicos de elétrons e de dose no paciente. 


\section{FUNDAMENTOS TEÓRICOS}

Como o objetivo do trabalho é a dosimetria de feixes clínicos de fótons e principalmente de elétrons, será apresentada uma revisão sobre a interação da radiação com a matéria.

\subsection{Interação da Radiação com a Matéria}

A interação da radiação com a matéria está ligada ao processo de transferência de energia ao meio e pode ocorrer tanto com o núcleo atômico quanto com os elétrons. Se as interações ocorrerem com o núcleo atômico, pode haver perda colisional ou radioativa. Porém, se as interações ocorrem com os elétrons, a energia transferida ao meio pode acarretar dois fenômenos (Sprawls, 1993; Knoll, 2000; Saw, 2002):

1. Ionização: a energia absorvida pelo elétron deve ser suficiente para que haja o rompimento da sua ligação atômica. A radiação interage com o material removendo elétrons do átomo, com isso este passa a ter excesso de cargas positivas;

2. Excitação: um elétron em um átomo absorve a energia de um fóton realizando um salto quântico para um nível superior de sua órbita. A radiação interage com o material e transfere parte ou toda sua energia para elétrons do material alvo. A energia transferida não é suficiente para retirar elétrons do átomo.

\subsubsection{Fótons}

Ao atravessar um objeto, um feixe de raios-X ou raios gama pode penetrar na matéria sem interagir com a mesma; pode interagir com a matéria e ser completamente absorvido, transferindo toda a sua energia para o material; ou pode interagir com a matéria e ser espalhado ou defletido da sua direção inicial, perdendo parte da sua energia (Sprawls, 1993). 
Os principais mecanismos de interação da radiação com a matéria são: Espalhamento Coerente, Efeito Fotoelétrico, Efeito Compton e Produção de Pares (Knoll, 2000).

Para fótons de energias inferiores a $10 \mathrm{MeV}$, o principal mecanismo de interação é a excitação eletrônica e dependendo da energia do fóton, pode ser realizada através dos efeitos Compton ou Fotoelétrico. Quanto menor for a energia do fóton, maior será a probabilidade de ocorrer o feito Fotoelétrico. A probabilidade de ocorrência de cada tipo de efeito depende da energia do fóton incidente e do número atômico efetivo do material $\left(Z_{e f}\right)$ e pode ser observada na FIG. 1(Knoll,2000).

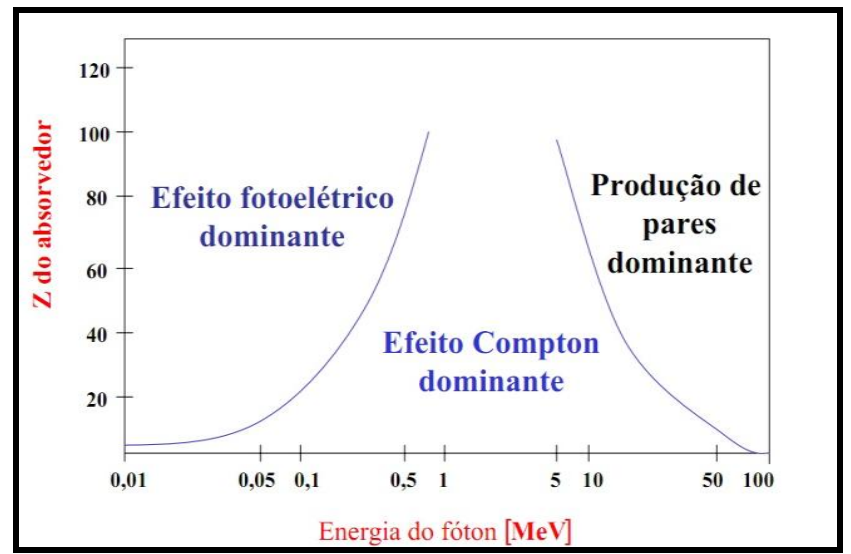

FIGURA 1 - Predominância das interações de fótons com a matéria em função da energia e do número atômico Z do material. Adaptado de Quoirin, 2004.

\subsubsection{Espalhamento Coerente}

No espalhamento coerente a radiação eletromagnética é tratada como onda. Esse processo corresponde à absorção e re-emissão da radiação pelo átomo, em uma direção diferente da de incidência. Após um fóton incidir sobre um elétron, este vibra com a mesma freqüência de oscilação do fóton incidente e como conseqüência o fóton é re-emitido com mesma energia (Sprawls, 1993; Khan, 1994). Neste tipo de interação não há transferência de energia ao átomo, a única conseqüência é o espalhamento do fóton com pequenas angulações.

Existem dois tipos de espalhamento coerente: o Espalhamento Thomson, quando a interação ocorre com o núcleo do átomo; e o Espalhamento Rayleigh, 
mostrado na FIG. 2, quando a interação envolve um elétron orbital (Curry et al, 1990; Khan, 1994).

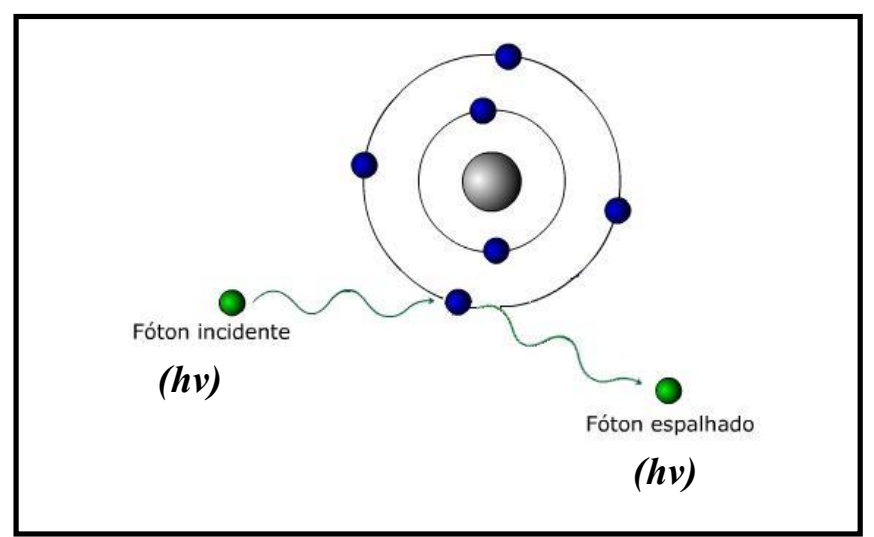

FIGURA 2 - Processo de Espalhamento Rayleigh. Adaptado de Quoirin, 2004.

A probabilidade de ocorrer o espalhamento coerente é inversamente proporcional à energia do fóton e diretamente proporcional ao quadrado do número atômico Z do material alvo (Curry et al, 1990; Khan, 1994).

\subsubsection{Efeito Fotoelétrico}

Um fóton interage com o átomo e ejeta um de seus elétrons orbitais. Nesse processo, toda a energia $h v$ do fóton é transferida ao elétron. Este tipo de interação pode ocorrer com elétrons nas camadas $\mathrm{K}, \mathrm{L}, \mathrm{M}$ ou $\mathrm{N}$. A energia cinética do elétron ejetado, ou também chamado de fotoelétron, é igual diferença entre a energia do fóton incidente e a energia de ligação do elétron com o núcleo, como mostrado através da EQ.1 (Khan, 1994):

$$
E_{C}=h v_{0}-E_{B}
$$

em que: $E_{C}=$ energia cinética do fotoelétron;

$h v_{0}=$ energia do fóton incidente;

$E_{B}=$ energia de ligação do elétron. 
Depois de o elétron ter sido ejetado do átomo, uma vacância é criada na camada deixando o átomo em estado de excitação. Essa vacância pode ser preenchida por um elétron de uma camada mais externa, ou seja, mais energética, emitindo os chamados Raios-X característicos. Há também a possibilidade de emissão de elétrons Auger, os quais são elétrons monoenergéticos produzidos pela absorção de Raios-X característicos internamente pelo átomo. Na FIG. 3 é mostrado o processo de interação por efeito fotoelétrico (Khan, 1994).

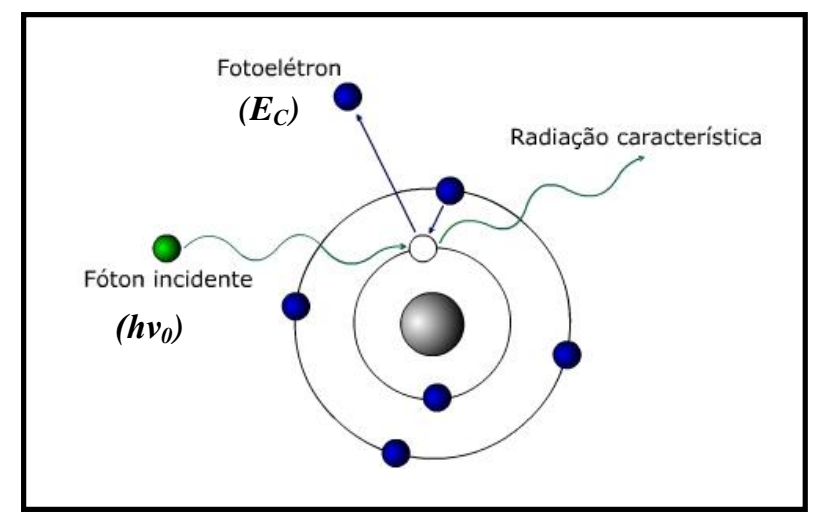

FIGURA 3 - Processo de Efeito Fotoelétrico. Adaptado de Quoirin, 2004.

A probabilidade de ocorrência do efeito fotoelétrico depende energia do fóton e do número atômico $\mathrm{Z}$ do material alvo. Ela é inversamente proporcional ao cubo da energia do feixe incidente e diretamente proporcional ao cubo do número atômico Z. O efeito fotoelétrico é predominante na interação de raios gama de baixa energia e materiais de alto número atômico (Curry et al, 1990; Khan, 1994).

\subsubsection{Efeito Compton}

O efeito Compton, também conhecido como espalhamento inelástico, ocorre quando um fóton interage com um elétron do átomo, denominado elétron livre. O termo "elétron livre" significa que a sua energia de ligação com o núcleo atômico é muito menor do que a energia do fóton incidente (Khan, 1994).

Neste tipo de interação o elétron absorve parte da energia do fóton incidente e esta é suficiente para removê-lo da estrutura atômica tornando o átomo ionizado. Um fóton de menor energia é produzido e espalhado em uma direção 
diferente da do fóton incidente. Uma vez que o efeito Compton envolve os elétrons livres do material, a probabilidade desse efeito ocorrer é independente do número atômico $\mathrm{Z}$ e depende somente do número de elétrons por grama de material, ou seja, da densidade eletrônica do material alvo (Khan, 1994). Na FIG. 4 é ilustrado o espalhamento de um fóton por um elétron livre do material.

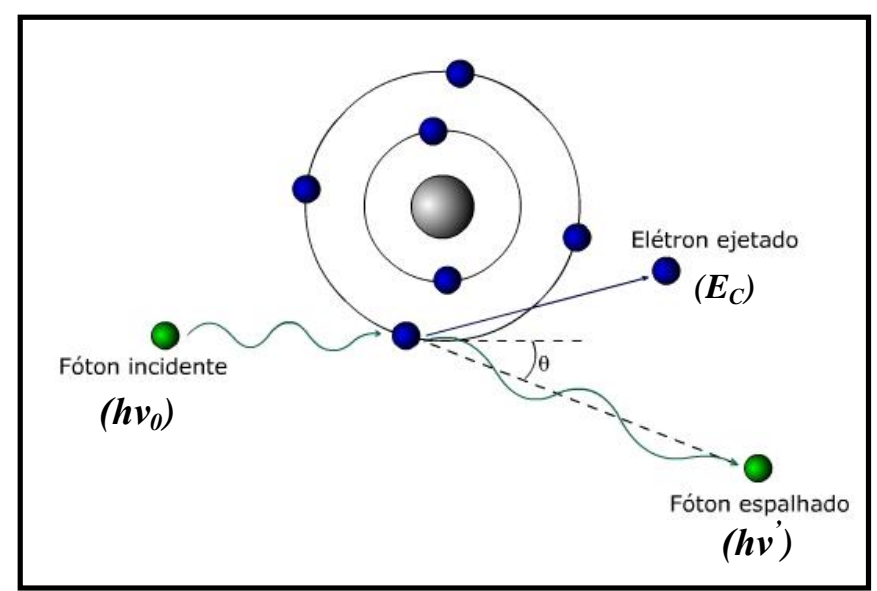

FIGURA 4 - Ilustração do Efeito Compton. Adaptado de Quoirin, 2004.

0 valor da energia do fóton espalhado é a diferença entre a energia do fóton incidente e a soma da energia de ligação do elétron e da energia cinética do elétron ejetado, como é mostrado na EQ. 2 (Khan, 1994):

$$
h v^{\prime}=h v_{0}-\left(E_{B}+E_{C}\right)
$$

EQ. 2

em que: $h v^{\prime}=$ energia do fóton espalhado;

$h v_{0}=$ energia do fóton incidente;

$E_{B}=$ energia de ligação do elétron;

$E_{C}=$ energia cinética do elétron ejetado.

\subsubsection{Produção de Pares}

A produção de pares ocorre quando o fóton possui energia superior a 1,022 MeV. Neste processo o fóton interage fortemente com o núcleo do átomo, cede toda sua energia a ele e gera, simultaneamente, duas partículas: um elétron e um 
pósitron. Uma vez que a energia de repouso dessas partículas é aproximadamente 0,511 MeV, é necessária uma energia de no mínimo $1,022 \mathrm{MeV}$ para criar o par elétron-pósitron. Essa energia mínima é chamada de energia limiar. Caso o fóton incidente possua energia superior a esse limiar, a energia em excesso é convertida em energia cinética para as duas partículas carregadas produzidas. Na FIG. 5 é ilustrado processo de Produção de Pares (Khan, 1994).

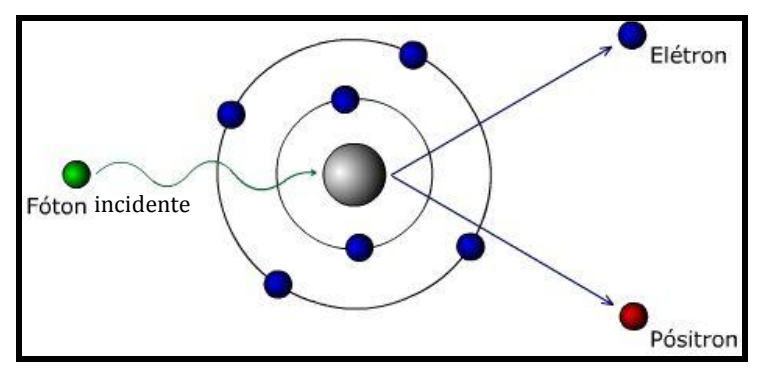

FIGURA 5 - Processo de Produção de Pares. Adaptado de Quoirin, 2004.

A probabilidade de ocorrer a produção de pares é diretamente proporcional a energia do feixe incidente e ao quadrado do número atômico $\mathrm{Z}$ do material alvo.

\subsubsection{Elétrons}

O elétron, partícula carregada, pode perder energia cinética ou ter a direção de sua trajetória alterada a cada interação com os átomos do meio. As interações ou colisões de partículas carregadas ocorrem através de forças Colombianas entre o campo elétrico da partícula e de elétrons orbitais ou do núcleo atômico do material. As interações com os elétrons orbitais resultam em ionização e excitação do átomo. Já as interações entre a partícula e núcleo atômico resultam em perda de energia radiativa ou Bremsstralung (Khan, 1994).

0 tipo de interação que ocorrerá depende de um parâmetro de impacto " $b$ " da interação que é definido como a distância da trajetória do elétron antes da interação ao centro do núcleo atômico (IAEA, 2005). Na FIG. 6 é mostrada a interação de um elétron com um átomo de raio " $a$ " do meio que este elétron atravessa. 


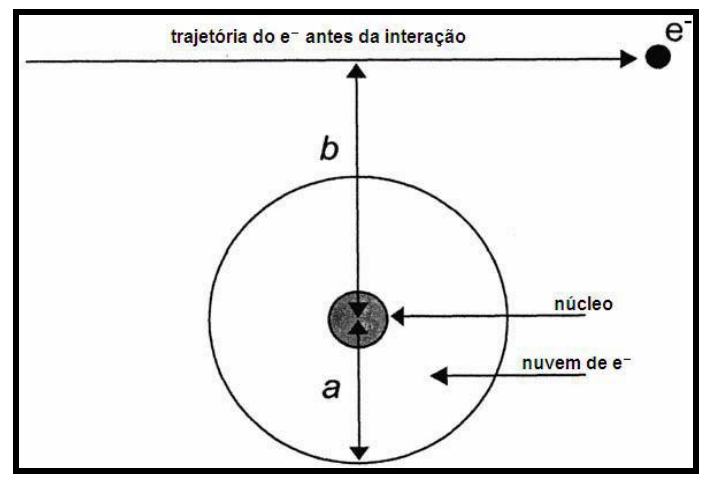

FIGURA 6 - Interação de um elétron com um átomo do meio. Adaptado de IAEA, 2005.

\subsubsection{Interações com elétrons orbitais}

Se $b>>a$ ou $b \approx a$, o elétron interage com os elétrons orbitais. Estas interações resultam na excitação (transferência de um elétron do átomo de sua órbita para outra de menor energia) e na ionização (ejeção de um elétron do átomo). As perdas de energia ocorrem por colisões, elásticas ou inelásticas, com os elétrons orbitais do meio. Essas colisões são representadas pelo poder de freamento colisional na descrição estatística do feixe de elétrons (IAEA, 2005).

\subsection{Colisões elásticas}

Nas colisões em que $b>>a$, o elétron sofre uma colisão elástica com o átomo como um todo. Somente uma pequena parte de sua energia cinética é transferida aos elétrons orbitais (IAEA, 2005).

\subsection{Colisões inelásticas}

Se $b \approx a$, parte significativa da energia cinética do elétron incidente é transferida ao elétron orbital através de uma interação inelástica, implicando na possibilidade de espalhamento do elétron incidente (IAEA, 2005).

\subsubsection{Interações com núcleos atômicos}

Se $b<<a$, o elétron interage com o núcleo atômico resultando em perdas de energia através da emissão de um fóton de radiação de freamento (Bremsstrahlung) e 
pelo espalhamento do elétron. São caracterizadas pelo poder de freamento radiativo (IAEA, 2005).

A relação de Larmor define a potência $P$ que uma partícula de carga elétrica $q$ emitida na forma de fótons ao ser acelerada com uma aceleração $a_{q}$. Essa relação, EQ. 3, rege a produção da radiação de freamento (IAEA, 2005):

$$
P=\frac{q^{2} \cdot a_{q}^{2}}{6 \cdot \pi \cdot \varepsilon_{0} \cdot c^{3}}
$$

em que: $\pi=3,14159265359$ é a razão da circunferência pelo diâmetro de um círculo; $\varepsilon_{0}=$ a permissividade elétrica do vácuo; $c=$ velocidade da luz no vácuo.

\subsection{Radiação Ionizante na Medicina}

A radiação ionizante é capaz de danificar células do corpo humano, sadias ou não. Desse modo, as radiações ionizantes podem ser aplicadas em diversas áreas médicas para finalidade diagnóstica ou terapêuticas (Mahesh et al, 1989). Dentre essas áreas estão:

$\checkmark$ Radiodiagnóstico: exames de Raios-X convencionais, tomografias computadorizadas, mamografia, angiografias digitais;

$\checkmark$ Medicina Nuclear: cintilografias, tomografia por emissão de pósitrons;

$\checkmark$ Radioterapia: teleterapia e braquiterapia.

Em radiodiagnóstico, os equipamentos de Raios-X são bastante utilizados para procedimentos relacionados à radiologia do corpo humano. Dentre as modalidades de exames diagnósticos, a mamografia destaca-se pela capacidade de atuar no rastreamento do câncer de mama (Sprawls, 1993).

$\mathrm{Na}$ área da medicina nuclear, a radiação ionizante é proveniente de radioisótopos com meia-vida curta que são utilizados para a verificação do 
funcionamento de determinados órgãos internos. As fontes de radiação mais utilizadas são Iodo-131, Tecnécio-99m, Cobalto-57, Cromo-51, dentre outros. Este método associado à tomografia computadorizada permite a reconstrução tridimensional funcional de patologias (Sprawls, 1993).

Em radioterapia, o tratamento consiste em aplicar doses elevadas de radiação através de equipamentos como aceleradores lineares, com o objetivo de eliminar as células não-sadias (células alvo) e causar o menor dano possível aos tecidos sadios adjacentes. Os feixes de elétrons de energias altas têm sido empregados em radioterapia desde o início de 1950 e o intervalo de energia mais utilizado para feixes de elétrons é de 4 a $15 \mathrm{MeV}$. Esse tipo de feixe proporciona uma uniformidade na dose no volume alvo, minimizando a dose recebida pelas regiões vizinhas (Khan, 1992).

\subsection{Radioterapia}

Ao observar que os Raios-X apresentavam propriedades biológicas, iniciou-se o seu uso para a finalidade terapêutica. Nos primórdios da Radioterapia, a dose administrada era o tanto quanto o paciente fosse capaz de tolerar. Esse limite de dose tolerado pelo paciente era normalmente estabelecido pela tolerância da sua pele, chamada de dose eritema (Salvajoli et al, 1999).

Assim como a cirurgia e a quimioterapia, a radioterapia é uma das formas convencionais de tratamento do câncer que, através do uso da radiação ionizante, visa danificar as moléculas de DNA do tumor. 0 tratamento do câncer através da radioterapia teve seu início em 1902 com o Dr. Henri-Alexandre Danlos, o qual realizou um tratamento com fonte radioativa de rádio colocada diretamente na superfície de um tumor (Perez, 2004; IAEA, 2005).

0 principal objetivo desse tipo de terapia é a partir de uma determinada dose de radiação provocar a destruição de células cancerígenas produzindo o menor dano possível aos tecidos saudáveis ao redor do tumor. Vários mecanismos, como a inativação de sistemas vitais para a célula e sua incapacidade de reprodução, podem ser responsáveis pela morte celular (Hall, 1988; DeVita, 2000).

A radioterapia pode ser classificada em telerapia e braquiterapia. A Teleterapia emprega uma fonte de radiação externa colocada a certa distância da 
região a ser tratada enquanto na braquiterapia a fonte radioativa está em contato direto com a região do tumor (Cunningham, 1983; Khan, 1994; DeVita, 2000).

A cada dia são apresentados novos avanços tecnológicos e inovações e não importa a maneira com que o tumor é tratado, o que é realmente importante é que a Radioterapia caminha para atingir um único objetivo, o de aumentar a taxa de cura dos pacientes submetidos a esse tratamento.

\subsubsection{Aplicação de elétrons}

Desde o início de 1950, os elétrons de energias altas têm sido aplicados em medicina. Mesmo o tratamento convencional com Raios-X sendo uma opção de tratamento, as características da curva de Porcentagem de Dose Profunda (PDP) proporcionam uma concentração de dose na região alvo. Esse fato é uma vantagem clínica a ser considerada (IAEA, 2005).

Considerando o poder de penetração, a PDP aumenta com a energia do feixe e depende da lei do inverso do quadrado da distância e da atenuação exponencial devido à interação da radiação com o meio. Ao penetrar o meio atenuador, o feixe de radiação começa a ionizá-lo, liberando elétrons. Esses elétrons percorrem um caminho, depositam energia ao longo dele e, em certa distância em relação à superfície, a troca de energia é máxima. Essa região recebe o nome de região de Build up. A PDP aumenta ao longo dessa região até atingir a PDP máxima, ou seja, 100\%, que é o seu limite. A fluência de elétrons e, portanto, a dose absorvida, aumentam com a profundidade antes de chegar ao Build up. A dose absorvida mede a quantidade de energia depositada em uma determinada massa de um meio absorvente (Johns e Cunningham, 1974; Khan, 1984).

Atualmente, os feixes de elétrons de megavoltagem são uma importante modalidade de Radioterapia, que muitas vezes são a única opção de tratamento de tumores superficiais com menos de $5 \mathrm{~cm}$ de profundidade (Metcalfe et al, 2007).

A radioterapia com arco de elétrons é uma técnica que utiliza um feixe de elétrons em rotação para o tratamento de tumores superficiais cujos volumes seguem superfícies curvas. Apesar de apresentar bons resultados clínicos alguns fatores relacionados a esta técnica ainda são pouco compreendidos e fazem com que ela não seja muito aplicada (Metcalfe et al, 2007). 


\subsubsection{Aceleradores Lineares}

Após a descoberta dos Raios-X em 1895 por Röentgen, iniciaram-se os tratamentos superficiais, como de câncer de pele. Em meados de 1920, com o advento das unidades de Raios- $\mathrm{X}$, puderam ser realizados tratamentos de tumores mais profundos. A partir de 1950 surgiram as máquinas operando com fontes radioativas, como o ${ }^{60} \mathrm{Co}$, e os betatrons. No início dos anos 60 já eram desenvolvidos e comercializados os primeiros aceleradores lineares de elétrons, que produzem feixes de fótons de energia alta (Scaff, 1997).

Os equipamentos mais utilizados atualmente em departamentos médicos para produção de radiação ionizante para fins terapêuticos são os aceleradores lineares (LINACs - Linear accelerator). Esses equipamentos usam ondas eletromagnéticas de alta freqüência para acelerar partículas carregadas, como os elétrons. A aceleração dos elétrons ocorre em um tubo acelerador mantido em vácuo, que possui anéis concêntricos separados entre si.

Os aceleradores lineares médicos aceleram elétrons até energias cinéticas de 4 a $25 \mathrm{MeV}$ aplicando campos não-conservativos de microondas no intervalo de freqüência que vai de $10^{3} \mathrm{MHz}$ a $10^{4} \mathrm{MHz}$, com a maioria das máquinas operando na freqüência de $2856 \mathrm{MHz}$ (IAEA, 2005).

Alguns tipos de LINACs disponíveis para o uso clínico produzem Raios-X de baixa megavoltagem (4 ou $6 \mathrm{MV}$ ), enquanto outros fornecem tanto Raios-X quanto elétrons de diversas energias. Um LINAC moderno típico, produz fótons de duas energias (6 e $18 \mathrm{MV}$ ) e elétrons de várias energias (6, 9, 12, 16 e $22 \mathrm{MeV}$ ) (IAEA,2005). Na FIG. 7 é apresentado o Acelerador modelo Clinac 2100C pertencente ao Hospital Israelita Albert Einstein (HIAE). 


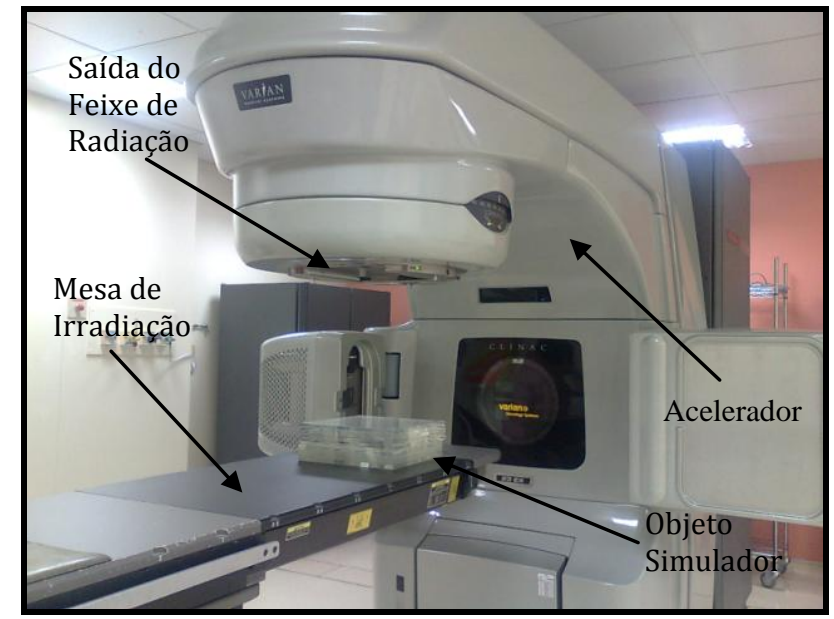

FIGURA 7 - Acelerador Linear da marca Varian, modelo Clinac 2100C, pertencente ao Setor de Radioterapia do HIAE.

\subsubsection{Dosimetria em Radioterapia}

Em tratamentos de radioterapia é necessário se ter a certeza de que o paciente está recebendo a dose correta prescrita. 0 principal objetivo da dosimetria em Radioterapia é determinar, com maior precisão, a dose absorvida pelo tumor. Isso pode ser feito através da calibração do feixe de radiação e da dosimetria de rotina para o controle de garantia de qualidade, tanto do equipamento de terapia quanto dos tratamentos (Metcalfe et al, 2007). Como existe a dificuldade de se fazer a dosimetria in vivo, recorre-se a cálculos que relacionam doses medidas em simuladores com a dose no paciente (Johns e Cunningham, 1974).

Através do seu relatório $\mathrm{n}$ ํ24, a Comissão Internacional de Medidas e Unidades de Radiação (ICRU) faz a seguinte recomendação quanto à incerteza total do tratamento radioterápico: "a evidência disponível para alguns tipos de tumores aponta a necessidade de exatidão de 5\% na liberação da dose no volume alvo se a erradicação do tumor primário for desejada" (ICRU 24, 1976). Com isso, são realizadas dosimetrias freqüentemente seguindo protocolos estabelecidos, nacionais ou internacionais, e como o Brasil não possui seu próprio protocolo este segue os protocolos da Agência Internacional de Energia Atômica (IAEA).

Os dosímetros mais utilizados na Medicina, como já mencionado, são as câmaras de ionização (Kehwar et al, 2006; Fragoso et al, 2008), os dosímetros Fricke (Boudou et al, 2005) e os dosímetros termoluminescentes (Butson et al, 2000; Metcalfe et al, 2007). 


\subsection{Dosimetria Termoluminescente}

\subsubsection{Termoluminescência (TL)}

A termoluminescência é explicada através do modelo de bandas para os níveis de energia dos elétrons nos sólidos. Certos materiais quando aquecidos, após receberem uma exposição à radiação ionizante, tornam-se capazes de emitir luz. Esses materiais são ditos termoluminescentes e são, em geral, cristais iônicos, nos quais a banda de valência (BV) se encontra repleta de elétrons e a banda de condução (BC) vazia, ambas separadas por uma faixa larga de estados energéticos não permitidos aos elétrons, conhecida como banda proibida (BP) (McKeever, 1985).

De um modo geral, quando os elétrons de um sólido são excitados por absorção de radiação eletromagnética ou por outro processo qualquer, eles não permanecem por muito tempo nos respectivos níveis mais altos, decaindo por vários processos competitivos. Se o processo de decaimento mais provável envolve a emissão de radiação eletromagnética na região visível do espectro, dizemos que existe luminescência. Nos sólidos, a luminescência está ligada às impurezas e aos defeitos da estrutura cristalina. A FIG. 8 esquematiza os processos de excitação e estimulação térmica em um cristal TL (McKeever, 1985).

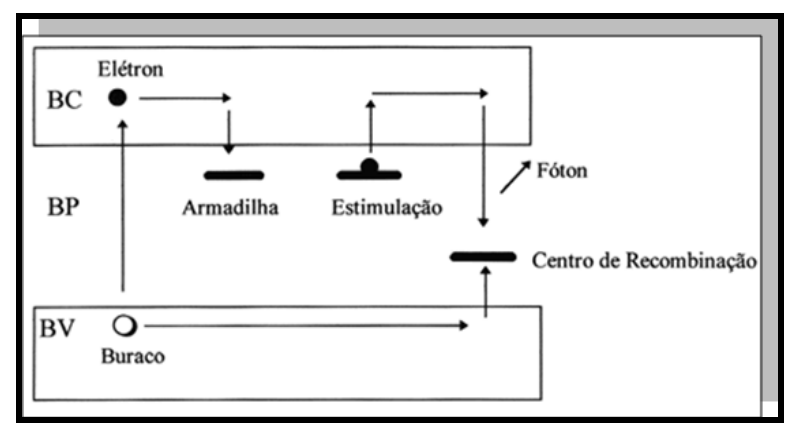

FIGURA 8 - Excitação e estimulação térmica em um cristal TL (McKeever, 1985).

Quando um elétron da banda de valência é transferido para a banda de condução, deixa uma lacuna, ou seja, um nível incompleto. Se a estrutura cristalina do sólido em questão não contém defeitos nem impurezas, o elétron volta à banda de valência com a emissão de radiação eletromagnética com uma energia muito alta para ficar na região visível do espectro. Se a rede contiver algumas impurezas que originem níveis de energia entre as bandas de valência e de condução, um elétron de um nível 
de energia de impureza inferior pode preencher a lacuna na banda de valência, e um elétron da banda de condução pode preencher um dos níveis de energia de impureza superiores, com a emissão, nos dois casos, de radiação eletromagnética com energia muito baixa para ficar na região visível do espectro. Um elétron pode passar de um nível de energia de impureza superior para um nível de energia de impureza inferior que esteja vazio, com a emissão de radiação eletromagnética com energia que a situe na região visível do espectro, e isso é o que constitui a luminescência (McKeever, 1985).

Em certos casos, o elétron da banda de condução pode passar para um nível de energia chamado armadilha, do qual ele não pode passar ao nível de energia de impureza mais baixo, por uma transição radioativa, sem violar um ou outro princípio de conservação. 0 elétron se encontra, então, em um estado metaestável, e permanece nesse estado por um tempo que pode ser de muitos segundos (muito grande para a escala atômica), até que algum processo o faça regressar à banda de condução, passando por todas as etapas descritas acima (McKeever, 1985).

A quantidade de luz é mensurável, aumentando a sua intensidade com a população de elétrons armadilhados, ou seja, essa última é dependente da dose absorvida pelo cristal (McKeever, 1985).

\subsubsection{História da Dosimetria Termoluminescente}

A termoluminescência é um fenômeno conhecido há muito tempo. Em 1663 a "Royal Society" era notificada sobre as novas observações de Robert Boyle. Ele notara que quando um diamante era aquecido no escuro emitia luz. Após essa descoberta vários cientistas, como Henry Becquerel, iniciaram seus trabalhos empregando o fenômeno da termoluminescência. Marie Curie, em 1904, percebeu que as propriedades termoluminescentes dos cristais podiam ser restauradas após estes serem expostos à radiação do rádio (Oberhofer e Scharmann, 1981; McKeever, 1985).

Entre 1930 e 1940, trabalhos experimentais e teóricos com a termoluminescência foram realizados por Urbach. Em 1945 foi desenvolvido por Randal e Wikins o primeiro modelo que permitiu a realização de cálculos quantitativos da cinética termoluminescente. Baseado nesse primeiro modelo, outros 
foram também desenvolvidos a fim de ajustar melhor a teoria aos resultados experimentais, como o modelo de dipolos e o modelos de competição de armadilhas (Cameron et al, 1968; Oberhofer e Scharmann, 1981).

Em 1950, Farrington Daniels sugeriu que o uso da termoluminescência poderia ser útil para a dosimetria da radiação e juntamente com seu grupo desenvolveu uma instrumentação para esse propósito. Sendo assim, as primeiras aplicações da termoluminescência em dosimetria foram feitas por Daniels e colaboradores utilizando detectores de fluoreto de lítio, LiF, para a quantificação da radiação após um teste com uma bomba (Cameron et al, 1968).

Os aspectos da dosimetria termoluminescente dos trabalhos de Daniels foram interrompidos em 1955. Porém, em 1960 na Universidade de Winconsin, J.R. Cameron retomou as pesquisas nessa área contando com a colaboração de Daniels e Johnson, um estudante graduado em geologia (Cameron et al, 1968).

\subsubsection{Aplicações Clínicas da Dosimetria Termoluminescente}

Os dosímetros termoluminescentes (DTLs) desempenham um papel importante na área de radioterapia devido a sua utilização para a dosimetria da radiação ionizante (Rudén, 1976; McKinlay, 1981; Hufton, 1984). Este tipo de dosímetro apresenta vantagens que o torna uma ferramenta útil para medidas em simuladores antropomórficos (Mansfield e Suntharalingam, 1976; Knöös et al, 1986; Cross et al, 1992; Kron et al, 1994) e para dosimetria "in vivo" em pacientes (Cross et al, 1992; Kron et al, 1994). É nesse contexto que surge a dosimetria TL como uma ferramenta extremamente versátil para a avaliação da dose absorvida por tecidos humanos devido à interação com a radiação ionizante. A grande variedade de materiais TL e suas diferentes formas físicas permitem a determinação da qualidade da radiação em um intervalo de doses de $\mu$ Gy a kGy (Campos, 1998).

Em Radioterapia, a maioria das medidas utilizando dosímetros termoluminescentes tem sido feita empregando o fluoreto de lítio (LiF), geralmente o TLD-100 (Olko et al, 2006; Livinstone et al, 2010; Nelson et al, 2010) comercializado pela Harshaw. Mais recentemente tem sido caracterizados e utilizados os micro dosímetros de LiF, que são detectores semelhantes aos TLD-100, porém com dimensões de $1 \times 1 \times 1 \mathrm{~mm}^{3}$. A alta sensibilidade e as dimensões mínimas permitem a 
construção de pequenos dosímetros que podem ser utilizados em regiões de gradientes agudos e em dosimetria in vivo. Esses dosímetros são resistentes e aplicáveis em várias formas e tamanhos (Moscovitch e Horowitz, 2007).

$\mathrm{O} \mathrm{CaSO}_{4}$ :Dy, embora apresente excelente linearidade de resposta com a radiação para um amplo intervalo de dose, que vai de $\mu$ Gy a Gy (Campos e Lima, 1986), apresenta dependência energética da resposta para radiação de fótons na região de efeito fotoelétrico devido ao seu número atômico efetivo alto $(15,3)$, o que pode ser contornado com o uso de filtros no porta dosímetro. No Brasil, a aplicação deste dosímetro em radioterapia seria de grande interesse, uma vez que o mesmo já é fabricado e comercializado pelo Laboratório de Materiais Dosimétricos da Gerência de Metrologia das Radiações (LMD-GMR) do IPEN (Campos, 1983).

Os principais parâmetros a serem investigados para a avaliação do desempenho de um dosímetro TL são:

1. Tamanho, forma, espessura e composição do dosímetro;

2. Sensibilidade TL para feixe de fótons e elétrons relativa à radiação gama do ${ }^{60} \mathrm{Co}$;

3. Dependência energética da resposta termoluminescente;

4. Intervalo de dose para utilização em feixes de fótons e de elétrons aplicados em dosimetria clínica;

5. Irradiação empregando simuladores;

6. Medidas de dose superficial e profunda;

7. Efeitos de perturbação;

8. Fatores de correção do decaimento térmico;

0 desempenho do DTL de $\mathrm{CaSO}_{4}$ :Dy aplicados na dosimetria de feixes de elétrons de alta energia foi estudado por Chatterjee et al (2009) em que analisaram as propriedades das respostas TL desses DTLs e estimaram doses recebidas por pacientes na pele e corpo inteiro. 


\subsubsection{Dosímetros Termoluminescentes}

\subsubsection{Propriedades Dosimétricas}

Para um material TL ser utilizado em dosimetria ele deve combinar algumas características específicas como (Campos, 1998):

$\checkmark$ Alta concentração de elétrons ou buracos e alta eficiência de emissão de luz associada com o processo de recombinação;

$\checkmark \quad$ Estabilidade de armadilhamento dos elétrons ou buracos nas armadilhas à temperatura em que o material vai ser utilizado (decaimento térmico);

$\checkmark$ Um espectro de emissão TL dentro da sensibilidade da fotomultiplicadora para evitar interferência da emissão incandescente, infravermelha, do próprio equipamento de medida. 0 recomendado é um espectro com comprimentos de onda entre 300 e $500 \mathrm{~nm}$;

$\checkmark$ Temperatura do pico principal entre 180 e $250{ }^{\circ} \mathrm{C}$;

$\checkmark$ Uma curva de emissão simples, de preferência com um único pico, para maior facilidade de operação e interpretação da leitura;

$\checkmark$ Fácil tratamento térmico de reutilização;

$\checkmark$ Resistência a diversos fatores ambientais tais como luz, umidade, solventes orgânicos, poluição e gases;

$\checkmark \quad$ Uma resposta que varie linearmente para um amplo intervalo de dose absorvida;

$\checkmark \quad$ Baixo custo e facilidade de obtenção.

É difícil encontrar um material com todas essas características, dessa forma, os dosímetros termoluminescentes comumente utilizados apresentam um compromisso razoável entre as características anteriormente enumeradas (Campos, 1998).

A dosimetria termoluminescente apresenta como desvantagens (Oberhofer e Scharmann, 1981):

$\checkmark$ Sensibilidade à luz UV;

$\checkmark$ Instabilidade de armazenamento;

$\checkmark \quad$ Tempo para a leitura de dose. 
Alguns parâmetros físicos relacionados às propriedades do material dosimétrico e às metodologias de medida podem influenciar a resposta $\mathrm{TL}$, entre eles estão (Oberhofer e Scharmann, 1981):

$\checkmark$ Variação da resposta TL com a dose;

$\checkmark$ Dose acumulada;

$\checkmark$ Taxa de dose de radiação;

$\checkmark$ Temperatura de armazenamento dos dosímetros;

$\checkmark$ Energia do feixe de radiação;

$\checkmark$ Direção do feixe de radiação;

$\checkmark$ Distância fonte-superfície;

$\checkmark$ Tamanho do campo de radiação;

$\checkmark$ Presença de modificadores do feixe;

$\checkmark$ Espessura da camada de retroespalhamento;

$\checkmark$ Profundidade da medida.

Durante a avaliação da resposta TL, alguns fatores como tratamento térmico dos detectores, metodologia de avaliação e testes de estabilidade da leitora termolumescente, devem ser considerados. Os parâmetros que devem ser avaliados durantes esses processos são (Oberhofer e Scharmann, 1981):

$\checkmark$ Reprodutibilidade do tratamento térmico pré-irradiação;

$\checkmark$ Reprodutibilidade do ciclo de aquecimento durante a leitura;

$\checkmark$ Reprodutibilidade do posicionamento do dosímeto na leitora;

$\checkmark$ Estabilidade eletrônica da leitora ou dos sistemas associadas a ela;

$\checkmark$ Variações nas leituras dos dosímetros não-irradiados;

$\checkmark$ Variações do fluxo de nitrogênio.

Esses fatores citados afetam a acurácia e a precisão das medidas, portanto, devem ser monitorados ou, através de fatores de correção específicos, considerar seus efeitos (Oberhofer e Scharmann, 1981).

Na TAB. 1 são mostradas algumas das características típicas dos dosímetros termoluminescentes relacionadas à sua aplicação na dosimetria das radiações. 
TABELA 1 - Características dos dosímetros termoluminescentes (Adaptado de Mahesh et al, 1989).

\begin{tabular}{|c|c|}
\hline Propriedade & Características dos DTLs \\
\hline 1. Integração ou taxa de dose & Integração \\
\hline 2. Intervalo de dose normal - - & $1 \mathrm{mGy}-100 \mathrm{~Gy}$ \\
\hline 3. Linearidade de resposta ---- & Possível supralinearidade \\
\hline 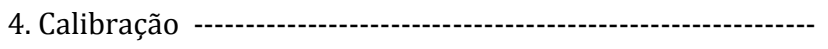 & Secundária \\
\hline 5. Precisão típica (coeficiente de variação) & \\
\hline (a) calibração do lote ---a- & $\pm 5 \%$ \\
\hline (b) calibração individual ----.-- & $\pm 1 \%$ \\
\hline 6. Equivalência aproximada ao tecido & Sim \\
\hline 7. Dependência com a taxa de dose - & Não \\
\hline 8. Espectrometria da dose - & Limitada \\
\hline 9. Medida dos gradientes de dose por meio do dosímetro ---- & Difícil \\
\hline 10. Decaimento relativo a dose armazenada & Baixo \\
\hline 11. gama e X detectado (dentro dos limites da dependência & \\
\hline da energia do fóton) - & Sim \\
\hline 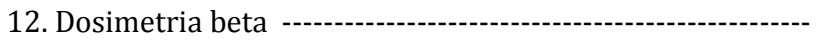 & Pode ser muito bom para dosímetros estreitos \\
\hline 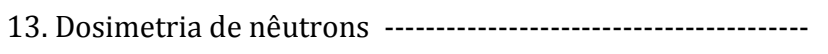 & Possível \\
\hline 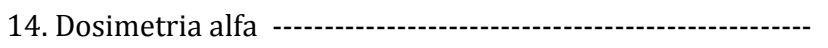 & Possível \\
\hline 15. Tamanho relativo -- & Pode ser muito pequeno \\
\hline 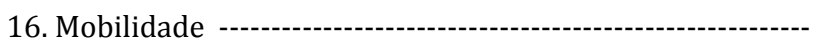 & Muito boa \\
\hline 17. Configurações geométricas disponíveis ----- & Ampla variedade \\
\hline 18. Efeitos direcionais - & Não-provável \\
\hline 19. Sensibilidade a condições ambientais ------------------ & Temperatura, oxigênio, luz, poeira \\
\hline 20. Resistência a ataque químico -- & Pode ser muito boa \\
\hline 21. Robustez & Boa \\
\hline 22. Avaliação rápida -------------------------- & Média \\
\hline 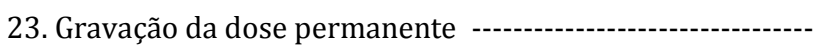 & Indireta \\
\hline 24. Reutilizável -- & Fácil \\
\hline 25. Medida de doses cumulativas & Não fácil \\
\hline 26. Apropriado para dosimetria de pele ---------------- & Sim \\
\hline 27. Apropriado para monitoramento de extremidade ------- & Sim \\
\hline 28. Apropriado para medidas in vivo - & $\operatorname{Sim}$ \\
\hline 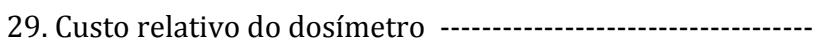 & Moderado \\
\hline 30. Custo do dispositivo de leitura -- & Alto \\
\hline 31. Custo da leitura -- & Baixo \\
\hline 32. Disponível comercialmente ---- & Sim \\
\hline 33. Habilidade pessoal necessária para avaliação ----------- & Não para trabalho de rotina \\
\hline
\end{tabular}

Para a monitoração in vivo, as principais vantagens dos DTLs são (Oberhofer e Scharmann, 1981): 
$\checkmark$ Sensibilidade a doses muito pequenas ( $5 \mu \mathrm{Sv}$ e $0,2 \mathrm{mSv})$;

$\checkmark$ Custo relativamente baixo;

$\checkmark$ Facilidade de uso devido ao seu pequeno tamanho;

$\checkmark$ Reutilizável após tratamento térmico específico;

$\checkmark$ Acurácia e precisão;

$\checkmark$ Resposta linear para um amplo intervalo de dose;

$\checkmark \quad$ Os materiais TLs consistem basicamente de um único material. Assim, a leitura do dosímetro TL geralmente é independente da distribuição angular da radiação. Este é um fator importante para medidas em geometria complexas e irregulares, onde se torna difícil estimar a direção na qual a radiação está incidindo.

\subsection{Curva de Emissão}

A curva de emissão TL é a melhor característica de um material TL e representa a variação da intensidade da resposta TL em função da temperatura de aquecimento ou do tempo de aquisição (Metcalfe et al, 2007). A curva TL de um material em função da temperatura apresenta picos e cada pico está relacionado a um tipo de armadilha, que pode ser de buracos ou elétrons. A formação de um pico de emissão TL está associada à probabilidade de escape do buraco ou elétron, da sua correspondente armadilha. Desse modo, quando a temperatura do material é menor que a do pico considerado, poucos portadores de cargas (buracos ou elétrons) são liberados, e a luz emitida é pouco intensa. Ao se aquecer o material, a probabilidade de escape aumenta, proporcionando um aumento da emissão TL, que é máxima na temperatura do pico. A intensidade da luminescência decresce, em seguida, pois há uma redução dos portadores de carga armadilhados (Campos, 1998). Cada material apresenta uma curva TL característica e estas serão apresentadas nos itens 3.4.5.1 e 3.4.6.1 para os dosímetros de LiF:Mg,Ti e $\mathrm{CaSO}_{4}$ :Dy respectivamente.

\subsection{Variação da Resposta TL com a Dose}

A curva de dose-resposta é definida como a relação entre a intensidade da resposta TL do dosímetro e a dose de radiação absorvida por este. 0 ideal é que um 
material dosimétrico apresente uma dose-resposta linear em um amplo intervalo de dose. Esses materiais apresentam um limite inferior de detecção (LID) abaixo do qual os dosímetros não conseguem diferenciar as doses com que foram irradiados.

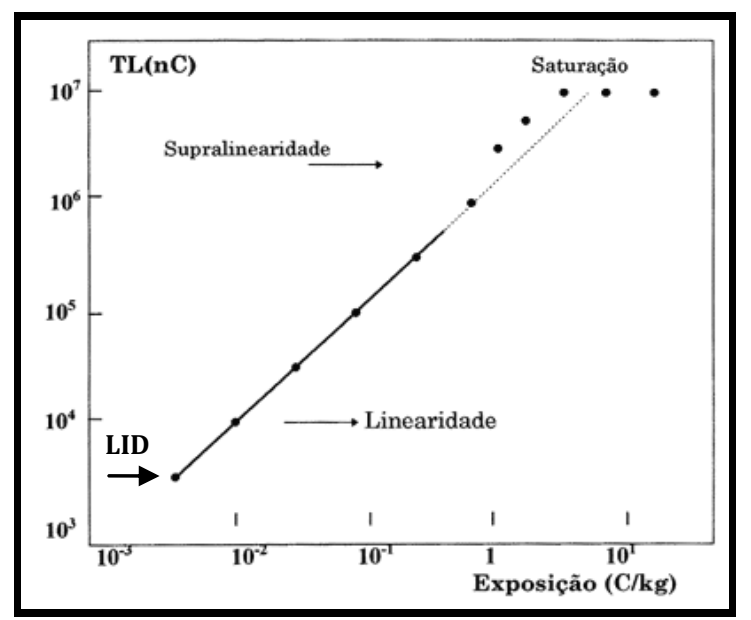

FIGURA 9 - Curva de dose-resposta de um material TL em função da exposição (Adaptado de Campos, 1998).

Como é mostrado na FIG. 9, a partir do LID até certo valor de dose, a curva apresenta comportamento linear e em determinado ponto, a quantidade de luz emitida cresce mais rápido do que na região linear e a essa região dá-se o nome de supralinear. Para valores muito altos de dose, a resposta TL pode saturar e com isso reduzir a sensibilidade do dosímetro (Oberhofer e Scharmann, 1981; McKeever et al, 1995).

Uma curva de dose-resposta ideal de um dosímetro termoluminescente é linear em todo o intervalo útil de exposição a fim de facilitar seu uso e simplificar sua calibração. Alguns DTLs podem não responder de forma linear, com isso é necessária uma calibração adequada para o intervalo de dose de interesse (Cameron et al, 1968).

\subsection{Sensibilidade}

A sensibilidade de um material TL é definida como a intensidade da resposta TL emitida por unidade de dose absorvida, EQ. 4 (McKeever et al, 1995).

$$
S_{D T L}=\frac{\text { resposta. } T L_{D T L}}{\text { Dose }}\left[\frac{\mu C}{G y}\right]
$$


Além da sensibilidade individual dos detectores, é calculado também a sua sensibilidade individual relativa à radiação de ${ }^{60}$ Co através da EQ. 5 :

$$
S_{D T L, E /{ }^{60} C o}=\frac{T L_{E}}{T L^{60} C o}
$$

em que: $S_{D T L, E /{ }^{60} C o}=$ sensibilidade TL individual relativa ao ${ }^{60} \mathrm{Co}$;

$T L_{E}=$ resposta $\mathrm{TL}$ do dosímetro irradiado com uma energia E;

$T L^{60} C_{o}=$ resposta $\mathrm{TL}$ do mesmo dosímetro irradiado para o feixe de ${ }^{60} \mathrm{Co}$ no ar.

Na prática, compara-se a resposta TL do material de interesse com a resposta TL do LiF (TLD-100), o que é denominado como sensibilidade relativa. 0 TLD-100 possui sensibilidade igual a 1 e a sensibilidade relativa é representada pela EQ. 6 (McKeever, 1995):

$$
S(D)=\frac{F(D)_{\text {material }}}{F(D)_{T L D-100}}
$$

em que: $S(D)=$ sensibilidade relativa;

$$
\begin{aligned}
& F(D)_{\text {material }}=\text { sensibilidade do material de interesse; } \\
& F(D)_{T L D-100}=\text { sensibilidade do } \mathrm{LiF}=1 .
\end{aligned}
$$

A sensibilidade depende do histórico de tratamento térmico e também da composição do material. A taxa de resfriamento após o tratamento térmico à alta temperatura e a taxa de aquecimento durante a leitura são fatores importantes que podem influenciar a sensibilidade. 


\subsection{Limite Inferior de Detecção (LID)}

O limite inferior de detecção, que pode ser definido como a menor dose discriminada a partir da dose zero, pode ser calculado através da variação da resposta TL de detectores não-irradiados, EQ.7 (Oberhofer e Scharmann, 1981):

$$
L I D=\left(R T_{0}+3 \sigma_{R T_{0}}\right) \cdot f_{c a l}
$$

em que: $R T_{0}=$ leitura média dos dosímetros não-irradiados;

$$
\begin{aligned}
& \sigma_{R T_{0}}=\text { desvio-padrão da medida dos dosímetros não-irradiados; } \\
& f_{c a l}=\text { fator de calibração. }
\end{aligned}
$$

Esse fator de calibração corresponde ao inverso do coeficiente angular da curva dose-resposta.

A resposta TL presente em dosímetros não-irradiados pode ser devido a alguns fatores como: triboluminescência, quimioluminescência, estimulação do detector por luz visível ou ultravioleta e sinais residuais de irradiações anteriores (Oberhofer e Scharmann, 1981).

\subsection{Estabilidade e Reprodutibilidade}

Existe um intervalo de tempo após a irradiação do dosímetro e antes da sua leitura que é importante para a estabilização das armadilhas do material. Durante esse intervalo pode haver ou não uma variação na intensidade da resposta TL, que é caracterizado como estabilidade e, no caso dos dosímetros termoluminescentes, é denominada como estabilidade físico-química. Durante repetidos processos térmicos e repetidas exposições, um fósforo utilizado para finalidade dosimétrica não deve sofrer alterações físico-químicas e se apresentar o mais insensível possível às mudanças externas, pois condições ambientais, como temperatura e umidade, podem influenciar a estabilidade do dosímetro (Oberhofer e Scharmann, 1981).

Como conseqüência da estabilidade do fósforo pode-se avaliar a reprodutibilidade de cada material, que está associada à precisão. A reprodutibilidade, para determinada dose, pode ser obtida através do cálculo do 
desvio-padrão de um conjunto de medidas, sob as mesmas condições de exposição e leitura (Oberhofer e Scharmann, 1981). Quanto menor o desvio-padrão, maior a precisão e com isso, melhor a reprodutibilidade.

\subsection{Decaimento Térmico do Sinal TL}

O processo no qual ocorre uma redução da resposta TL é denominado decaimento e é devido à liberação espontânea dos elétrons de suas armadilhas com a conseqüente emissão de luz. Esse decréscimo pode ter diversas causas, mas a principal é o decaimento da resposta TL em função da temperatura, ou seja, o decaimento térmico. Quanto menor for o intervalo de energia entre a banda de condução e a armadilha, maior a probabilidade de ocorrer a emissão espontânea (McKeever et al, 1995; Campos, 1998).

\subsection{Eficiência Intrínseca}

A eficiência intrínseca (EI) dos dosímetros relaciona a resposta TL, a dose de radiação fornecida aos dosímetros e as suas respectivas massas e pode ser definida através da EQ. 8:

$$
E I=\frac{\left(E_{T L} / m\right)}{D}
$$

EQ. 8

em que: $E I=$ eficiência intrínseca;

$E_{T L}=$ emissão termoluminescente;

$m$ = massa dos dosímetros;

$D=$ dose de radiação fornecida aos dosímetros.

Fazendo uma análise da EQ. 8, nota-se que a razão da resposta TL pela dose de radiação $\left(\frac{E_{T L}}{D}\right)$ corresponde ao coeficiente angular (A) da curva de doseresposta, EQ. 9: 


$$
\frac{E_{T L}}{D}=A=\frac{\Delta_{Y}}{\Delta_{X}}\left[\frac{\mu C}{G y}\right]
$$

Desse modo, para o cálculo da EI utiliza-se a EQ. 10:

$$
E I=\frac{A}{m}
$$

em que: $A$ = coeficiente angular da reta;

$m$ = massa dos dosímetros.

\subsubsection{Tratamento Térmico}

O tratamento térmico tem como objetivo restituir ao dosímetro as condições existentes antes da sua primeira irradiação. Esse processo de aquecimento remove os sinais residuais de exposições anteriores esvaziando e estabilizando as armadilhas. Isso faz com que os dosímetros estejam aptos para uma nova utilização sem perder suas propriedades dosimétricas (Cameron et al, 1968; Campos, 1998).

A sensibilidade pode ser influenciada pelo tratamento térmico com isso, é de extrema importância que os dosímetros sejam submetidos a tratamentos iguais. 0 tratamento térmico influi também na estrutura da curva de emissão TL, pois a reprodutibilidade da resposta TL está relacionada com a reprodutibilidade das taxas de aquecimento e resfriamento do fósforo. Desse modo, para se manter essas taxas reprodutíveis, um forno capaz de manter a temperatura pré-estabelecida em um grande intervalo de tempo é fundamental para a dosimetria TL (Cameron et al, 1968; Oberhofer e Scharmann, 1981).

\subsubsection{Armazenamento e manuseio}

É importante evitar a exposição dos dosímetros à radiação ultravioleta (UV), pois esta pode aumentar a radiação de fundo (Background) e o decaimento térmico da resposta TL. Porém, esses efeitos não alteram significantemente as avaliações de doses características de tratamentos radioterápicos (Cameron et al, 1968). 
A melhor maneira para se manusear os dosímetros é com o auxilio de pinças. Esse procedimento evita a contaminação dos detectores, mas caso isso ocorra, é necessário recorrer a métodos de limpeza adequados a cada tipo de fósforo e submetê-los a nova calibração (Oberhofer e Scharmann, 1981).

\subsubsection{Fluoreto de Lítio dopado com Magnésio e Titânio - LiF:Mg,Ti}

O LiF:Mg,Ti é um dos materiais termoluminescentes mais utilizados e estudados na área da dosimetria em radioterapia (Mackinlay, 1981; Metcalfe et al, 1997). Esse dosímetro foi desenvolvido pela Harshaw Chemical Company Inc., USA em colaboração com Cameron.

A Harshaw comercializa o fluoreto de lítio (LiF) como TLD-100 e seus variantes isotópicos TLD-600 e TLD-700 na forma de pó, discos, bastões e pastilhas. A forma mais utilizada do TLD-100 é a pastilha, com 3,1 x 3,1 $\mathrm{mm}^{2}$ de área e espessuras que variam entre 0,14 $\mathrm{mm}$ a 0,90 mm (Oberhofer e Scharmann, 1981; Kron et al, 1994; McKeever et al, 1995).

Esse fósforo possui algumas características que justificam sua popularidade. Entre elas estão seu número atômico efetivo próximo ao do tecido humano, sua boa sensibilidade e uma grande confiabilidade nas medidas (McKeever et al, 1995). Além disso, a dependência da sua resposta com a energia, a taxa de dose e as temperaturas de utilização e armazenamento são consideradas pequenas no intervalo de doses utilizadas em radioterapia (Rúden, 1976; Nunes, 2008).

A aplicação do LiF:Mg,Ti na radioterapia é bastante recomendável pois com ele é possível obter, na prática clínica, uma precisão melhor que $\pm 5 \%$ nas medidas (Rúden, 1976). Na TAB. 2 são apresentadas algumas das características principais dos TLD-100. 
TABELA 2 - Propriedades do TLD-100 (Adaptado de Mackinlay, 1981; Mahesh et al, 1989; Metcalfe et al, 2007).

\begin{tabular}{|c|c|}
\hline Propriedades & TLD-100 \\
\hline \multirow[t]{2}{*}{ Constituição Isotópica } & 7,4 \\
\hline & 92,6 \\
\hline 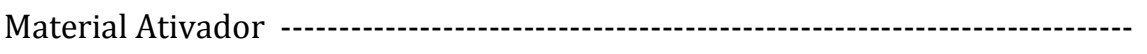 & $\mathrm{Mg}, \mathrm{Ti}$ \\
\hline Número Atômico Efetivo -------------------. & 8,2 \\
\hline 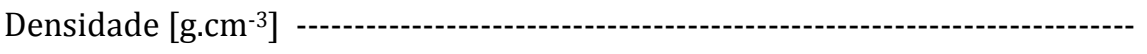 & 2,64 \\
\hline Máximo Comprimento de Onda da Luz Emitida [nm] - & 400 \\
\hline Decaimento Térmico da Resposta TL do Pico Principal a $20^{\circ} \mathrm{C}$ & $<10 \%$ ao ano \\
\hline Intervalo Útil de Dose - & $50 \mu \mathrm{Gy}$ a $10^{3} \mathrm{~Gy}$ \\
\hline Supralinearidade (radiação de fótons) [Gy] ----- & 1 \\
\hline Tratamento Térmico Pré-Irradiação --------. & $\begin{array}{l}400^{\circ} \mathrm{C} \text { por } 1 \mathrm{~h} \\
-100^{\circ} \mathrm{C} \text { por } 2 \mathrm{~h}\end{array}$ \\
\hline Antecedência máxima da Irradiação --------- & $24 \mathrm{~h}$ \\
\hline
\end{tabular}

\subsubsection{Curva de Emissão}

Na FIG. 10 é apresentada a curva de emissão do LiF:Mg,Ti. Pode-se observar que, até uma temperatura de $250^{\circ} \mathrm{C}$, existem seis diferentes picos de emissão que estão relacionados a diferentes armadilhas. Para finalidade dosimétrica, são utilizados os picos IV e V para a avaliação da leitura da dose no LiF:Mg,Ti.

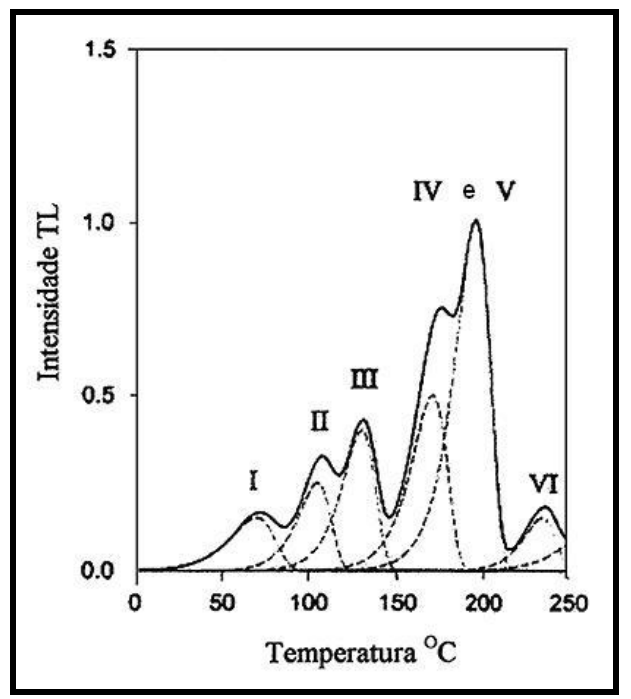

FIGURA 10 - Curva de emissão TL do LiF:Mg,Ti. Adaptado de Metcalfe et al, 2007. 
Na TAB. 3 são apresentadas as características como diferenças energéticas, temperatura de leitura e meia vida à temperatura ambiente, dos seis picos de emissão do TLD-100.

TABELA 3 - Características dos picos de emissão do LiF:Mg,Ti (Adaptado de Metcalfe et al, 2007).

\begin{tabular}{cccc}
\hline \multirow{2}{*}{ Pico } & $\begin{array}{c}\text { Diferenças } \\
\text { Energéticas } \\
\text { Aproximadas } \\
{[\mathrm{eV}]}\end{array}$ & $\begin{array}{c}\text { Temperatura de } \\
\text { Leitura } \\
{\left[{ }^{\circ} \mathrm{C}\right]}\end{array}$ & $\begin{array}{c}\text { Meia-Vida à } \\
\text { Temperatura } \\
\text { Ambiente }\end{array}$ \\
\hline I & 1,04 & & \\
II & 1,07 & 70 & 10 minutos \\
III & 1,05 & 105 & 20 horas \\
IV & 1,53 & 130 & 6 meses \\
V & 2,21 & 195 & 10 anos \\
VI & 1,70 & 235 & 80 anos \\
\hline
\end{tabular}

\subsubsection{Dose-Resposta e LID}

Para a prática da dosimetria termoluminescente é importante observar que o pico de emissão avaliado pode influenciar a supralinearidade e os vários picos na curva podem apresentar comportamento supralinear distinto. A composição química, as temperaturas de aquecimento e a taxa de resfriamento interferem no comportamento supralinear do LiF:Mg,Ti (Metcalfe et al, 2007).

0 LID do LiF:Mg,Ti é aproximadamente $500 \mu \mathrm{Gy}$ e sua resposta é linear até doses da ordem de 1 Gy. Acima dessa região de linearidade de dose a resposta é denominada supralinear e satura em doses de aproximadamente $10^{3}$ Gy. É recomendado se utilizar, na prática, o dosímetro termoluminescente na região linear (Metcalfe et al, 2007).

\subsubsection{Sensibilidade}

A sensibilidade dos dosímetros de $\mathrm{LiF}: \mathrm{Mg}, \mathrm{Ti}$ sofre uma perda de aproximadamente $1,5 \%$ a cada 10 Gy de radiação absorvida. A sua reprodutibilidade é de 1,1\% para um mesmo valor de dose e varia em até $5 \%$ para cada etapa dos ciclos de leitura (Cameron et al, 1968; Eggermont et al, 1971). 


\subsubsection{Decaimento Térmico}

Os vários picos da curva de emissão TL do LiF:Mg,Ti decaem, à temperatura ambiente, com meias-vidas em um intervalo que varia de minutos a anos como já foi visto na TAB. 3. O LiF:Mg,Ti apresenta decaimento térmico da resposta TL de 5 a 10\% por ano à temperatura ambiente. Os picos de meias-vidas curtas possuem leituras pequenas e seus sinais são considerados indesejáveis. Através de técnicas de tratamentos térmicos pré e pós-irradiação, esses sinais indesejáveis podem ser eliminados (Metcalfe et al, 2007).

\subsubsection{Sulfato de Cálcio dopado com Disprósio - $\mathrm{CaSO}_{4}: \mathrm{Dy}$}

$\mathrm{O} \mathrm{CaSO}_{4}$ :Dy é um dosímetro termoluminescente desenvolvido e produzido pelo Laboratório de Materiais Dosimétricos do Instituto de Pesquisas Energéticas e Nucleares (LMD/IPEN). Esse DTL é comercializado na forma de pó e pastilhas de $6 \mathrm{~mm}$ de diâmetro e espessuras de 0,2 e 0,8 $\mathrm{mm}$. Ainda pouco explorado na área da radioterapia, o $\mathrm{CaSO}_{4}$ :Dy é utilizado em medidas de dose em radioproteção e na monitoração das radiações beta e de fótons (Nunes, 2008).

$\mathrm{Na}$ TAB. 4 são apresentadas as propriedades dosimétricas e físicoquímicas desse detector (Campos e Lima, 1986; Campos e Lima, 1987).

TABELA 4 - Propriedades dosimétricas e físico-químicas do CaSO 4 :Dy. (Adaptado de Campos, 1983;

Campos e Lima, 1986; Mahesh et al, 1989).

\begin{tabular}{|c|c|}
\hline Propriedade & $\mathrm{CaSO}_{4}: \mathrm{Dy}$ \\
\hline 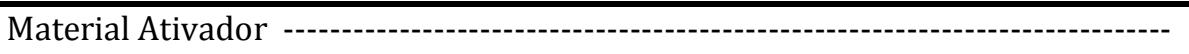 & Dy \\
\hline Número Atômico Efetivo (Z) --.-- & 15,3 \\
\hline Densidade [g.cm³] - & 4,93 \\
\hline Decaimento Térmico do Pico Principal à Temperatura Ambiente --- & $5 \%$ ao ano \\
\hline 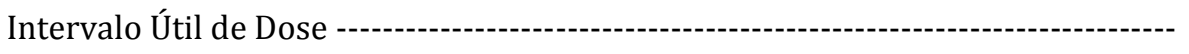 & $\mu \mathrm{Gy}$ a $10^{3} \mathrm{~Gy}$ \\
\hline Supralinearidade (radiação de fótons) [Gy] - & 100 \\
\hline 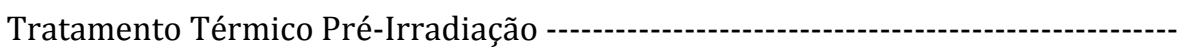 & $300^{\circ} \mathrm{C}$ por $3 \mathrm{~h}$ \\
\hline 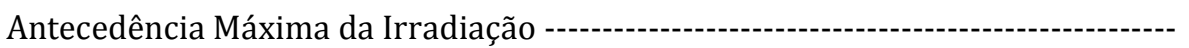 & $24 \mathrm{~h}$ \\
\hline
\end{tabular}


Embora possua número atômico efetivo superior ao do tecido humano, o $\mathrm{CaSO}_{4}$ :Dy, assim como o LiF:Mg,Ti, apresenta dependência energética com a taxa de dose e com temperaturas de utilização e armazenamento pequenas no intervalo de doses utilizado em radioterapia. Essas características possibilitam o uso do $\mathrm{CaSO}_{4}$ :Dy como uma nova alternativa para a dosimetria clínica.

\subsubsection{Curva de Emissão}

A curva de emissão do $\mathrm{CaSO}_{4}$ :Dy é mostrada na FIG. 11 e nela pode ser observado dois picos de emissão distintos: o primeiro em uma temperatura de $145^{\circ} \mathrm{C}$ e o segundo em $250^{\circ} \mathrm{C}$ Estes picos estão associados a armadilhas de dois diferentes níveis de energia (Campos e Lima, 1986).

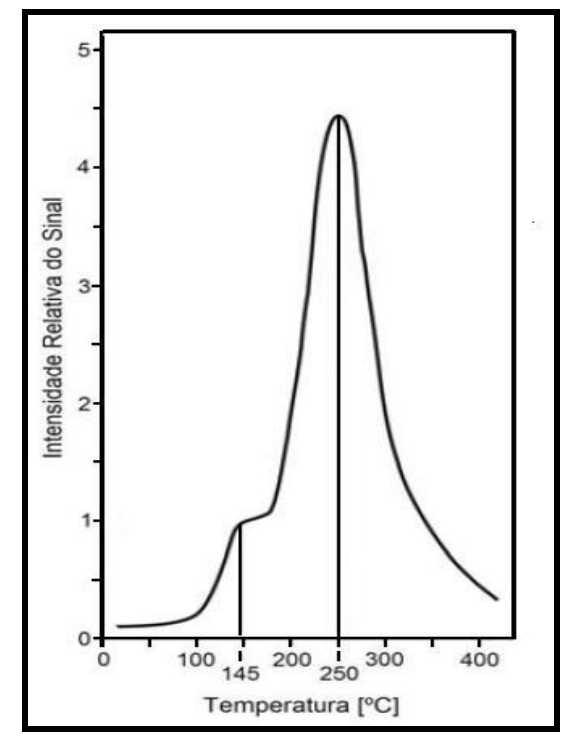

FIGURA 11 - Curva de emissão TL do $\mathrm{CaSO}_{4}$ :Dy. Adaptado de Campos e Lima, 1986.

\subsubsection{Dose-Resposta e LID}

A supralinearidade do $\mathrm{CaSO}_{4}$ :Dy depende do pico de emissão considerado, pois como já foi dito, os picos de emissão podem apresentar comportamentos supralineares distintos. 0 histórico de tratamentos térmicos, temperaturas de aquecimento, as taxas de resfriamento e possíveis danos no detector após irradiações com altas doses podem influenciar fortemente esse comportamento (Campos e Lima, 1986). 
0 LID do $\mathrm{CaSO}_{4}$ :Dy é de $10 \mu \mathrm{Gy}$, sua resposta é linear até doses de 10 Gy e a resposta TL satura em aproximadamente $10^{4}$ Gy (Campos e Lima, 1986; McKeever et al, 1995). Se os detectores forem utilizados na região supralinear é necessário que as leituras sejam corrigidas através de uma curva de calibração verificada periodicamente com o dosímetro e a leitora a serem utilizados. Para uma maior precisão nas medidas é recomendado que na dosimetria clínica se utilize os detectores apenas na região linear (IAEA, 2005).

\subsubsection{Sensibilidade}

$0 \mathrm{CaSO}_{4}$ :Dy apresenta uma perda de aproximadamente $2 \%$ a cada $10 \mathrm{~Gy}$ de radiação absorvida e a sua reprodutibilidade chega a até 1,95\% para 20 ciclos de leitura com as mesmas condições (Cameron et al, 1968; Eggermont et al, 1971).

As taxas de aquecimento e de resfriamento relacionadas ao tratamento térmico à alta temperatura possuem bastante influência sobre a sensibilidade TL do detector (Oberhofer e Scharmann, 1981).

\subsubsection{Decaimento Térmico}

Se for armazenado em blindagem de chumbo à temperatura ambiente, 0 $\mathrm{CaSO}_{4}$ :Dy apresenta um decaimento térmico da resposta TL de aproximadamente $5 \%$ ao ano (Campos e Lima, 1986).

\subsection{Objetos Simuladores}

Mesmo a água sendo o objeto simulador padrão para dosimetria de feixes de elétrons e fótons, vários materiais sólidos como poliestireno, PMMA, água sólida WT1 e água sólida RMI-457 são utilizados para a realização de medidas dosimétricas. Esses simuladores são constituídos por diferentes tipos de plásticos que possuem densidade, densidade eletrônica (número de elétrons por grama) e número atômico efetivo semelhantes aos da água (IAEA, 2005).

A ICRU em suas publicações "ICRU Report 44" e "ICRU Report 48" definem alguns tipos de simuladores de acordo com suas características físicas e, entre eles 
estão os simuladores padrão, que possuem pelo menos $30 \mathrm{~cm}$ de lado; os simuladores de referência, homogêneo e de características bem conhecidas; simuladores padrões de água; e simulador antropomórfico, heterogêneo e com formato do corpo humano. É recomendada a construção dos simuladores com materiais equivalentes ao tecido humano com uma referência ao PMMA (ICRU, 1988; ICRU, 1992). A ISO, em sua publicação DIS 4037, recomenda um simulador preenchido com água e com as mesmas dimensões estabelecidas pela ICRU Report 44 (ISO, 1996).

Na TAB. 5 é apresentada a composição química, a densidade nominal ( $\rho)$, o número atômico efetivo $\left(\mathrm{Z}_{\mathrm{ef}}\right)$ e o fator de escalonamento de profundidade $\left(\mathrm{f}_{\mathrm{pl}}\right)$ dos principais simuladores utilizados na dosimetria em radioterapia, PMMA, Água Sólida RMI-457 e Água.

TABELA 5 - Características físico-químicas e fator de escalonamento de profundidades para o PMMA, água sólida RMI-457 e água (Adaptado de IAEA, 2000).

\begin{tabular}{ccccc}
\hline & & PMMA & AS & Água \\
\hline \multirow{2}{*}{ Composição } & $\mathrm{H}$ & 0,0805 & 0,0809 & 0,1119 \\
química & $\mathrm{C}$ & 0,5998 & 0,6722 & \\
{$[\%$ massa] } & $\mathrm{N}$ & & 0,0240 & \\
& $\mathrm{O}$ & 0,3196 & 0,1984 & 0,8881 \\
& $\mathrm{Cl}$ & & 0,0013 & \\
& $\mathrm{Ca}$ & & 0,0232 & \\
& $\rho\left(\mathrm{g} . \mathrm{cm}^{-3}\right)$ & 1,19 & 1,03 & 1,00 \\
& $\mathrm{Z}_{\mathrm{ef}}$ & 5,85 & 5,96 & 1,000 \\
\hline
\end{tabular}

\subsection{Protocolos de Dosimetria}

Desde o surgimento da radioterapia, o principal objetivo da dosimetria nessa área é o de determinar, com maior acurácia e exatidão possíveis, a dose absorvida pelo tumor. Isso pode ser feito através da calibração do feixe de radiação e da dosimetria de rotina para o controle de qualidade, tanto dos equipamentos de terapia quanto dos tratamentos dos pacientes (Metcalfe et al, 2007).

Por ser uma técnica simples, com ótima resolução espacial e habilidade para cálculo de dose absorvida em períodos extensos, a dosimetria TL tem se 
destacado entre as diversas técnicas dosimétricas. 0 principal uso da dosimetria TL refere-se à dosimetria pessoal e a estudos de distribuição de dose de feixes de elétrons e fótons utilizando objetos simuladores (Robar et al, 1996).

No que diz respeito à calibração de feixes de fótons e elétrons de energias altas, até 1983 vários documentos de diferentes organizações apresentavam uma série de métodos baseados no uso de uma câmara de ionização calibrada para radiação de fótons do ${ }^{60} \mathrm{Co}$ e Raios-X de $2 \mathrm{MV}$ e rastreável ao Laboratório Nacional de Padrões Metrológicos (Nunes, 2008).

A publicação do Task Group no 21 (TG-21) pela AAPM propôs uma nova abordagem para a calibração dos feixes de radiação de fótons do ${ }^{60} \mathrm{Co}$, Raios-X de tensões de aceleração entre 2 e $50 \mathrm{MV}$, e de elétrons de energias máximas entre 5 e $50 \mathrm{MeV}$, com a determinação da dose na água e permitindo o uso de objetos simuladores plásticos na dosimetria de rotina para o controle de qualidade (AAPM, 1983).

A International Atomic Energy Agency (IAEA) publicou, em 1987, o código de práticas Technical Reports Series no 277 (TRS-227) na qual fazia recomendações quanto à determinação da dose na água a partir de medidas feitas com uma câmara de ionização em feixes de fótons e elétrons de energias altas baseadas em padrões primárias de kerma no ar (IAEA, 1987). Em 1997, dez anos depois, este código foi atualizado e complementado por uma segunda edição e pela publicação do TRS-381 que discute o uso de câmaras de ionização de placas paralelas e a calibração das câmaras em termos de dose na água diretamente em um simulador de água (IAEA, 1997; Nunes, 2008).

O Task Group no1 (TG-51), escrito pelo Comitê de Radioterapia da AAPM publicado em 1999, consiste de um protocolo para a dosimetria de referência clínica em feixes utilizados em Radioterapia: feixes de fótons com energias nominais entre a do ${ }^{60} \mathrm{Co}$ e $50 \mathrm{MV}$ e feixe de elétrons com energias nominais entre 4 e $50 \mathrm{MeV}$. Este protocolo visa à calibração dos feixes de radiação por meio de uma câmara de ionização calibrada em termos de dose absorvida na água e rastreável a um laboratório padrão primário (AAPM, 1999).

Em 2000, acompanhando os aperfeiçoamentos introduzidos pela AAPM, a IAEA publica um novo código de práticas, o Technical Reports Series no 398 (TRS-398) em que apresenta uma abordagem internacionalmente unificada para a calibração de 
feixes aplicados à Radioterapia, incluindo feixes de elétrons de energia de incidência mais provável entre 3 e $50 \mathrm{MeV}$, seguindo ainda o uso de câmaras de ionização calibradas em dose na água e rastreáveis a um laboratório padrão primário (IAEA, 2000). Diferentemente do TG-51, o TRS-398 não exclui completamente o uso de objetos simuladores de plásticos, podendo assim ser empregados na calibração dos feixes de fótons de energias baixas. 


\section{MATERIAIS E MÉTODOS}

\subsection{Dosímetros termoluminescentes (DTLs)}

Inicialmente foram utilizados lotes de cada tipo de dosímetro contendo:

$\checkmark 200$ dosímetros termoluminescentes de $\mathrm{CaSO}_{4}$ :Dy, fabricados pelo IPEN de $6 \mathrm{~mm}$ de diâmetro, 0,8 mm de espessura;

$\checkmark 160$ dosímetros termoluminescentes de LiF:Mg,Ti (TLD-100), fabricados pela Harshaw de 3,15 mm de lado, 0,9 $\mathrm{mm}$ de espessura;

$\checkmark 85$ microdosímetros termoluminescentes de LiF:Mg,Ti (TLD-100), fabricados pela Harshaw de 1,0 mm de lado, 1,0 $\mathrm{mm}$ de espessura.

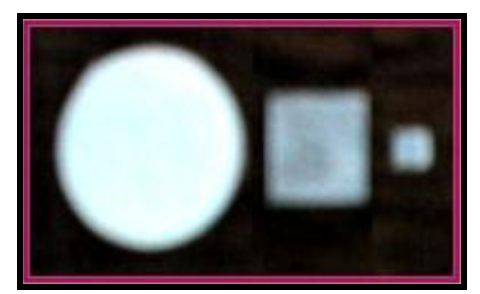

FIGURA 12 - Dosímetros TL de CaSO 4 :Dy, LiF:Mg,Ti e $\mu \mathrm{LiF}: M g, T i$, respectivamente.

Todos os dosímetros foram selecionados de acordo com a sua sensibilidade e reprodutibilidade. Com isso, os lotes iniciais de $\mathrm{CaSO}_{4}: \mathrm{Dy}$ e $\mathrm{LiF}: \mathrm{Mg}$,Ti foram reduzidos a 100 DTLs cada. O lote de microdosímetros de LiF:Mg,Ti se manteve como no início. As sensibilidades individuais ao ${ }^{60} \mathrm{Co}$ dos dosímetros selecionados variam no máximo 5\% para cada fósforo.

\subsection{Objetos simuladores}

As irradiações foram realizadas no Hospital Israelita Albert Einstein utilizando-se os objetos simuladores:

$\checkmark$ Placas de água sólida RMI-457 de dimensões 30 x $30 \mathrm{~cm}^{2}$ e espessuras variadas;

$\checkmark$ Placas de PMMA de dimensões $30 \times 30 \mathrm{~cm}^{2}$ e espessuras variadas;

$\checkmark$ Água (simulador cúbico de PMMA com dimensões $40,0 \times 40,0 \times 40,0 \mathrm{~cm}^{3}$ preenchido com água destilada). 


\subsection{Fontes de radiação ionizante}

\subsubsection{Irradiação gama}

Para esse tipo de irradiação, foram utilizadas fontes de ${ }^{60}$ Co dos Laboratórios do IPEN.

$\checkmark$ Fonte de ${ }^{60}$ Co do Laboratório de Materiais Dosimétricos, LMD/IPEN. Atividade nominal de 656,4 MBq em 09/12/2008 determinada por dosimetria com padrão secundário.

A fonte do LMD/IPEN (geometria $4 \pi$ ) possui dois aros em que o material pode ser irradiado, com 15 e $34 \mathrm{~cm}$ de diâmetro, como mostrado na FIG. 13.

$\checkmark$ Fonte de ${ }^{60}$ Co do Laboratório de Calibração de Instrumentos, LCI/IPEN. Atividade nominal de 111,0 GBq em 04/05/2007 determinada por dosimetria com padrão secundário.

A fonte do LCI-IPEN é uma unidade de teleterapia de ${ }^{60}$ Co que emite um feixe de radiação no sentido do eixo central do cabeçote do tratamento.

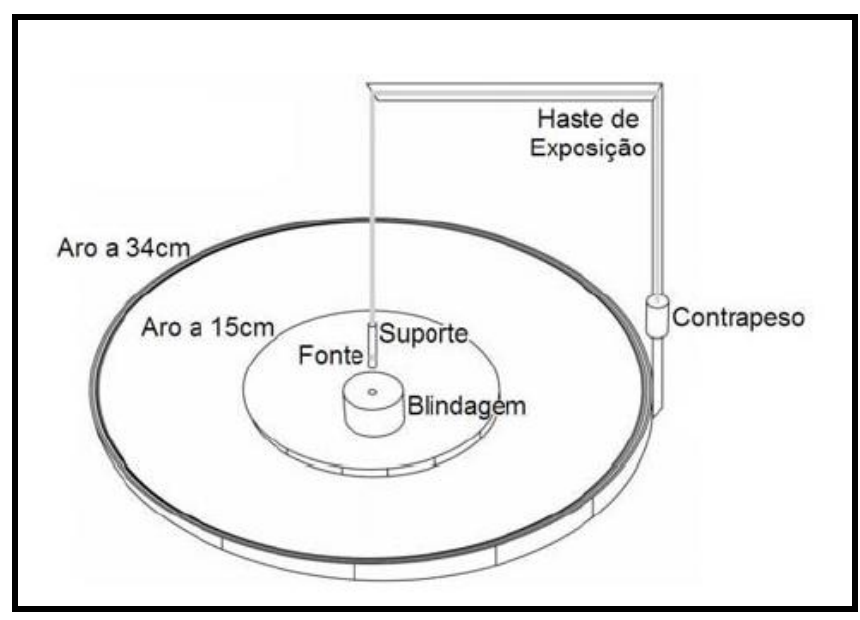

FIGURA 13 - Arranjo experimental da fonte de ${ }^{60}$ Co do LMD/IPEN (Nunes, 2008). 


\subsubsection{Irradiação com feixe de elétrons e fótons}

As irradiações foram realizadas no HIAE com o auxílio dos físicos responsáveis pelo Setor de Radioterapia. Foram utilizados os seguintes equipamentos:

$\checkmark$ Acelerador ${ }^{1}$ linear marca Varian, modelo Clinac 2100 C (para feixe de elétrons);

$\checkmark$ Acelerador ${ }^{1}$ linear marca Varian, modelo 23 EX (para feixe de fótons).

Os DTLs foram posicionados na profundidade de máxima dose e para assegurar o retroespalhamento do feixe foi utilizado, sob os DTLs, $5 \mathrm{~cm}$ de placas de mesmo material do objeto simulador em uso. Nesta geometria o feixe de radiação incide perpendicularmente sobre a mesa do acelerador atravessando o objeto simulador.

Nas FIG. 14 e 15 são mostrados os sistemas de irradiação dos DTLs para o simulador de PMMA e para o de água, respectivamente. 0 arranjo para irradiação com simulador de água sólida RMI-457 foi o mesmo do utilizado para o simulador de PMMA.

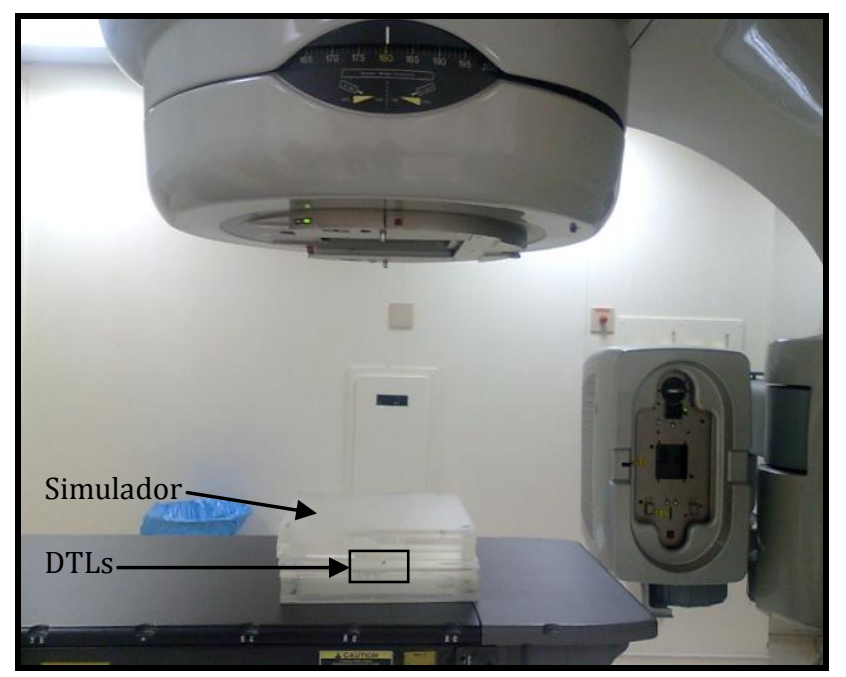

FIGURA 14 - Arranjo experimental do sistema de irradiação dos dosímetros em objeto simulador de PMMA. 


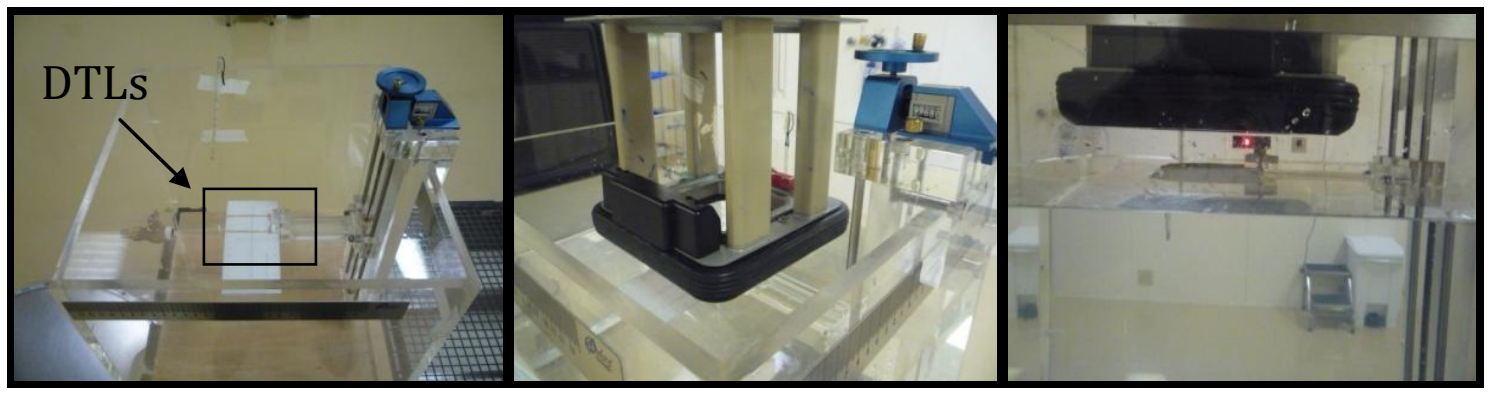

(a)

(b)

(c)

FIGURA 15 - (a) Objeto simulador de água; (b) Aplicador para irradiação com feixes de elétrons; (c) Arranjo experimental da irradiação dos DTLs em objeto simulador de água.

Para cada tipo de feixe e valores de energia selecionados foram utilizadas diferentes espessuras de material simulador para a irradiação dos DTLs, como mostra a TAB. 6. Essas espessuras representam as profundidades de máxima dose, valores calculados e fornecidos pelos físicos do Hospital. Para todos os simuladores foram utilizadas as mesmas espessuras.

TABELA 6 - Profundidades de máxima dose utilizadas para a irradiação dos DTLs.

\begin{tabular}{ccc}
\hline Irradiação & Energia & Profundidade \\
\hline Fótons & $6 \mathrm{MV}$ & $5 \mathrm{~cm}$ \\
& $15 \mathrm{MV}$ & $5 \mathrm{~cm}$ \\
\hline & $4 \mathrm{MeV}$ & $1,0 \mathrm{~cm}$ \\
& $6 \mathrm{MeV}$ & $1,2 \mathrm{~cm}$ \\
Elétrons & $9 \mathrm{MeV}$ & $2,0 \mathrm{~cm}$ \\
& $12 \mathrm{MeV}$ & $2,4 \mathrm{~cm}$ \\
& $16 \mathrm{MeV}$ & $1,7 \mathrm{~cm}$ \\
\hline
\end{tabular}

\subsection{Tratamento térmico dos dosímetros}

Os tratamentos térmicos foram realizados utilizando os equipamentos:

Forno mufla marca VULCAN, modelo 3-550 PD;

Estufa cirúrgica marca FANEN, modelo 315-IEA 11200. 
Após serem acomodados nas bandejas de alumínio, com o auxílio da pinça, os detectores foram submetidos a métodos de tratamento distintos. Os dosímetros LiF:Mg,Ti e $\mu \mathrm{LiF}: M g$,Ti receberam o tratamento térmico em duas etapas. A primeira, de 1 hora a $400^{\circ} \mathrm{C}$, no forno mufla $V U L C A N$ e a segunda, de 2 horas a $100^{\circ} \mathrm{C}$, na estufa cirúrgica FANEN. Os detectores $\mathrm{CaSO}_{4}$ :Dy possuem apenas uma etapa no tratamento térmico, de 3 horas a $300^{\circ} \mathrm{C}$, e esta foi realizada no forno mufla VULCAN. Nas FIG. 16 (a), (b) e (c) são mostrados o forno Vulcan, a estufa cirúrgica FANEM e a bandeja de alumínio com os DTLs de $\mathrm{CaSO}_{4}$ :Dy.

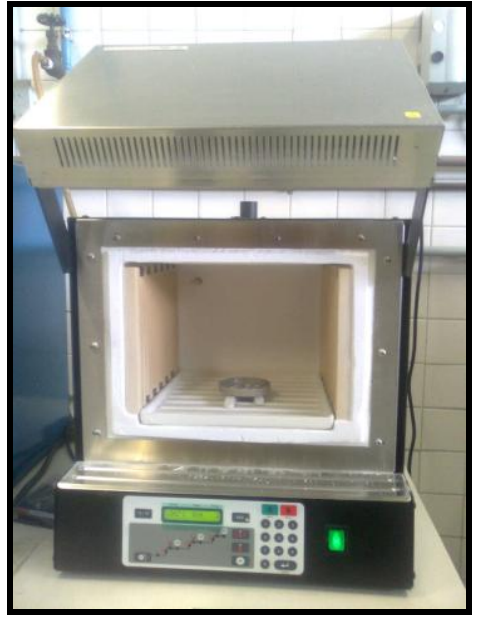

(a)

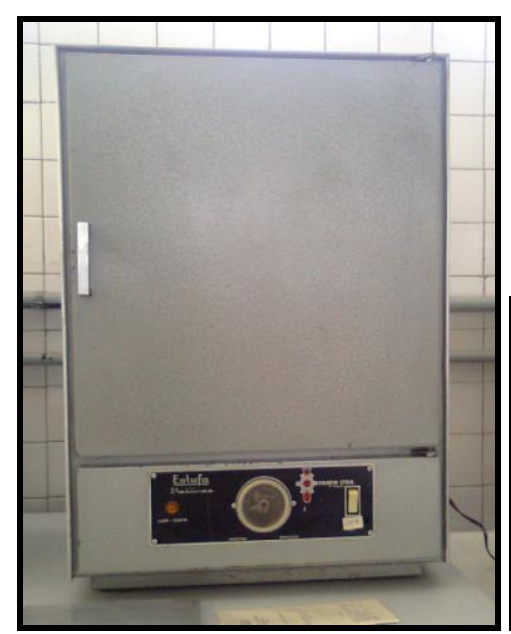

(b)

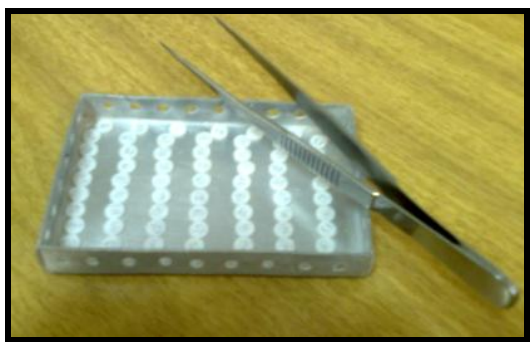

(c)

FIGURA 16 - (a) Forno tipo mufla marca VULCAN; (b) Estufa cirúrgica marca FANEM; (c) Dosímetros de $\mathrm{CaSO}_{4}$ :Dy acomodados na bandeja de alumínio.

Ao serem retiradas do forno e da estufa as bandejas de alumínio foram colocadas sob uma placa de alumínio para que atingissem a temperatura ambiente e os dosímetros pudessem ser assim, embalados e submetidos à irradiação.

\subsection{Acondicionamento dos dosímetros}

\footnotetext{
$\checkmark$ Placas de PMMA;

$\checkmark$ Papel Paraná;

$\checkmark$ Papel alumínio;

$\checkmark$ Plástico resistente;

$\checkmark$ Pinça;

$\checkmark$ Seladora de plástico manual.
} 
Para a irradiação utilizando radiação gama de ${ }^{60} \mathrm{Co}$, os DTLs foram irradiados, simultaneamente, acomodados em placas de acrílico, lado a lado, como mostrado na FIG. 17. Utilizou-se o papel Paraná para dar suporte ao dosímetros e impedir que estes se movimentassem. Esse arranjo experimental teve como objetivo facilitar o posicionamento dos DTLs, garantir a sua reprodutibilidade, evitar perdas de pastilhas e assegurar, com as placas de PMMA, o equilíbrio eletrônico na irradiação.

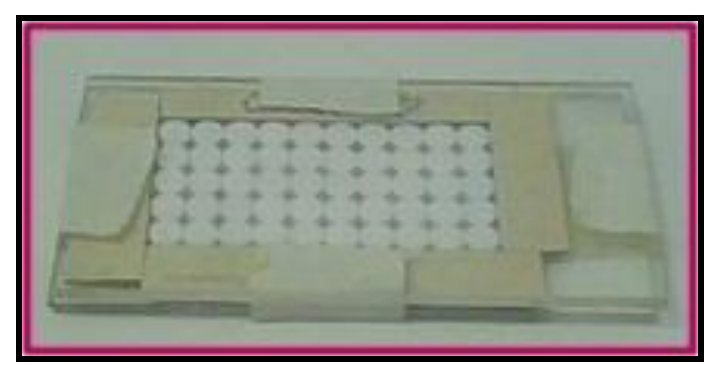

FIGURA 17 - Posicionamento dos DTLs de $\mathrm{CaSO}_{4}$ :Dy, em placas de PMMA, para irradiação no ar em fonte de ${ }^{60} \mathrm{Co}$.

As pastilhas foram enumeradas e os conjuntos de placas de PMMA (FIG. 17) afixados por meio de garras metálicas ao aro para se garantir a reprodutibilidade do posicionamento dos DTLs, como mostrado na FIG. 18.

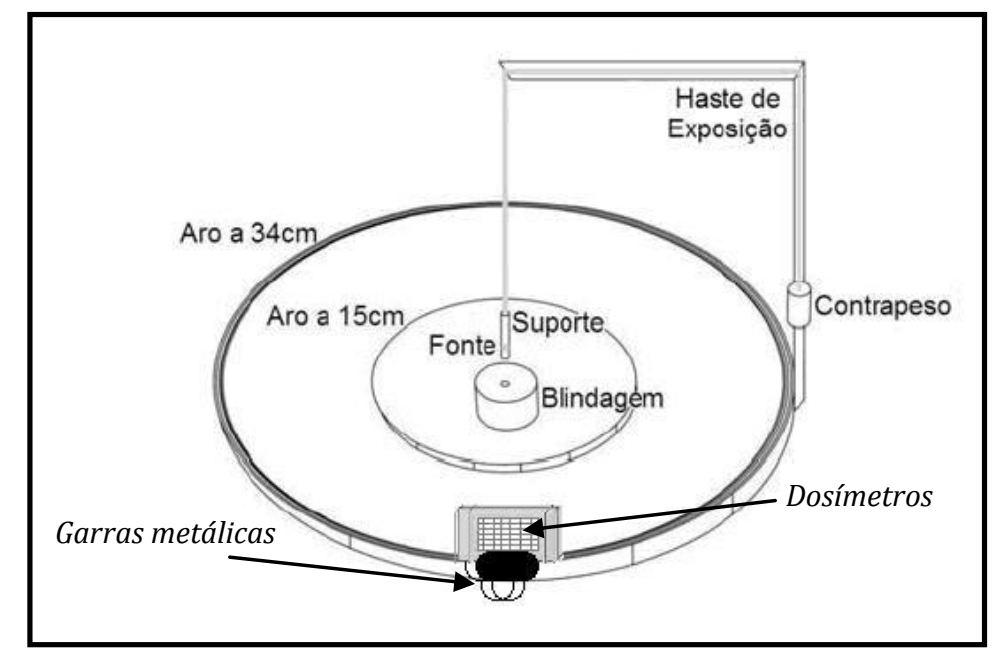

FIGURA 18 - Irradiação dos DTLs no aro a $34 \mathrm{~cm}$ da fonte de ${ }^{60} \mathrm{Co}$ do LMD/IPEN. Adaptado de Nunes, 2008.

No caso das irradiações feitas no HIAE, utilizando os simuladores de água sólida RMI-457, PMMA e água, os grupos de dosímetros foram embalados com 
plástico resistente e as embalagens foram seladas a fim de impedir o contato dos dosímetros com a água, como é mostrado na FIG. 19. É importante salientar que antes das irradiações foram feitos testes com papel simulando o dosímetro para ter certeza que as embalagens estivessem impermeáveis, pois os dosímetros foram imersos na água.

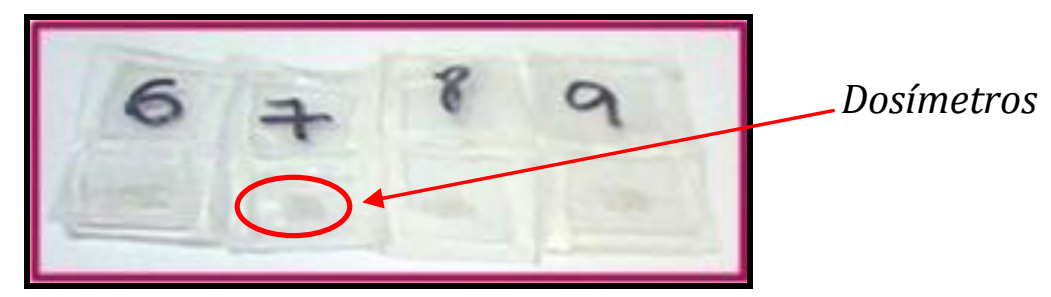

FIGURA 19 - Dosímetros embalados em plástico resistente para irradiação no acelerador linear.

Todos os lotes eram envolvidos com papel alumínio até o momento da irradiação e após a mesma. Esse procedimento evita a sensibilização através da luz ultravioleta.

\subsection{Leitura do sinal termoluminescente}

A leitura do sinal TL foi feita utilizando:

$\checkmark$ Leitora termoluminescente, marca Harshaw, modelo 3500;

$\checkmark$ Programa de aquisição de dados TLDSHELL para ambiente DOS.

Uma leitora TL, FIG. 20 (a), é constituída de um dispositivo para aquecer o dosímetro e uma fotomultiplicadora para captar a luz TL. A leitora possui uma prancheta metálica, FIG. 20 (b), onde o DTL é colocado e aquecido de acordo com o seu protocolo de leitura. Os fótons de termoluminescência produzidos, ao atingirem a janela do tubo fotomultiplicador, dão origem ao sinal TL.

0 ajuste da temperatura é feito em três fases, o pré-aquecimento, a aquisição e o tratamento, cada uma com tempos e temperaturas independentes e definidos pelo protocolo de leitura. 


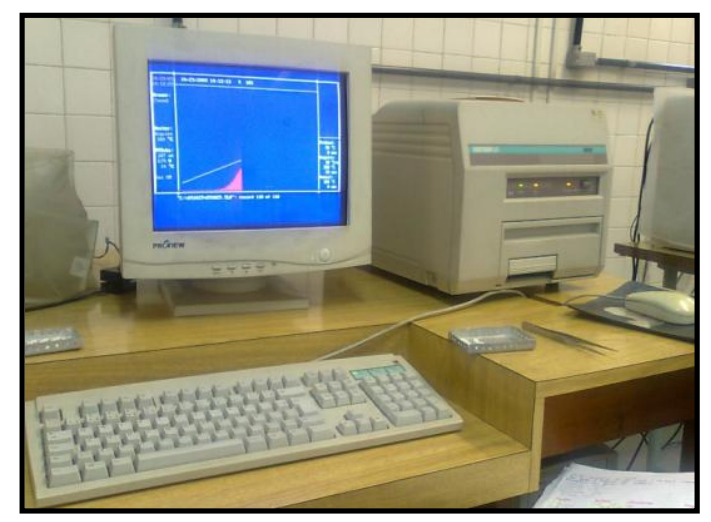

(a)

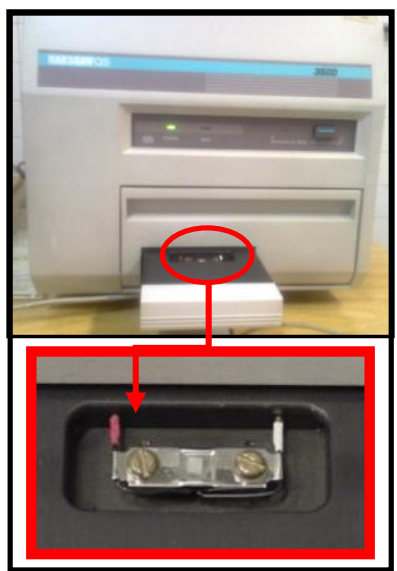

(b)

FIGURA 20 - (a) Sistema de leitura TL (leitora TL Harshaw e computador com o sistema de aquisição de dados TLDSHELL); (b) Prancheta metálica da leitora TL

O Programa de aquisição, TLDSHELL, possui protocolos de leitura desenvolvidos para os dosímetros comercializados pela Harshaw, assim como protocolos parametrizados pelo usuário que permitem o ajuste da taxa de aquecimento, dos tempos e das temperaturas de cada fase, possibilitando a leitura de vários tipos de DTLs, incluindo o $\mathrm{CaSO}_{4}: \mathrm{Dy}$.

Os protocolos utilizados foram os de número 3, 7 e 9, para o $\mathrm{LiF}: \mathrm{Mg}, \mathrm{Ti}$, microLiF:Mg,Ti e $\mathrm{CaSO}_{4}$ :Dy respectivamente. Estes diferem entre si quanto à temperatura de aquecimento e tempo total de aquisição da resposta TL. Para os protocolos 3 e 7 a temperatura se eleva até $300^{\circ} \mathrm{C}$ e o tempo total é igual 33,33 s. Já o protocolo utilizado para pastilhas de $\mathrm{CaSO}_{4}$ :Dy, número 9 , a temperatura atinge $350^{\circ} \mathrm{C}$ e o sistema se mantém nessa temperatura por mais 6,66 s.

A leitura do sinal TL dos dosímetros foi feita sempre entre 24 e 32 horas depois da irradiação e foi iniciada pelos DTLs de fluoreto de lítio, dado que seu decaimento térmico é mais intenso que o do sulfato de cálcio. Esse tempo de espera ocorre para que haja a estabilização das armadilhas dos DTLs. A umidade do ar e a temperatura da sala de leitura foram monitoradas para que estivessem sempre abaixo de $50 \%$ e $20^{\circ} \mathrm{C}$, respectivamente. 


\subsection{Teste de estabilidade da leitora}

Foram feitos sistematicamente dois testes para verificar se a leitora não apresenta qualquer tipo de variação, teste da luz padrão interna (Test Light) e teste da razão sinal/ruído (PMT Noise). Ao se iniciar um ciclo de leituras dos DTLs, 10 leituras da razão sinal/ruído e da luz padrão interna foram realizadas. Essa verificação é feita também no fim do ciclo de leituras. Se a variância do conjunto de 10 leituras fosse maior que 5\%, os valores eram rejeitados e as irradiações repetidas.

É necessário que alguns parâmetros sejam verificados periodicamente para se assegurar a estabilidade do sistema de dosimetria TL, como mostrado na TAB. 7 (IAEA, 2005).

TABELA 7 - Controle de qualidade dos DTLs utilizados na dosimetria do feixe de radiação.

\begin{tabular}{lll}
\hline Parâmetro & Frequência & Observações \\
\hline Temperatura do forno & Na seleção dos DTLs & Ou suspeita de problemas \\
Sensibilidade individual ao ${ }^{60} \mathrm{Co}$ & Mensalmente & Comparar com referência \\
Curvas de emissão & Mensalmente & Comparar com referência \\
Sinal/Ruído & A cada leitura & Variação dentro de $10 \%$ \\
Luz Padrão & A cada leitura & Variação dentro de $10 \%$ \\
\hline
\end{tabular}

\subsection{Seleção dos dosímetros}

Para a seleção inicial, os DTLs foram irradiados no aro de $34 \mathrm{~cm}$ da fonte de ${ }^{60}$ Co do LMD/IPEN, com as seguintes doses:

\footnotetext{
$\checkmark$ 0,356 mGy para LiF:Mg,Ti e $\mu \mathrm{LiF}: M g, T i ;$

$\checkmark$ 1,721 mGy para $\mathrm{CaSO}_{4}: \mathrm{Dy}$.
}

Após a leitura TL dos dosímetros, foi realizado o cálculo da sensibilidade individual de cada fósforo utilizando a EQ. 4 (item 3.4.4.1.3).

Os DTLs selecionados foram numerados e agrupados em subconjuntos de cinco pastilhas cada, de acordo com os seus valores de sensibilidade em relação ao ${ }^{60} \mathrm{Co}$. Estes foram submetidos a três irradiações na mesma fonte de ${ }^{60} \mathrm{Co}$, com doses de 3,278 mGy, no LMD/IPEN, para que fosse verificada a sua reprodutibilidade. Para essas irradiações, os detectores foram arranjados da mesma maneira como descrito 
no item 4.5. Esses valores devem respeitar uma variação máxima de $\pm 5 \%$ da resposta TL média.

A sensibilidade mais provável é determinada por meio do ajuste de uma gaussiana ao histograma das sensibilidades individuais dos DTLs. Cada leitura é uma variável aleatória independente que tem a mesma densidade de probabilidade das demais, assim, o teorema do limite central se aplica (Vuolo, 1992).

\subsection{Curvas de dose-resposta}

\subsubsection{Radiação Gama}

Os dosímetros selecionados foram irradiados no ar e em condições de equilíbrio eletrônico com doses de $5 \times 10^{-4}, 1 \times 10^{-3}, 5 \times 10^{-2}, 5 \times 10^{-1}, 1,5$ e 10 Gy para o levantamento das curvas de dose-resposta dos três detectores para o ${ }^{60} \mathrm{Co}$. Essas irradiações foram realizadas na fonte de radiação gama de ${ }^{60} \mathrm{Co}$ do LCI/IPEN.

\subsubsection{Feixe de Elétrons e Fótons}

No HIAE os dosímetros foram irradiados utilizando feixes de elétrons e fótons com os valores de energias e doses mostrados na TAB. 8. Essas irradiações foram feitas para os três simuladores, PMMA, água sólida e água.

TABELA 8 - Valores de energia e doses utilizados para irradiação dos DTLs no HIAE.

\begin{tabular}{cccc}
\hline Elétrons & Doses [Gy] & Fótons & Doses [Gy] \\
\hline $4 \mathrm{MeV}$ & 0,$5 ; 1,0 ; 5,0$ & & \\
$6 \mathrm{MeV}$ & 0,$1 ; 0,5 ; 1,0 ; 5,0 ; 10$ & $6 \mathrm{MV}$ & 0,$5 ; 1,0 ; 5,0$ \\
$9 \mathrm{MeV}$ & 0,$5 ; 1,0 ; 5,0$ & & \\
$12 \mathrm{MeV}$ & 0,$5 ; 1,0 ; 5,0$ & $15 \mathrm{MV}$ & 0,$1 ; 0,5 ; 1,0 ; 5,0 ; 10$ \\
$16 \mathrm{MeV}$ & 0,$5 ; 1,0 ; 5,0$ & & \\
\hline
\end{tabular}

Com as leituras dos DTLs feitas foram levantadas as curvas de resposta TL em função da dose de radiação para todos os tipos e valores de energia, assim como para todos os simuladores utilizados. 
Os dosímetros foram irradiados com cinco valores de doses 0,$1 ; 0,5 ; 1,0 ; 5,0$ e 10 Gy somente para o feixe de fótons de 15 MV e feixe de elétrons de $6 \mathrm{MeV}$. Para os demais valores de energia as irradiações foram feitas com apenas três doses $(0,5 ; 1,0$ e 5,0 Gy) para comparação. Isso foi feito para otimizar os processos de irradiação, utilizando o aparelho radioterápico o menor tempo possível, não atrapalhando a rotina clínica do Setor de Radioterapia do HIAE.

\subsection{Sensibilidade média dos grupos de DTLs}

Com base em todas as leituras das respostas TL dos três tipos de detectores feitas para o levantamento das curvas dose-resposta, foram calculadas as médias das respostas TL levando em consideração o objeto simulador, a energia e o tipo de feixe de radiação utilizados. Após isso, foi calculada a sensibilidade individual dos DTLs através da EQ. 4, apresentada no item 3.4.4.1.3., e a sensibilidade média de todas as leituras no intervalo de dose de radiação empregado $\left(5 \times 10^{-4}\right.$ a 10 Gy para o ${ }^{60}$ Co e 0,1 a 10 Gy para fótons e elétrons).

\subsection{Reprodutibilidade da resposta TL aos feixes de elétrons e fótons}

A sensibilidade TL individual relativa ao ${ }^{60} \mathrm{Co}$ foi calculada para cada dosímetro, utilizando a EQ. 5 (item 3.4.4.1.3), para a dose de 1 Gy.

Em seguida, foi calculada a sensibilidade relativa média e o seu desviopadrão, de acordo com o tipo de feixe de radiação e energia avaliadas. Assim, a reprodutibilidade da resposta TL aos feixes de elétrons e fótons de determinada energia pode ser dada como a razão entre o desvio-padrão da média e a própria sensibilidade relativa média.

\subsection{Limite inferior de detecção (LID)}

O limite inferior de detecção relaciona a resposta TL de dosímetros nãoirradiados, três vezes seu desvio-padrão $(3 \sigma)$ e um fator de calibração e foi calculado de acordo com a EQ. 7 do item 3.4.4.1.4. 


\subsection{Eficiência intrínseca dos DTLs}

Através da EQ. 10 (item 3.4.4.1.7) foi calculada a eficiência intrínseca dos detectores. Os coeficientes angulares das curvas dose-resposta dos DTLs utilizados foram fornecidos pelo programa de confecção dos gráficos, Origin 7.5.

\subsection{Incertezas nas medidas}

De acordo com as especificações do Guia para Expressões da Incerteza de Medições - ISO GUM (ISO, 1995), as incertezas nos resultados medidos estão agrupadas em duas categorias, tipo A e tipo B. A incerteza do tipo A é calculada empregando métodos estatísticos e a do tipo B é estimada de outras formas (nãoestatísticas) exigindo conhecimento da distribuição de probabilidade associada à incerteza (Vuolo, 1992).

Com isso, as incertezas do tipo A são de caráter aleatório, ou seja, devido à dispersão dos resultados obtidos em torno de um valor verdadeiro. As incertezas do tipo B são incertezas originadas de erros instrumentais, ambientais e observacionais. A incerteza total das medidas é dada pela EQ. 12 (Vuolo, 1992):

$$
\sigma_{\text {Total }}^{2}=\sigma_{\text {Estatistico }}^{2}+\sigma_{\text {Sistemático }}^{2}
$$

em que: $\quad \sigma_{\text {Total }}=$ Incerteza total;

$\sigma_{\text {Estatístico }}=$ Incerteza associada ao erro estatístico;

$\sigma_{\text {Sistemátio }}=$ Incerteza associada ao erro sistemático.

Para o cálculo das incertezas do tipo A foram utilizadas as EQ. 13 e 14:

$\checkmark$ Cálculo do desvio padrão da amostra:

$$
\sigma\left(y_{i}\right)=\sqrt{\frac{1}{n-1} \sum_{i=1}^{n}\left(y_{i}-\bar{y}\right)^{2}}
$$


$\checkmark$ Cálculo do desvio padrão da média:

$$
\sigma(\bar{y})=\frac{\sigma(y)}{\sqrt{n}}
$$

EQ. 14 


\section{RESULTADOS E DISCUSSÃO}

\subsection{Teste de estabilidade da leitora}

Na FIG. 21 estão representadas as médias de luz padrão de cada dia, a média de todos os dias de leitura e os limites de aceitação ( \pm 5 \% em relação à média), em função da data de leitura. As médias de razão sinal/ruído de cada dia, a média de todos os dias de leitura e os limites de aceitação ( $\pm 5 \%$ em relação à média), em função da data de leitura, são apresentadas na FIG. 22.

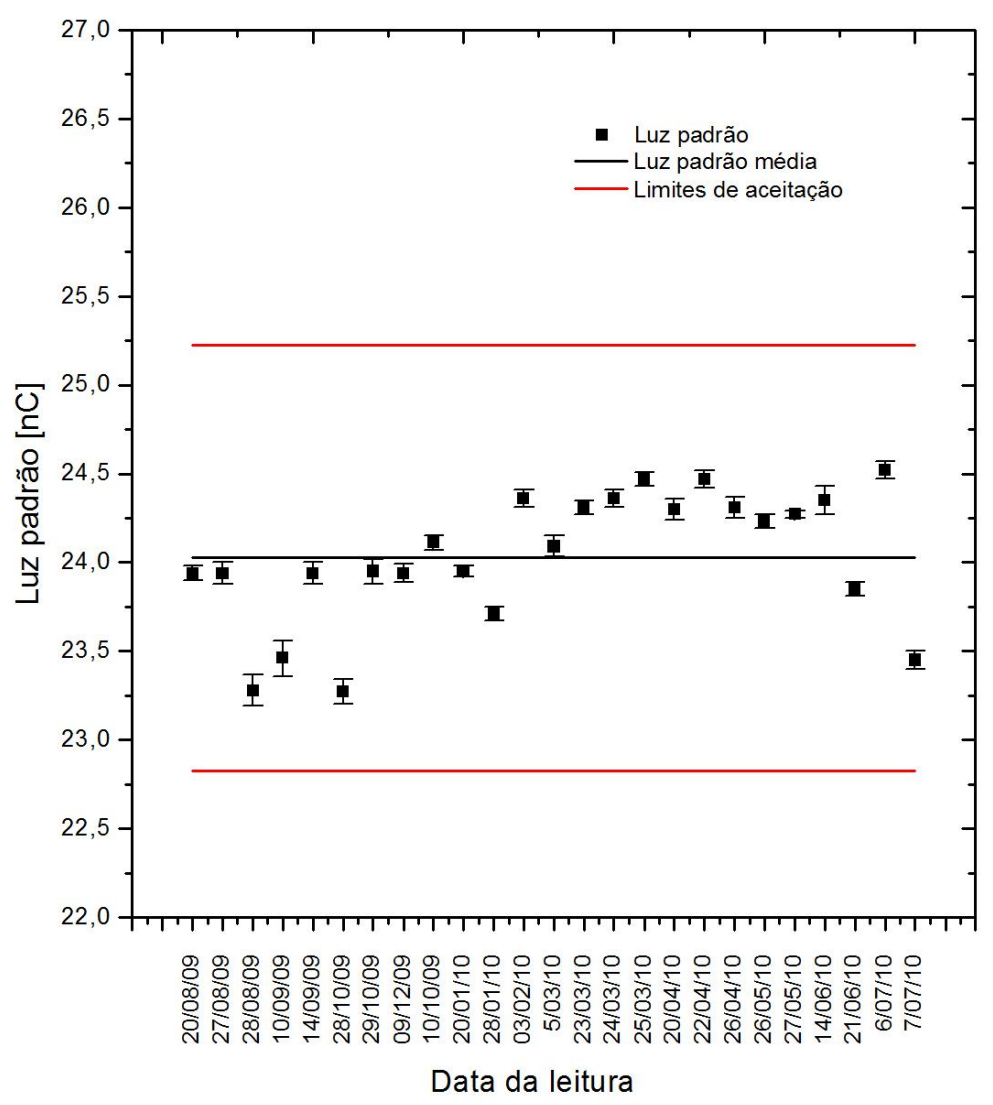

FIGURA 21 - Média das leituras de luz padrão de cada dia, médias de todos os dias de leitura e limite máximo de aceitação. 

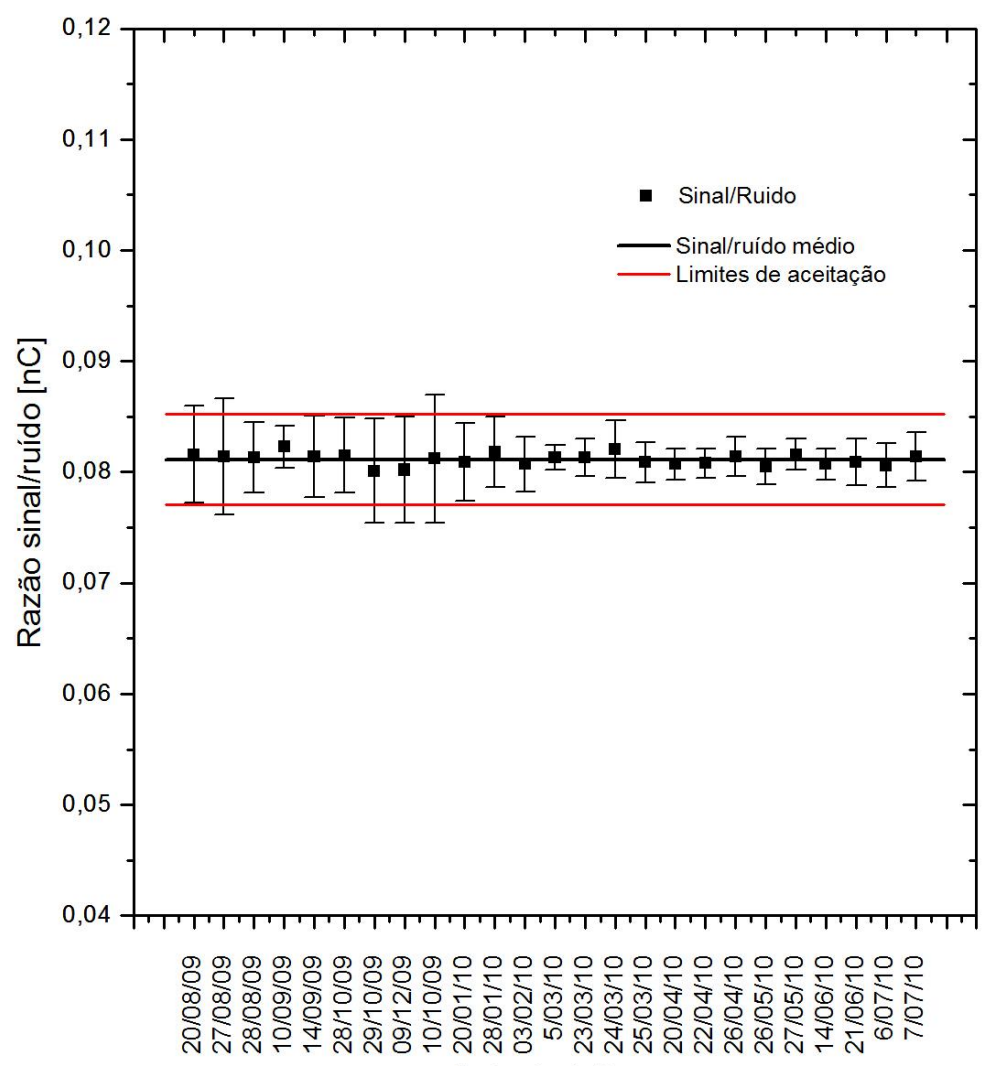

$$
\text { Data da leitura }
$$

FIGURA 22 - Média das leituras de razão sinal/ruído de cada dia, médias de todos os dias de leitura e limite máximo de aceitação.

Todos os valores obtidos para as médias das leituras de luz padrão de cada dia encontram-se dentro dos limites aceitáveis. Os valores obtidos para a média das leituras da razão sinal/ruído de cada dia de leitura também se encontram todos dentro dos limites de aceitação. Tomando por base os resultados, nota-se que a leitora apresentou boa estabilidade não sendo necessário repetir nenhuma leitura, ou seja, nenhuma irradiação.

\subsection{Seleção dos dosímetros}

Como os dosímetros de LiF:Mg,Ti já haviam sido utilizados anteriormente e não estavam separados por lotes de mesma sensibilidade, sua seleção teve que ser feita de forma mais minuciosa do que os demais. Os detectores de $\mathrm{CaSO}_{4}$ :Dy, eram novos e de dois lotes diferentes e $\mu \mathrm{LiF}: \mathrm{Mg}$,Ti, pertenciam ao mesmo lote recém adquirido mas haviam sido utilizados algumas vezes.

Inicialmente contava-se com lotes de 200 pastilhas de $\mathrm{CaSO}_{4} \mathrm{Dy}$, 160 pastilhas de LiF:Mg,Ti e 85 pastilhas de microLiF:Mg,Ti. Após a seleção inicial e cálculo das sensibilidades, os dosímetros saturados foram eliminados, as irradiações 
repetidas e assim, os lotes foram reduzidos a 100 detectores de $\mathrm{CaSO}_{4}: \mathrm{Dy}$, 100 detectores de LiF:Mg,Ti e se manteve o lote de 85 detectores de microLiF:Mg,Ti. Essa seleção fez com que se obtivesse lotes mais homogêneos e com sensibilidades próximas a fim de se garantir medidas precisas e confiáveis.

Os histogramas das sensibilidades das respostas TL do $\mathrm{CaSO}_{4}$ :Dy, obtidos para a seleção dos dosímetros são apresentados na FIG. 23 (a), (b) e (c), e a FIG. 23 (d) mostra o histograma dos dosímetros já selecionados.

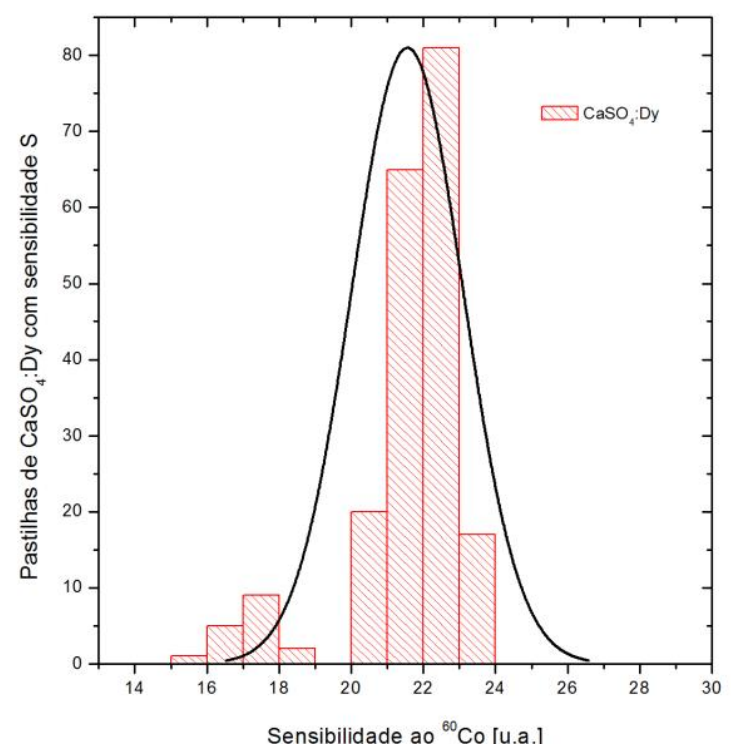

(a)

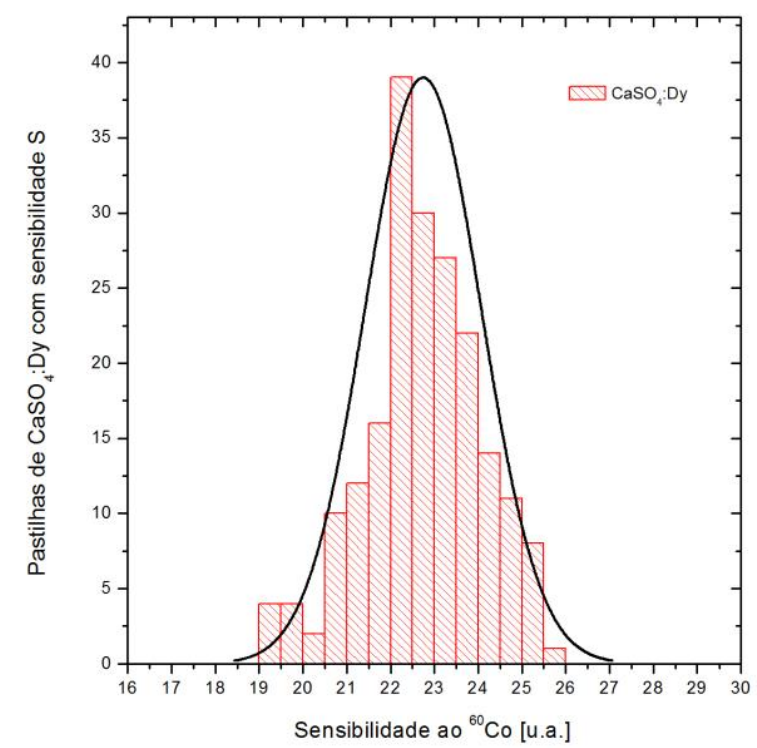

(c)

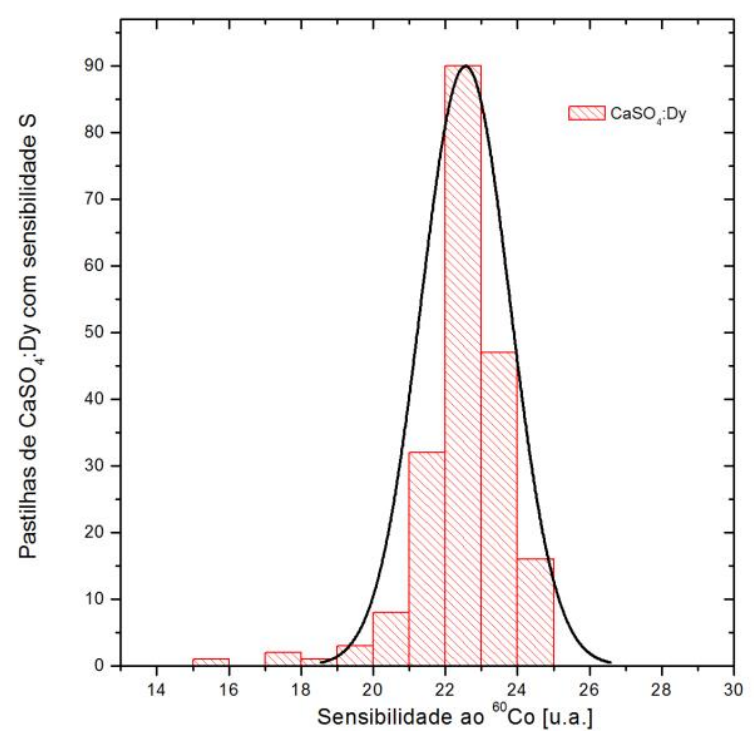

(b)

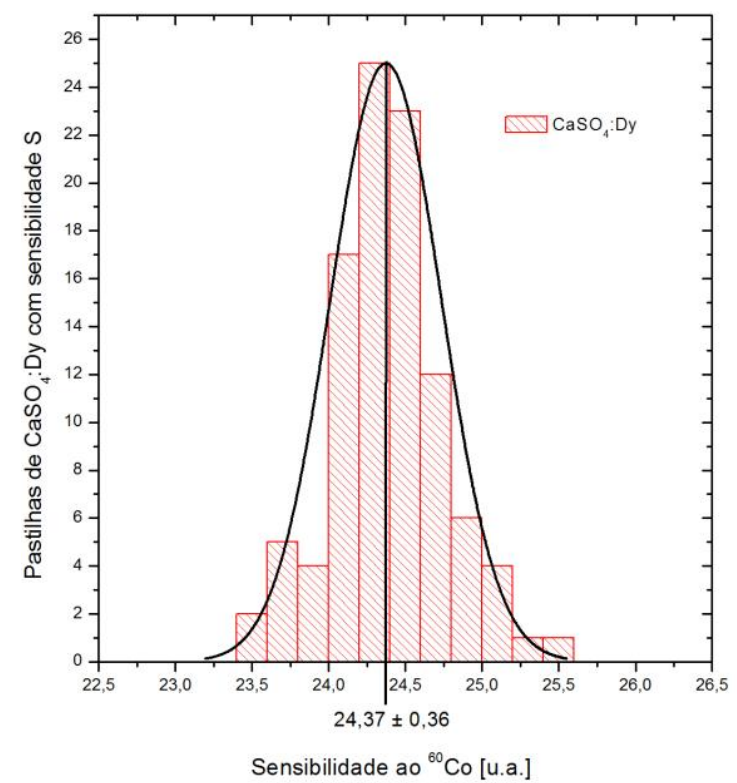

(d)

FIGURA 23 - Histogramas da sensibilidade da resposta TL das pastilhas de CaSO (a) primeira, (b) segunda e (c) terceira irradiação para seleção dos dosímetros; (d) histograma dos DTLs selecionados. 
Da mesma maneira, os histogramas das sensibilidades das respostas TL do LiF:Mg,Ti obtidos para a seleção dos DTLs são apresentados nas FIG. 24 (a), (b) e (c), e na FIG. 24 (d) é mostrado o histograma dos dosímetros já selecionados.

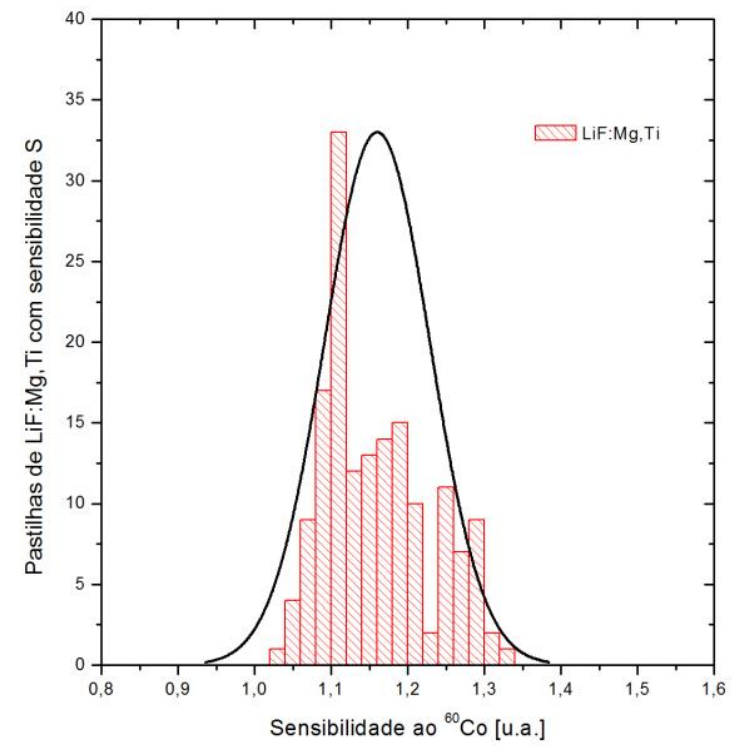

(a)

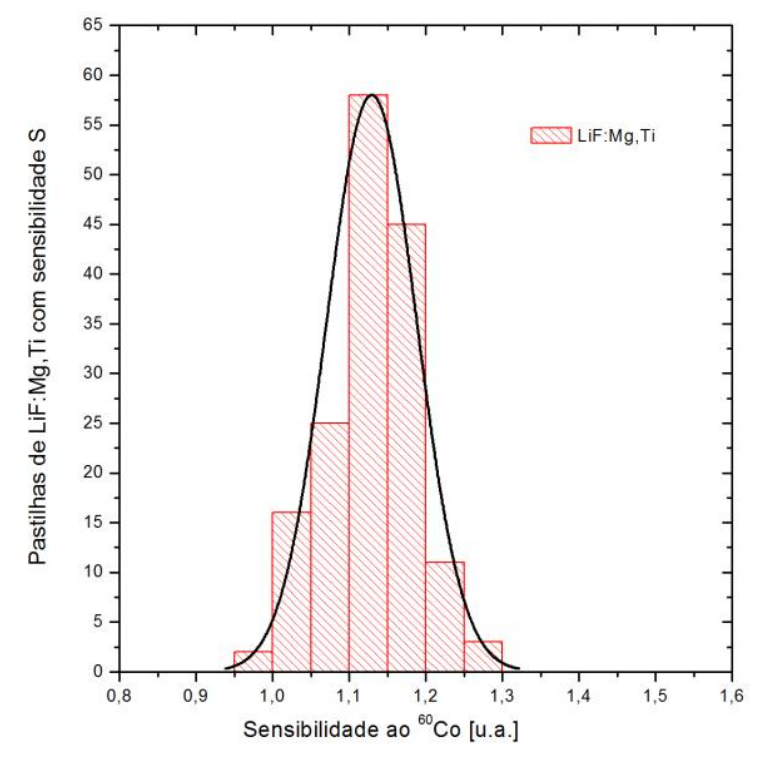

(c)

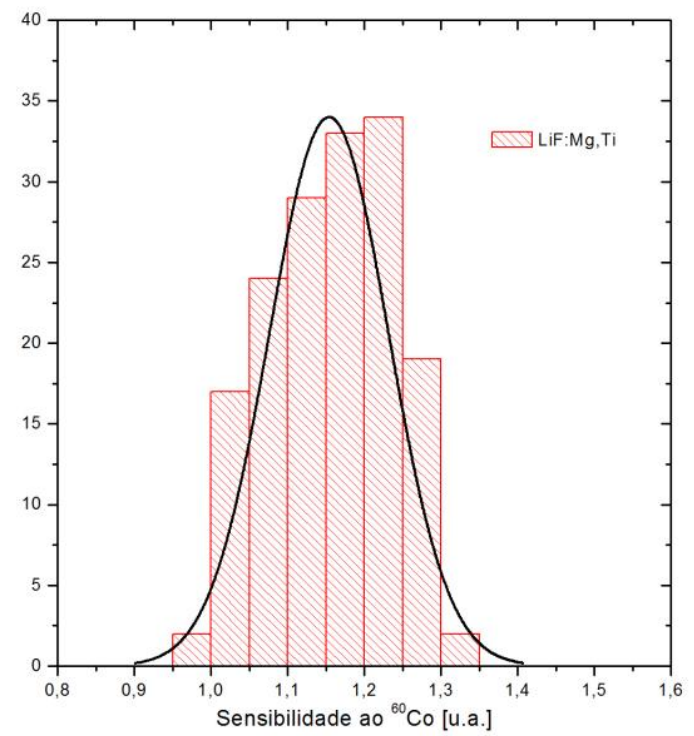

(b)

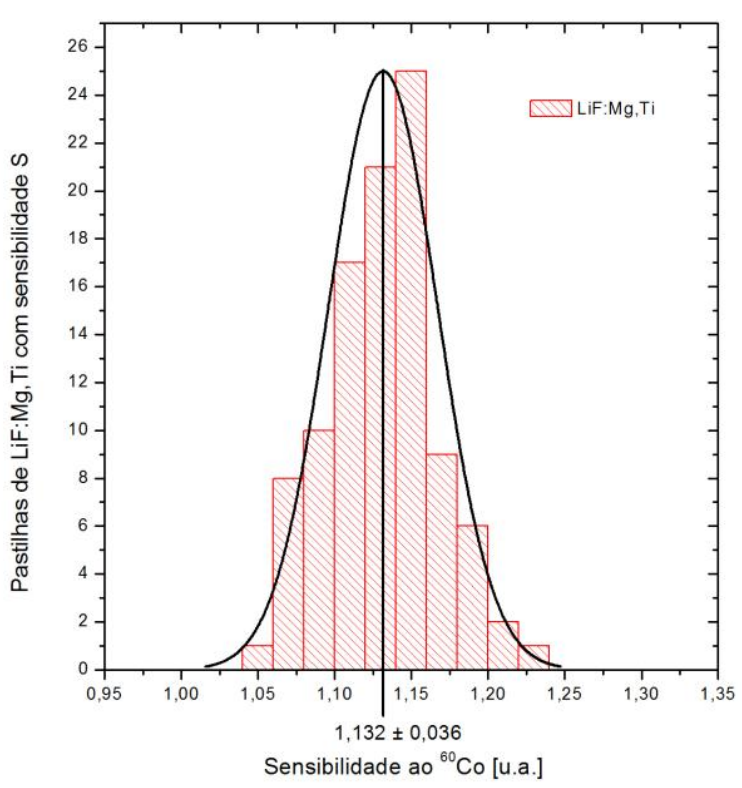

(d)

FIGURA 24 - Histogramas da sensibilidade da resposta TL das pastilhas de LiF:Mg,Ti na (a) primeira, (b) segunda e (c) terceira irradiação para seleção dos dosímetros; (d) histograma dos DTLs selecionados.

Por fim, na FIG. 25 (a), (b) e (c) são apresentados os histogramas das sensibilidades das respostas TL dos DTLs de $\mu \mathrm{LiF}: M g$,Ti obtidos para a seleção dos dosímetros, e na FIG. 25 (d) é mostrado o histograma dos dosímetros já selecionados. 


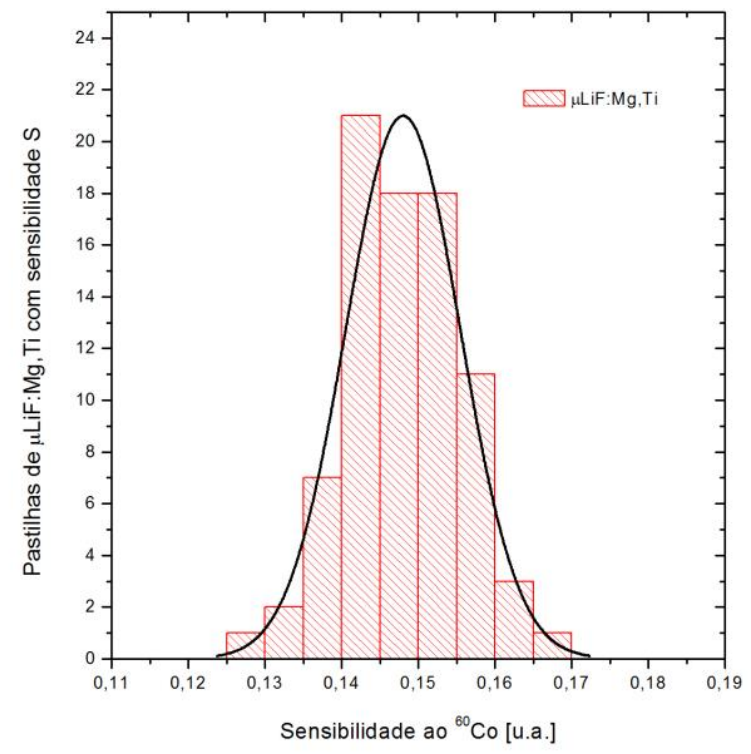

(a)

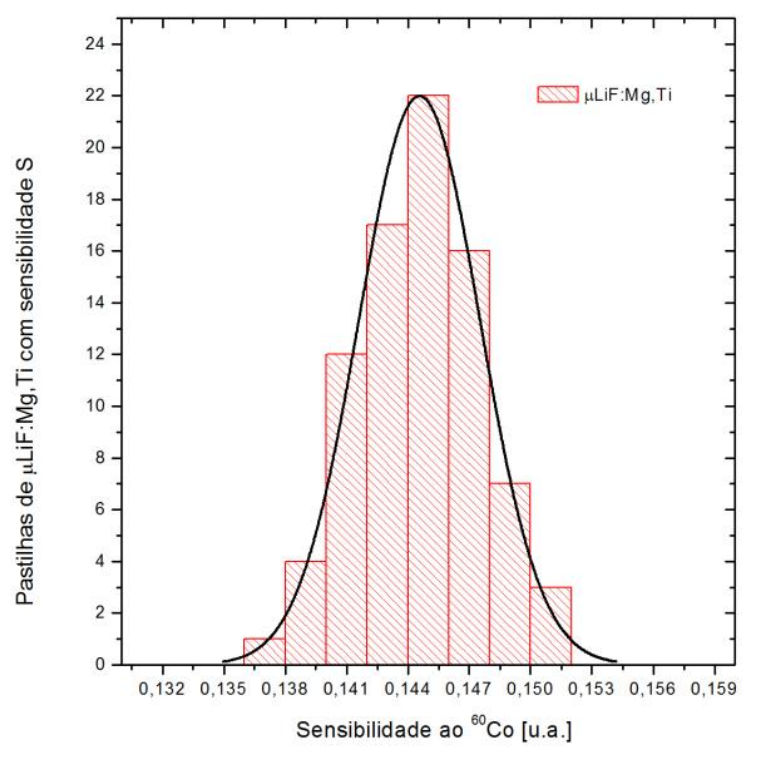

(c)

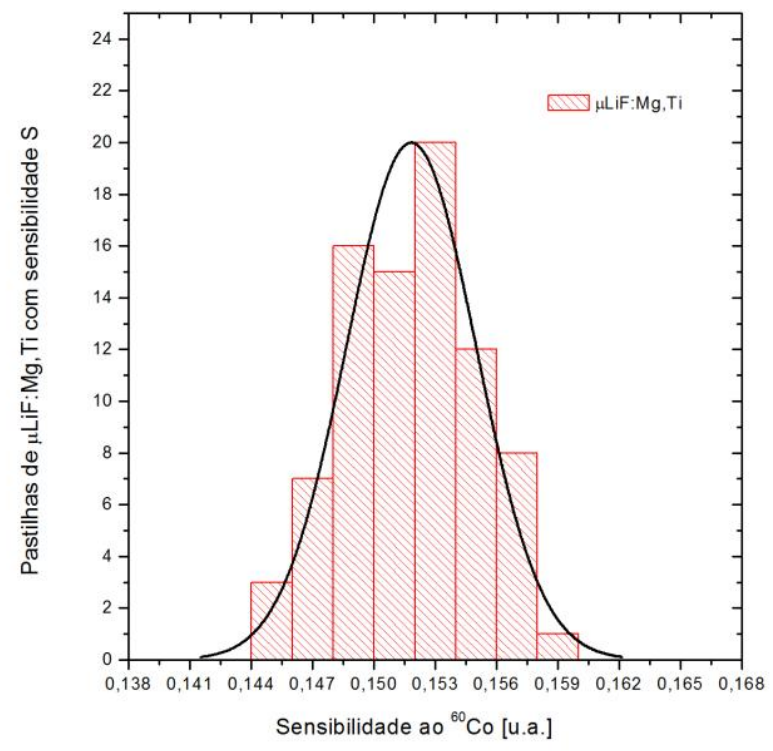

(b)

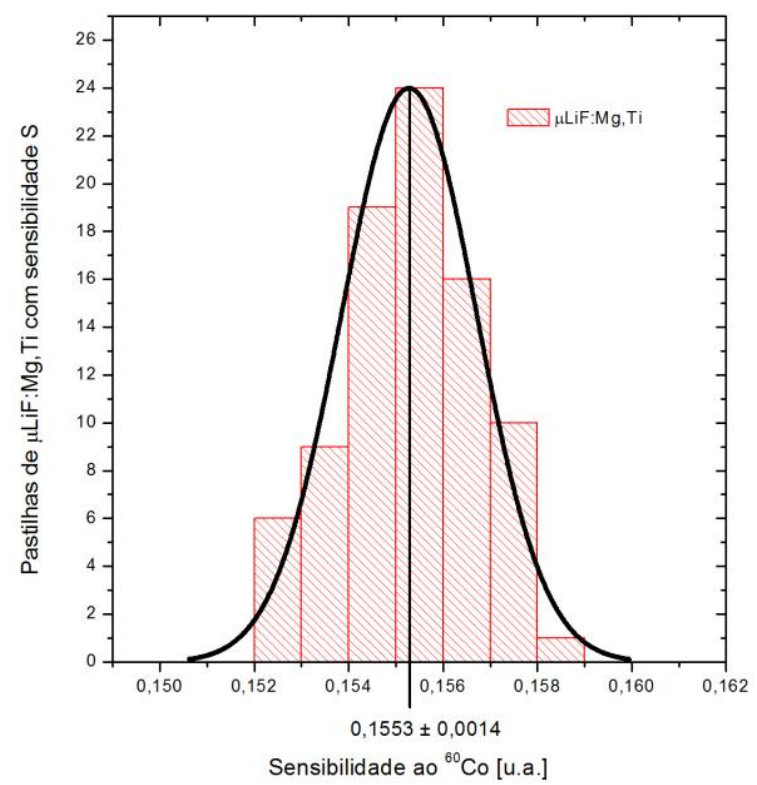

(d)

FIGURA 25 - Histogramas da sensibilidade da resposta TL das pastilhas de $\mu \mathrm{LiF}: M g$,Ti na

(a) primeira, (b) segunda e (c) terceira irradiação para seleção dos dosímetros; (d) histograma dos DTLs selecionados.

0 resultado do teste do qui-quadrado reduzido, aplicado às gaussianas ajustadas às sensibilidades individuais de cada leitura para a seleção dos DTLs, apresentadas nas FIG. 23 a 25, foi de 0,99. 


\subsection{Curvas de dose-resposta}

\subsubsection{Radiação gama}

Na FIG. 26 são apresentadas as curvas de dose-resposta dos três dosímetros para irradiação no ar em fonte de radiação gama do ${ }^{60} \mathrm{Co}$. Cada ponto da curva representa a média das cinco leituras e as barras de erro seus respectivos desvios-padrões da média $(\sigma)$ com nível de confiança de 95\%. É importante ressaltar que foi descontada a leitura de zero ou leitura de "Background" (BG) de cada pastilha utilizada.

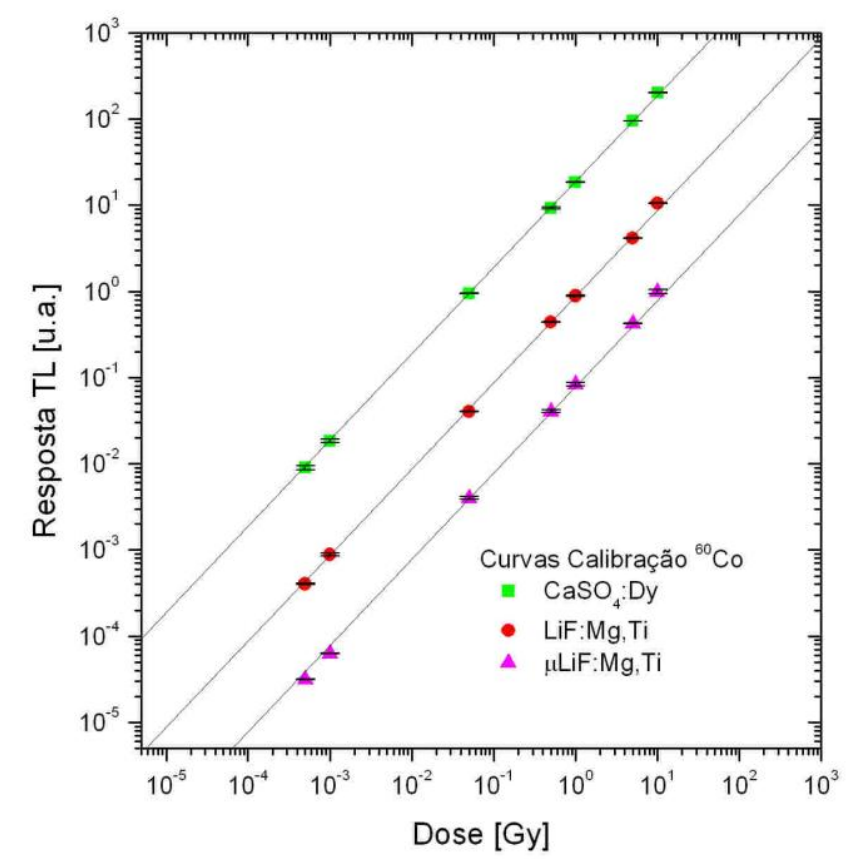

FIGURA 26 - Curva de dose-resposta dos dosímetros de LiF:Mg,Ti, $\mu \mathrm{LiF}: \mathrm{Mg}, \mathrm{Ti}$ e CaSO 4 :Dy à radiação de fótons do ${ }^{60} \mathrm{Co}$ para irradiações no ar.

Para os três tipos de detectores as curvas apresentaram comportamento linear no intervalo de dose estudado. Nota-se que para a maior dose utilizada, $10 \mathrm{~Gy}$, as respostas tendem a sair da linearidade. No caso dos DTLs de $\mu \mathrm{LiF}: \mathrm{Mg}, \mathrm{Ti}$, as menores doses também seguem essa tendência, comportamento que pode ser explicado pelo fato de seu limite inferior de detecção(LID) ser maior do que o dos outros DTLs. $0 \mu \mathrm{LiF}: \mathrm{Mg}$,Ti possui resposta TL bem menor do que a do $\mathrm{CaSO}_{4}$ :Dy e do LiF:Mg,Ti, pois a TL é um fenômeno volumétrico, dependente da massa e volume do matéria em questão. Assim, sua sensibilidade também é menor. 


\subsubsection{Feixes de Elétrons e Fótons}

Primeiramente serão apresentadas as curvas de dose-resposta do $\mathrm{CaSO}_{4}: \mathrm{Dy}, \mathrm{LiF}: \mathrm{Mg}$,Ti e $\mu \mathrm{LiF}: \mathrm{Mg}$,Ti irradiados no HIAE em feixe de fótons utilizando os simuladores de PMMA, água sólida e água. Na FIG. 27 (a), (b) e (c) são apresentadas as curvas de dose-resposta para o feixe de $6 \mathrm{MV}$.

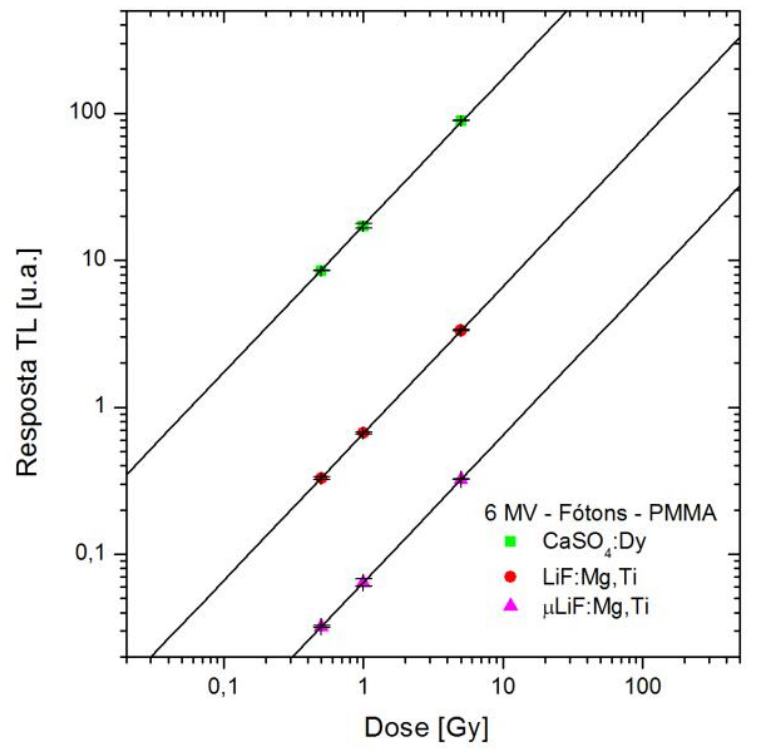

(a)

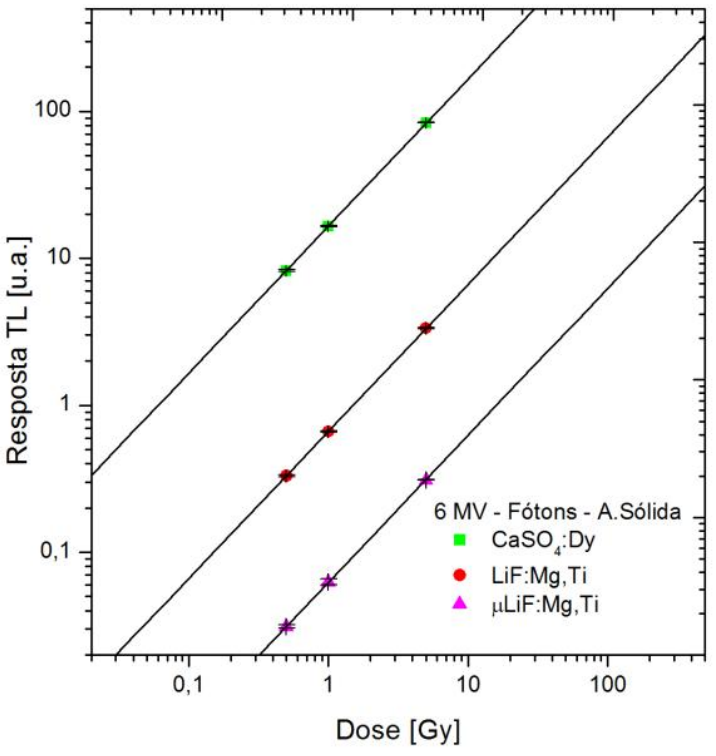

(b)

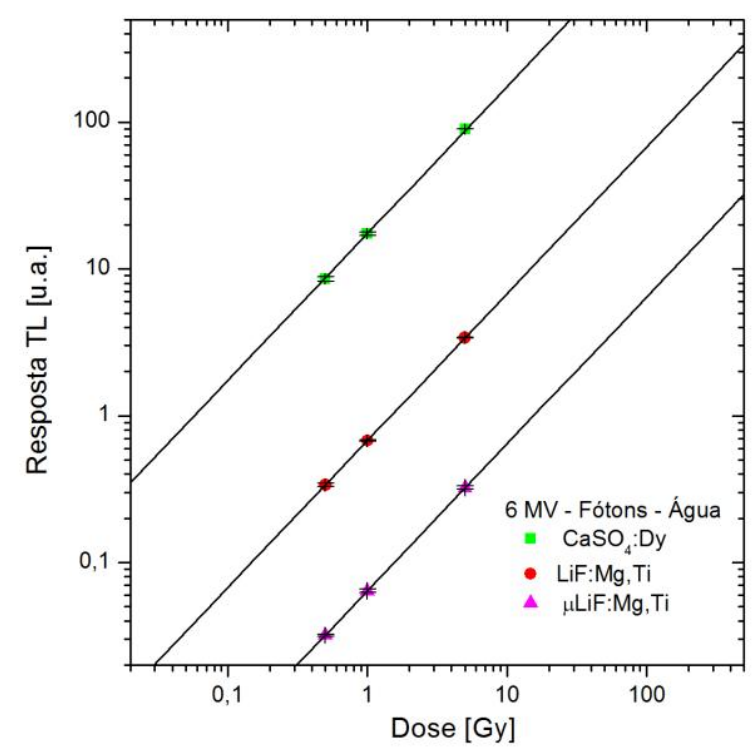

(c)

FIGURA 27 - Curvas de dose-resposta do $\mathrm{CaSO}_{4}: \mathrm{Dy}, \mathrm{LiF}: \mathrm{Mg}, \mathrm{Ti}$ e $\mu \mathrm{LiF}: \mathrm{Mg}$,Ti a fótons de $6 \mathrm{MV}$ em objetos simuladores de (a) PMMA, (b) Água Sólida e (c) Água. 
Nas FIG. 28 (a), (b) e (c) são apresentadas as curvas de dose-resposta do $\mathrm{CaSO}_{4}: \mathrm{Dy}, \mathrm{LiF}: \mathrm{Mg}$,Ti e $\mu \mathrm{LiF}: \mathrm{Mg}$,Ti para o feixe de fótons de $15 \mathrm{MV}$.

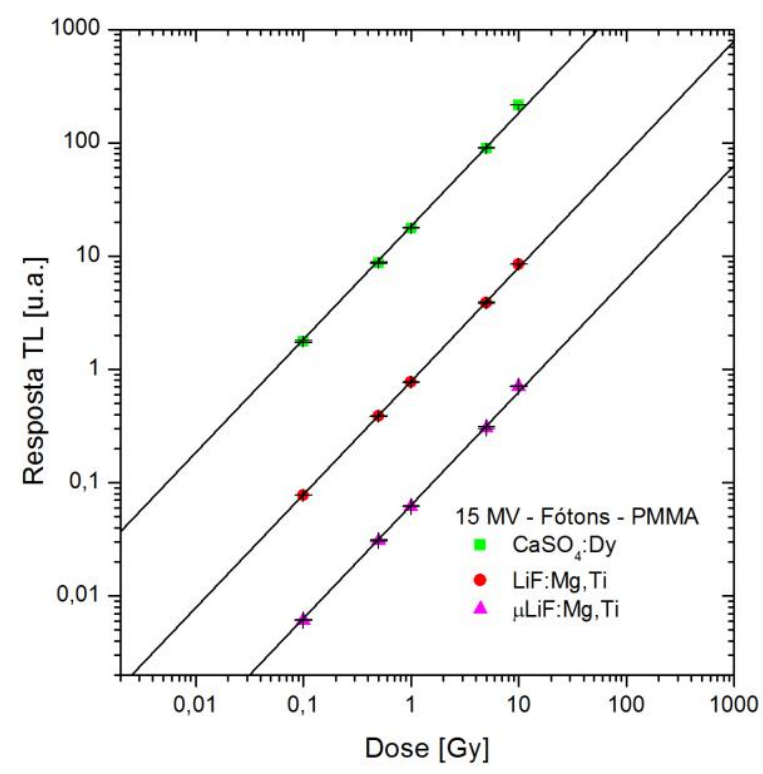

(a)

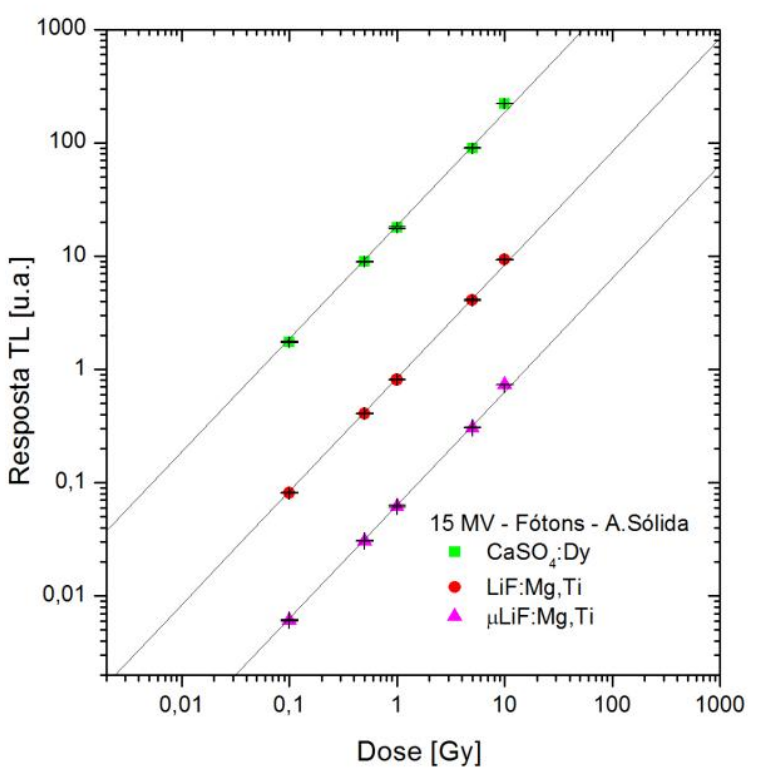

(b)

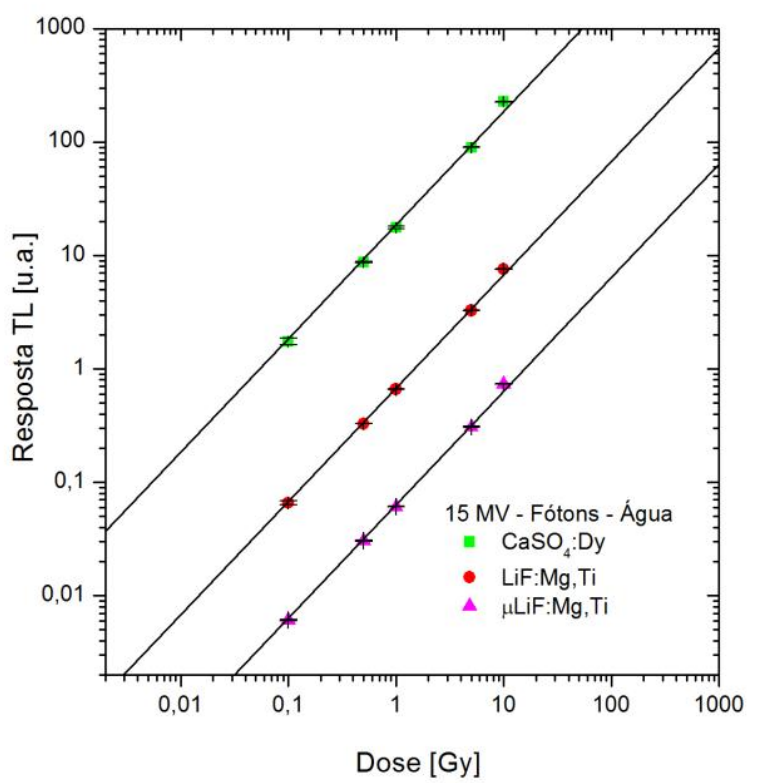

(c)

FIGURA 28 - Curvas de dose-resposta do $\mathrm{CaSO}_{4}$ :Dy, LiF:Mg,Ti e $\mu \mathrm{LiF}: \mathrm{Mg}$,Ti a fótons de $15 \mathrm{MV}$ em objetos simuladores de (a) PMMA, (b) Água Sólida e (c) Água.

Analisando as curvas de dose-resposta para o feixe de fótons, observa-se que, para os três tipos de dosímetros, todos os simuladores responderam da mesma 
maneira, não sendo notada diferença significativa nas suas respostas TL para as duas energias, 6 MV e 15 MV, do acelerador linear 23 EX.

Nas FIG. 29 a 33 são apresentadas as curvas de dose-resposta do $\mathrm{CaSO}_{4}$ :Dy, LiF:Mg,Ti e $\mu$ LiF:Mg,Ti irradiados em feixe de elétrons de 4 MeV (FIG. 29), $6 \mathrm{MeV}$ (FIG. 30), $9 \mathrm{MeV}$ (FIG. 31), $12 \mathrm{MeV}$ (FIG. 32) e $16 \mathrm{MeV}$ (FIG. 33), utilizando os mesmos simuladores de PMMA, água sólida e água.

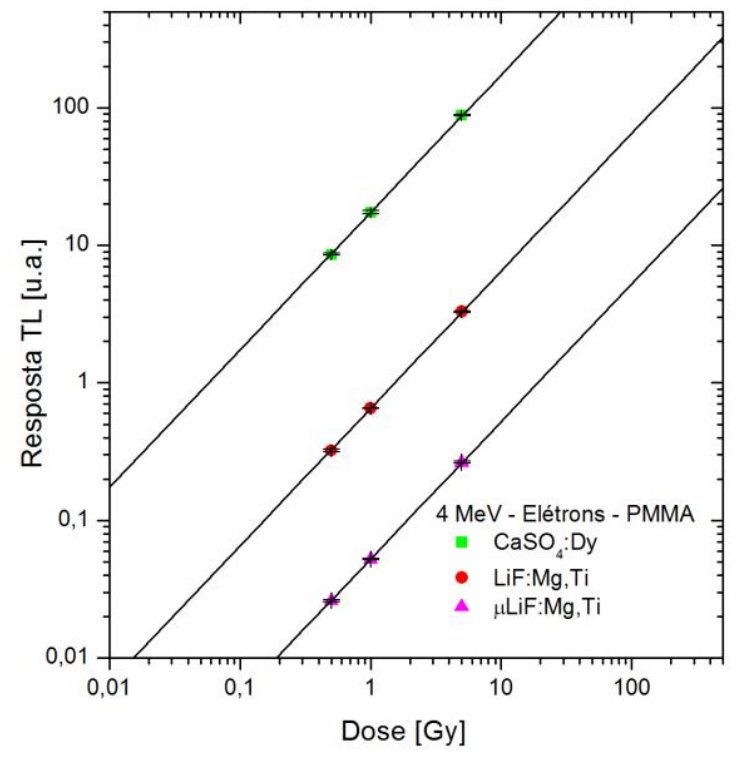

(a)

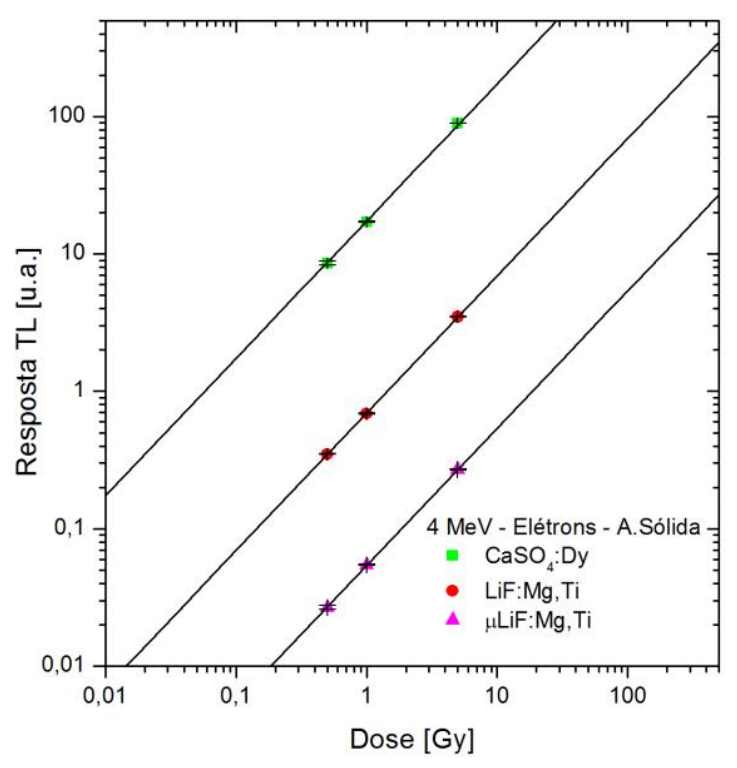

(b)

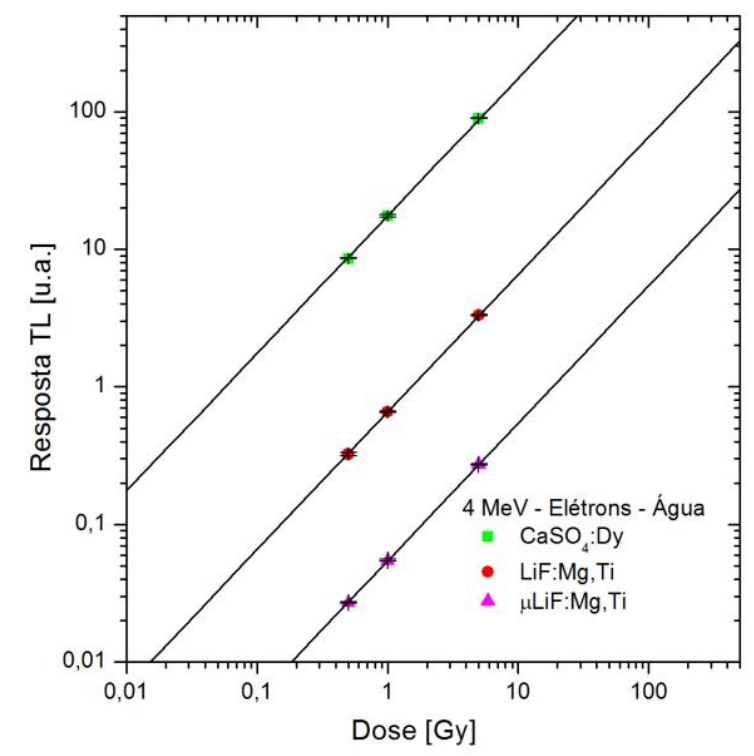

(c)

FIGURA 29 - Curvas de dose-resposta do $\mathrm{CaSO}_{4}$ :Dy, LiF:Mg,Ti e $\mu \mathrm{LiF}: \mathrm{Mg}$,Ti a elétrons de $4 \mathrm{MeV}$ em objetos simuladores de (a) PMMA, (b) Água Sólida e (c) Água. 


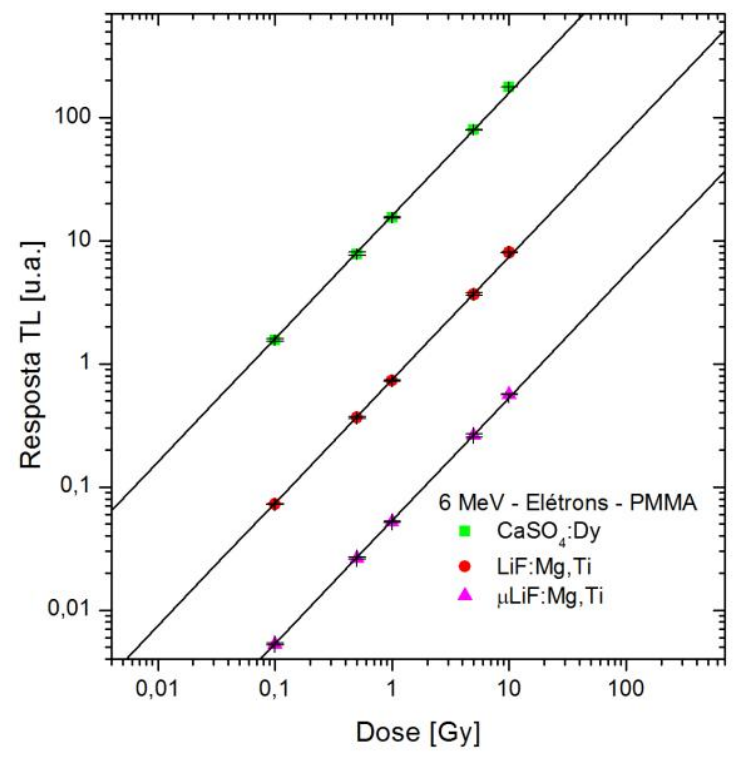

(a)

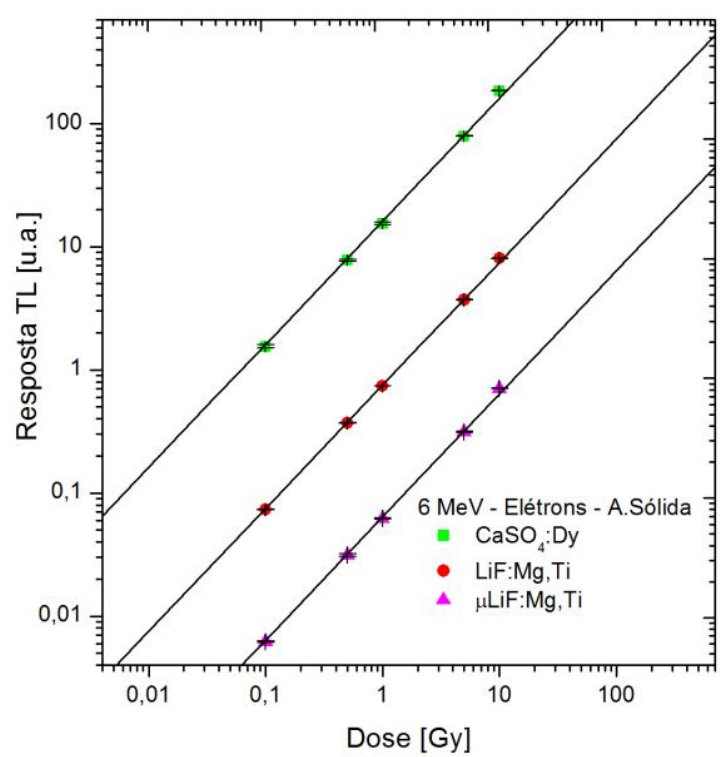

(b)

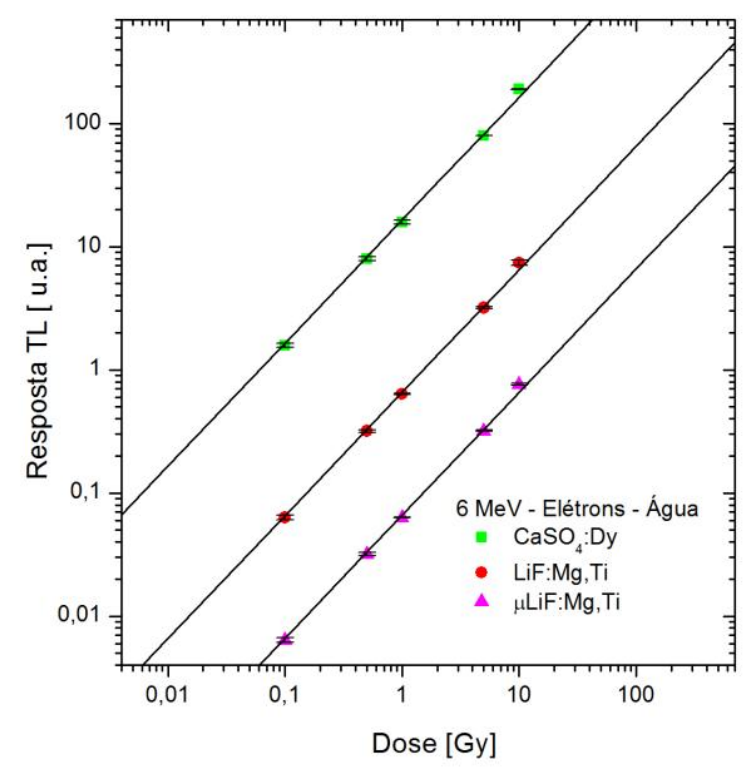

(c)

FIGURA 30 - Curvas de dose-resposta do $\mathrm{CaSO}_{4}: \mathrm{Dy}$, LiF:Mg,Ti e $\mu \mathrm{LiF}: \mathrm{Mg}$,Ti a elétrons de $6 \mathrm{MeV}$ em objetos simuladores de (a) PMMA, (b) Água Sólida e (c) Água. 


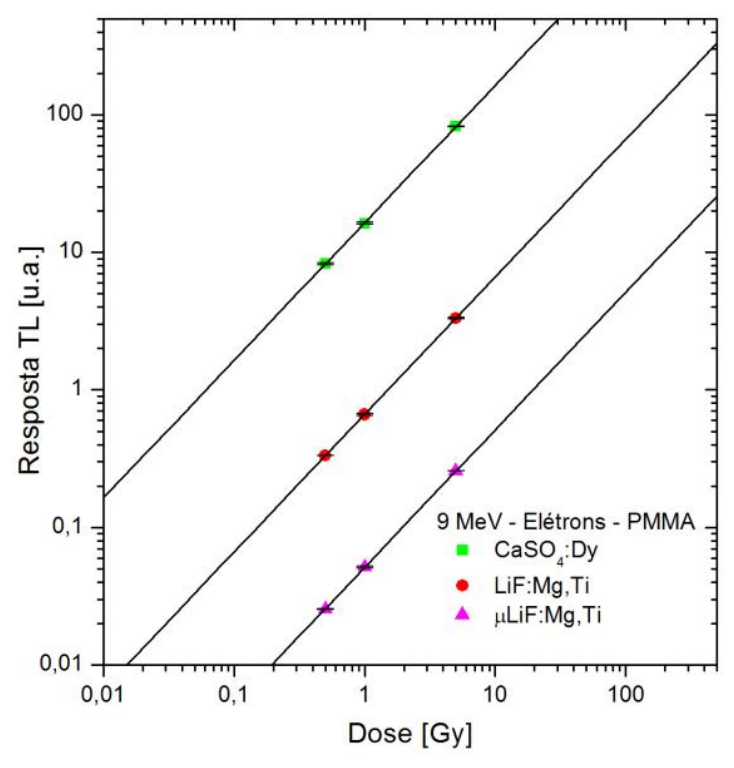

(a)

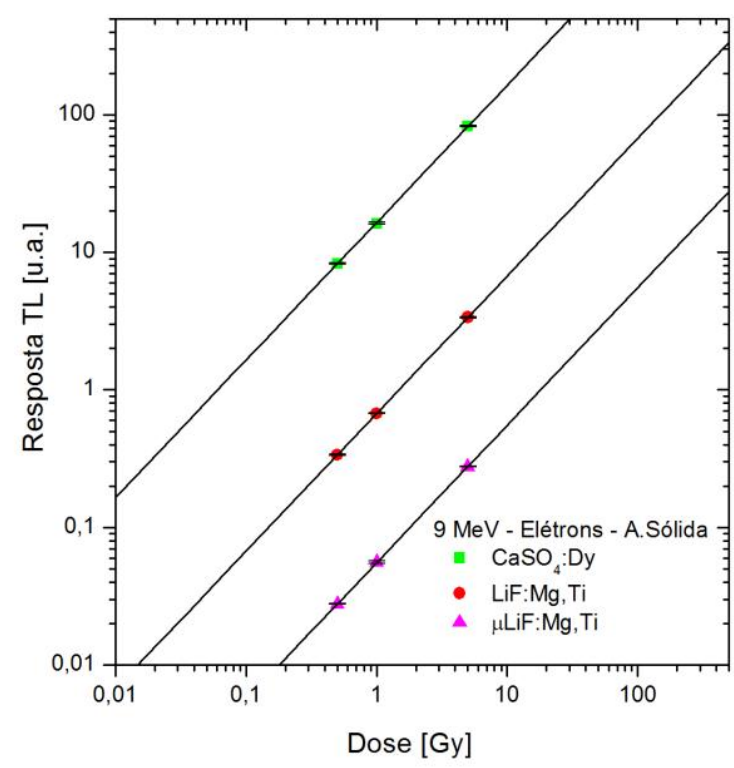

(b)

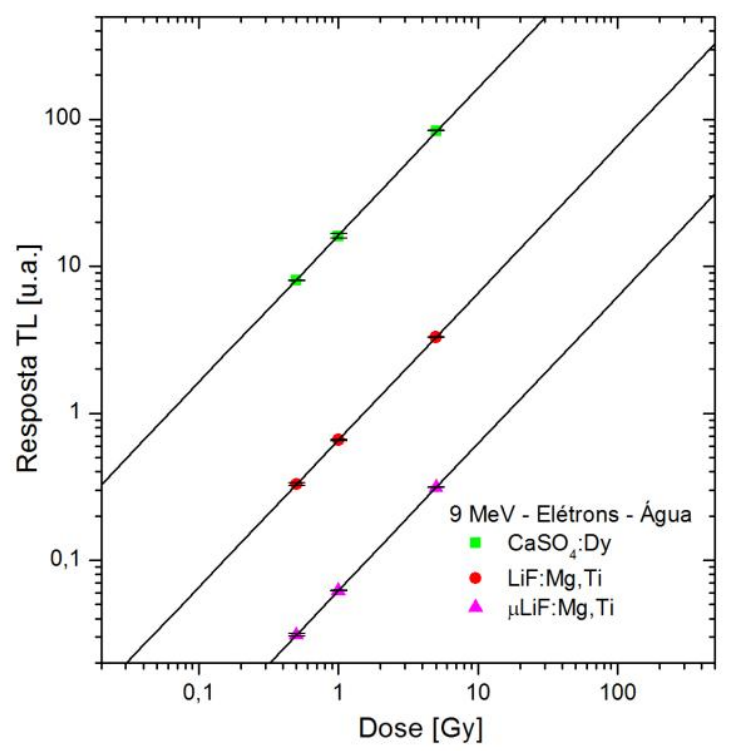

(c)

FIGURA 31 - Curvas de dose-resposta do $\mathrm{CaSO}_{4}$ :Dy, LiF:Mg,Ti e $\mu \mathrm{LiF}: \mathrm{Mg}$,Ti a elétrons de $9 \mathrm{MeV}$ em objetos simuladores de (a) PMMA, (b) Água Sólida e (c) Água. 


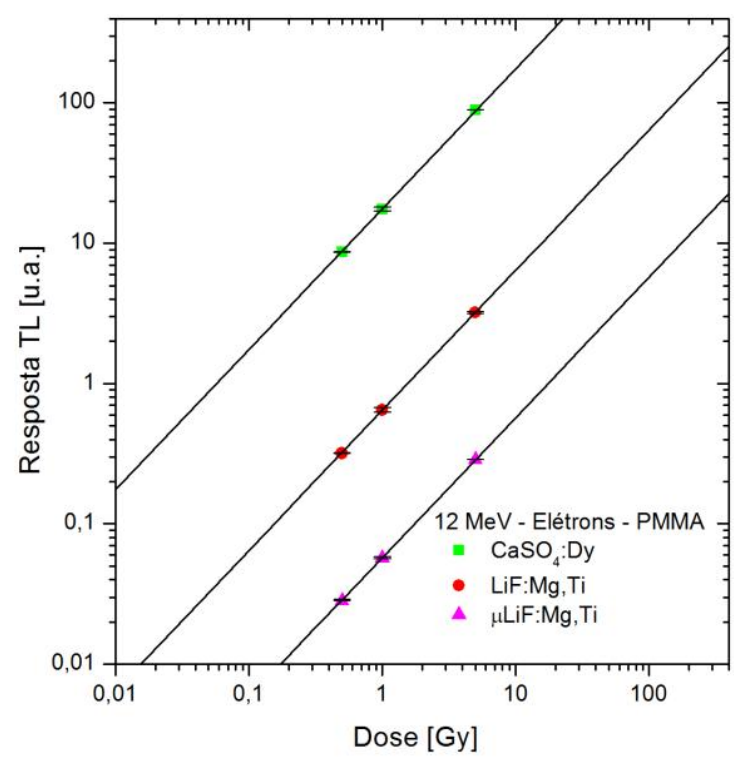

(a)

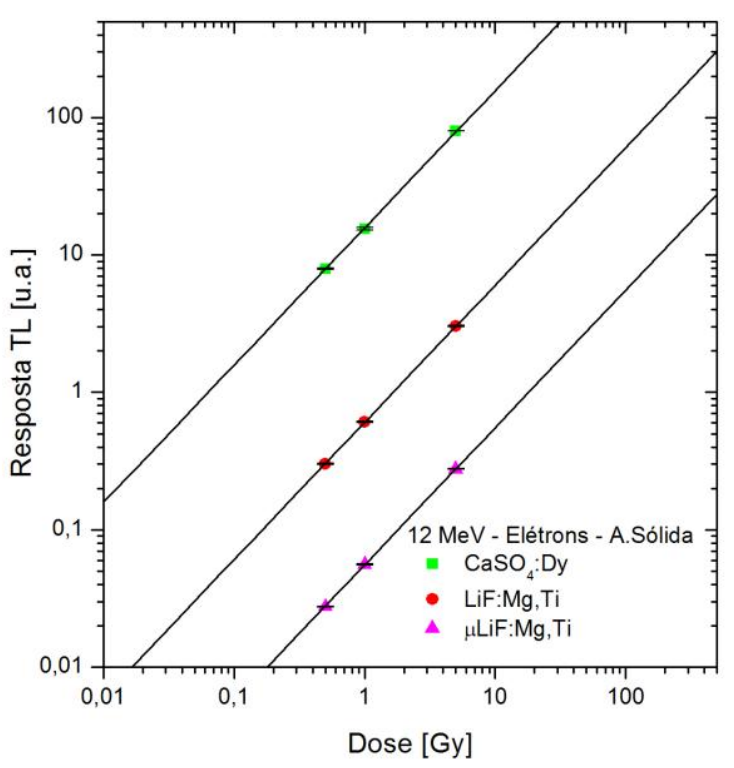

(b)

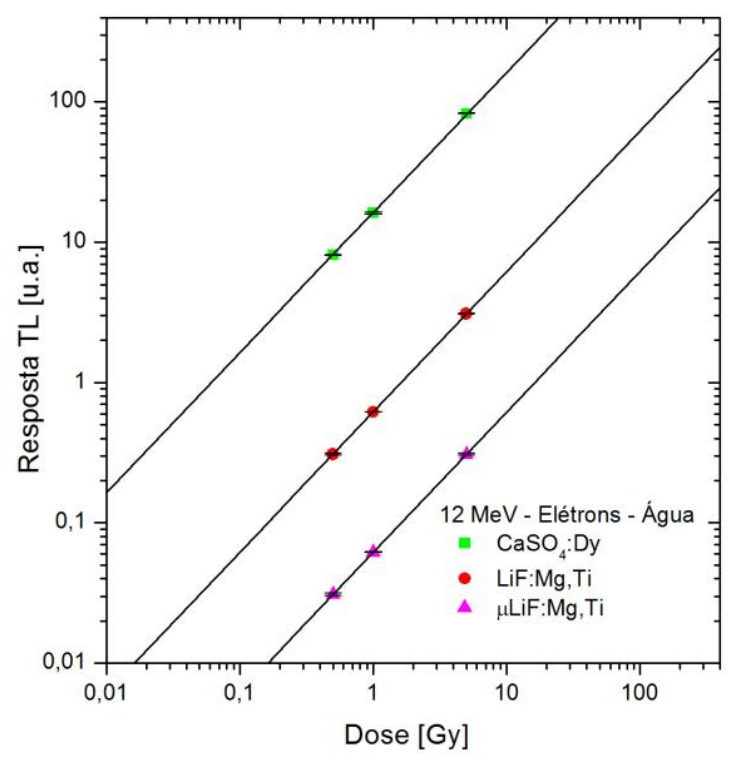

(c)

FIGURA 32 - Curvas de dose-resposta do $\mathrm{CaSO}_{4}$ :Dy, LiF:Mg,Ti e $\mu \mathrm{LiF}: \mathrm{Mg}$,Ti a elétrons de $12 \mathrm{MeV}$ em objetos simuladores de (a) PMMA, (b) Água Sólida e (c) Água. 


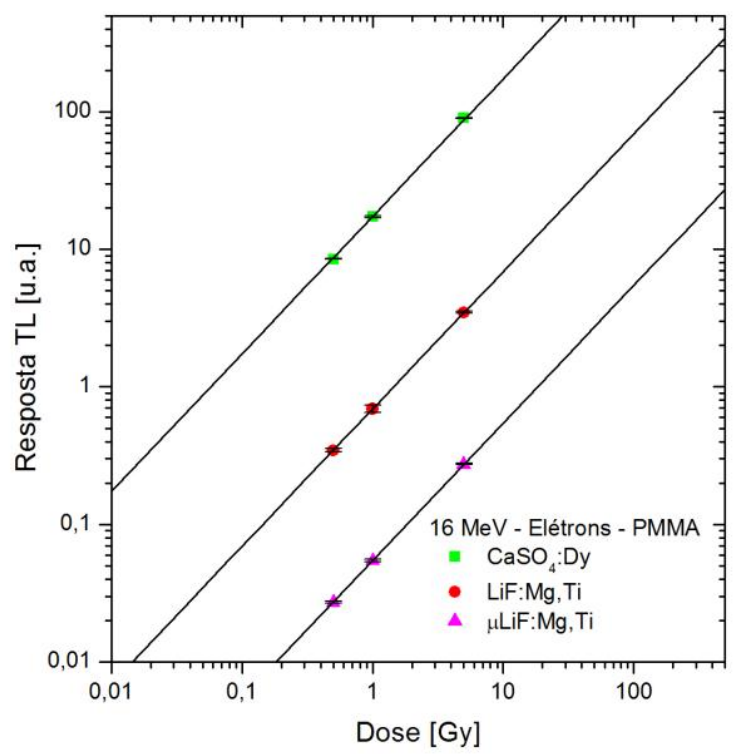

(a)

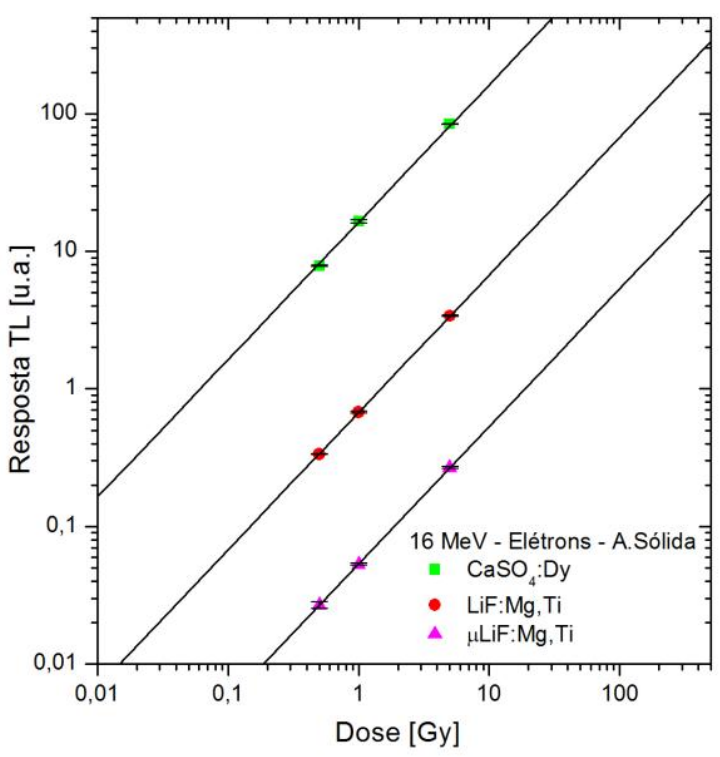

(b)

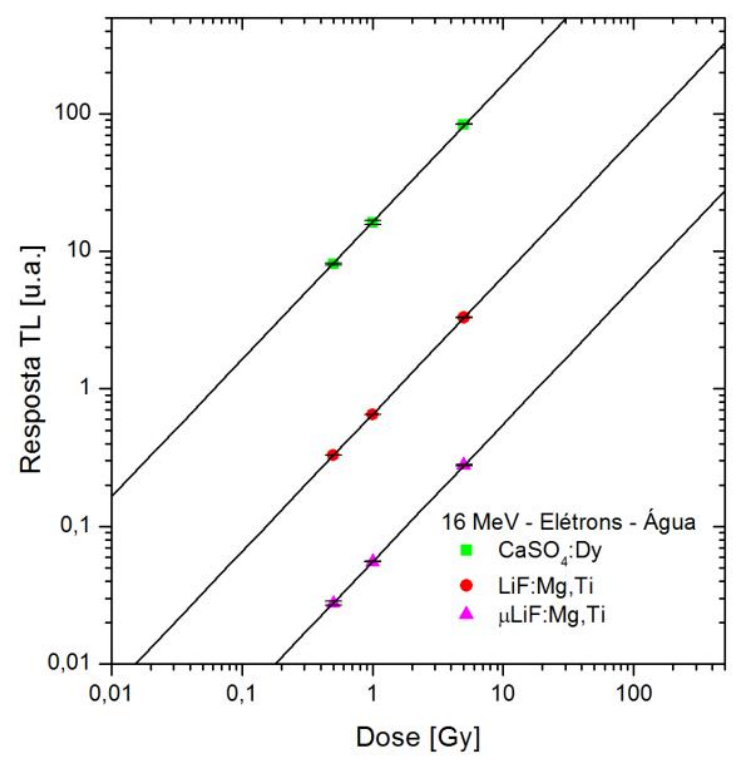

(c)

FIGURA 33 - Curvas de dose-resposta do $\mathrm{CaSO}_{4}$ :Dy, LiF:Mg,Ti e $\mu \mathrm{LiF}: \mathrm{Mg}$,Ti a elétrons de $16 \mathrm{MeV}$ em objetos simuladores de (a) PMMA, (b) Água Sólida e (c) Água.

Como esperado, não foram observadas diferenças significativas nas respostas dos três simuladores para o feixe de elétrons, para os dosímetros de $\mathrm{CaSO}_{4}$ :Dy, LiF:Mg,Ti e $\mu \mathrm{LiF}: M g$,Ti, para todos os valores de energia, $4 \mathrm{MeV}, 6 \mathrm{MeV}$, $9 \mathrm{MeV}, 12 \mathrm{MeV}$ e $16 \mathrm{MeV}$, do acelerador linear Clinac 2100. As curvas de dose- 
resposta tiveram o mesmo comportamento, linear até a dose de 5 Gy e com uma leve tendência à supralinearidade quando os dosímetros são irradiados com a dose de $10 \mathrm{~Gy}$.

\subsection{Sensibilidade média dos grupos de DTLs}

Na FIG. 34 são apresentados os valores de sensibilidade em função da dose, dos dosímetros de $\mathrm{CaSO}_{4}: \mathrm{Dy}, \mathrm{LiF}: \mathrm{Mg}$,Ti e $\mu \mathrm{LiF}: \mathrm{Mg}$,Ti, para irradiação no ar em fonte de ${ }^{60} \mathrm{Co}$.

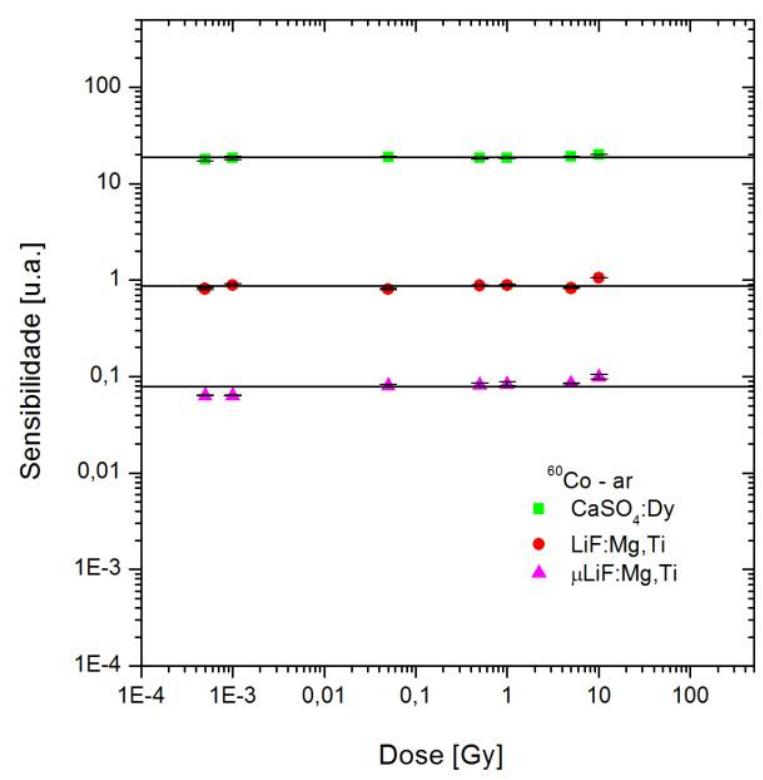

FIGURA 34 - Sensibilidade TL do $\mathrm{CaSO}_{4}$ :Dy, LiF: Mg,Ti e $\mu \mathrm{LiF}: \mathrm{Mg}$,Ti à radiação de fótons do ${ }^{60} \mathrm{Co}$ para irradiações no ar.

Os dosímetros de $\mathrm{CaSO}_{4}: \mathrm{Dy}, \mathrm{LiF}: \mathrm{Mg}, \mathrm{Ti}$ e $\mu \mathrm{LiF}: \mathrm{Mg}$,Ti apresentam um comportamento linear até a dose de 5 Gy. A partir de 10 Gy, pode ser observada uma variação no valor de sensibilidade para os três tipos de dosímetros.

As sensibilidades médias do $\mathrm{CaSO}_{4}: \mathrm{Dy}, \mathrm{LiF}: \mathrm{Mg}$,Ti e $\mu \mathrm{LiF}: \mathrm{Mg}$,Ti aos feixes de fótons são apresentadas nas FIG. 35 e 36. As irradiações foram feitas empregando os simuladores de PMMA, água sólida e água. 


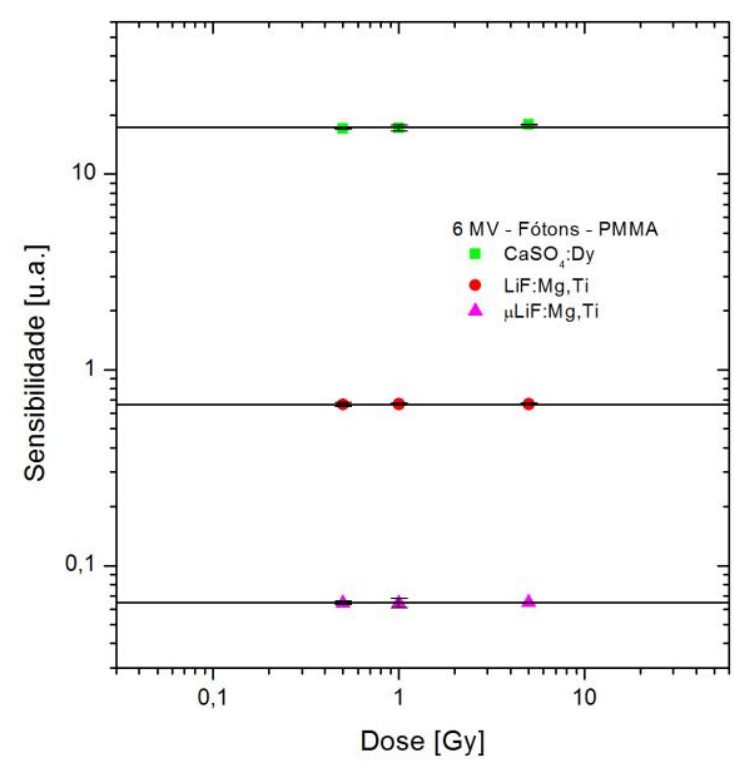

(a)

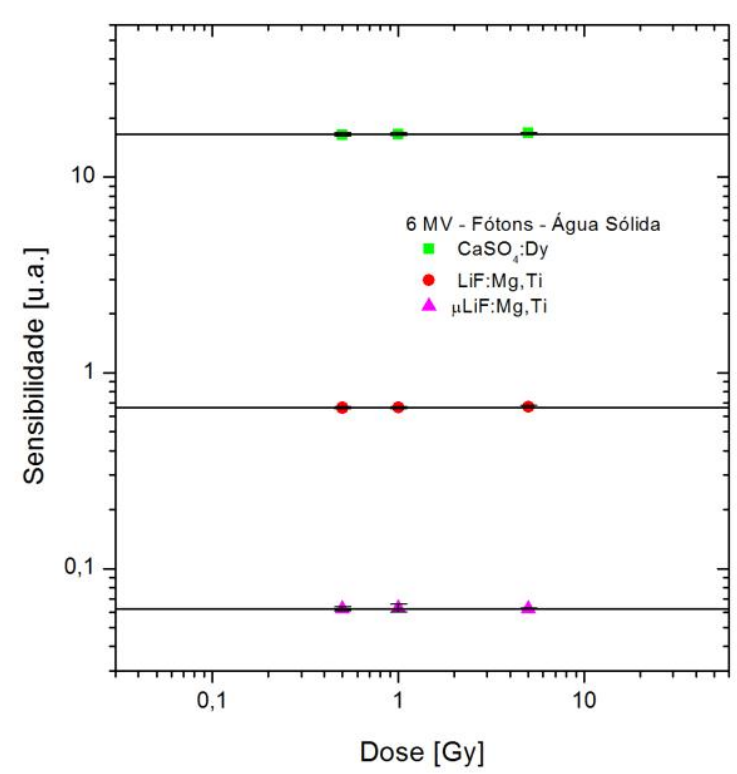

(b)

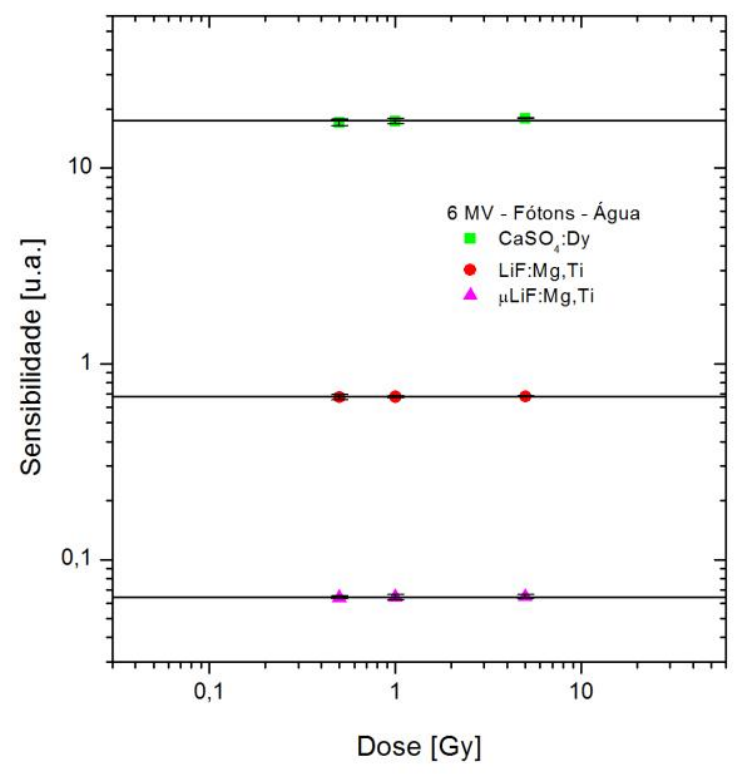

(c)

FIGURA 35 - Sensibilidade TL do $\mathrm{CaSO}_{4}$ :Dy, LiF: Mg,Ti e $\mu \mathrm{LiF}: \mathrm{Mg}$,Ti à radiação de fótons de $6 \mathrm{MV}$ para objeto simulador de (a) PMMA, (b) Água sólida e (c) Água. 


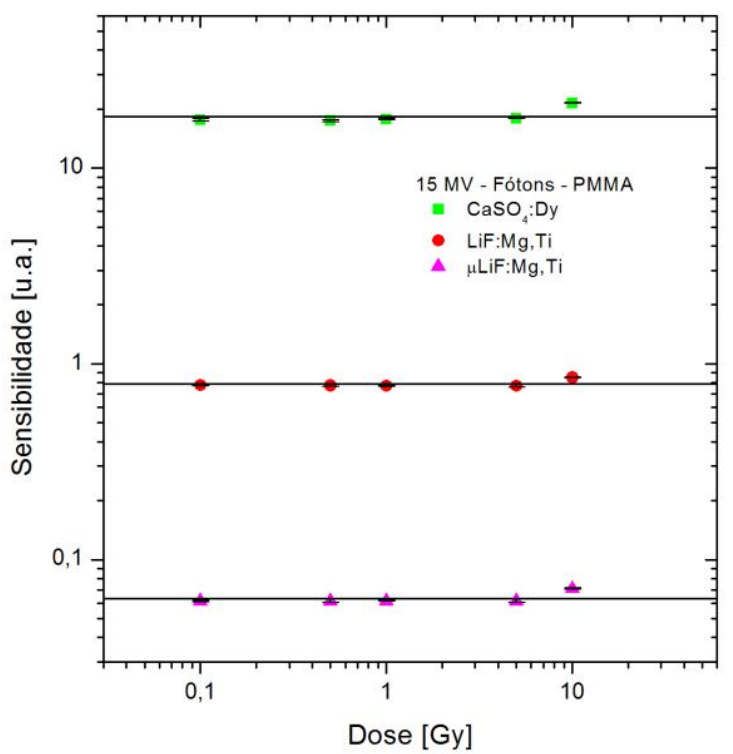

(a)

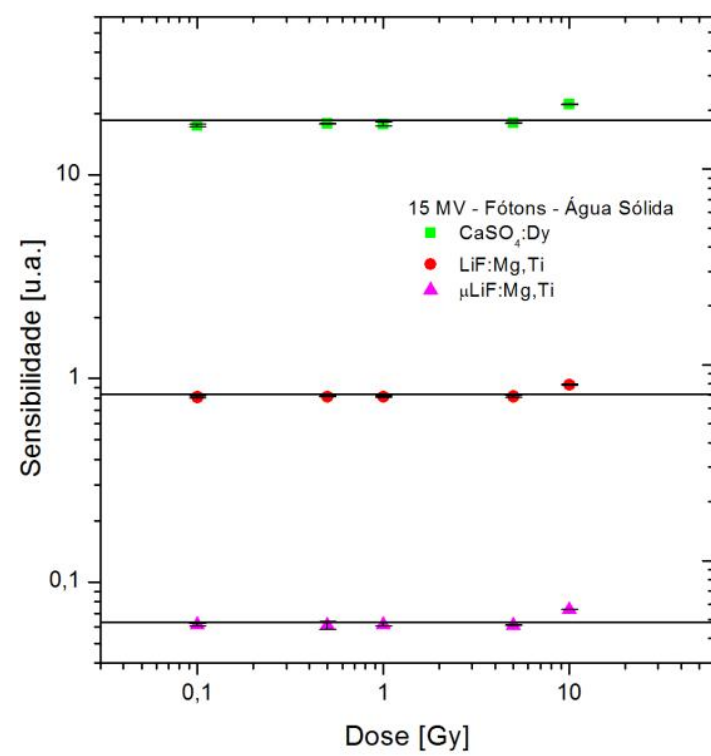

(b)

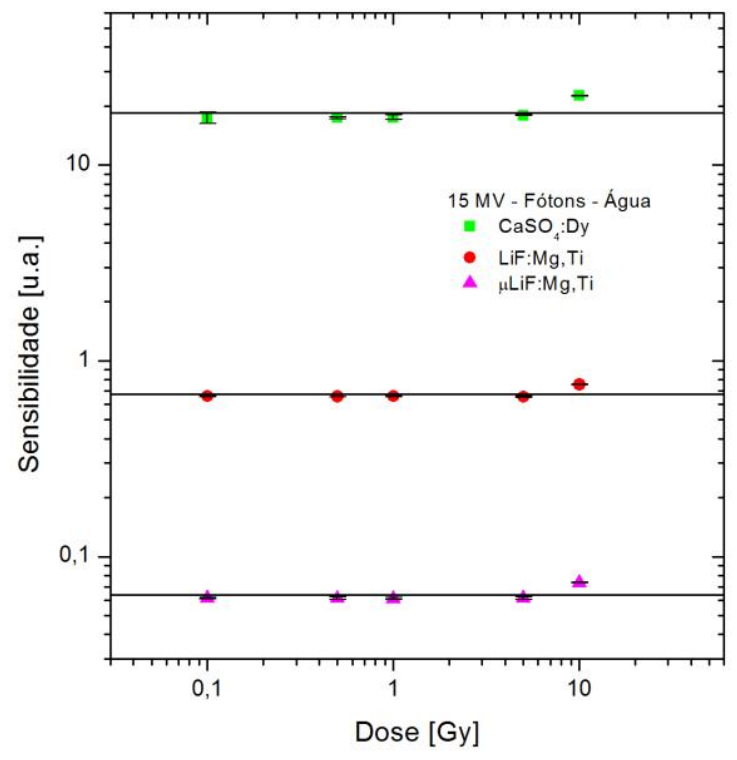

(c)

FIGURA 36 - Sensibilidade TL do $\mathrm{CaSO}_{4}$ :Dy, LiF: Mg,Ti e $\mu \mathrm{LiF}: \mathrm{Mg}$,Ti à radiação de fótons de $15 \mathrm{MV}$ para objeto simulador de (a) PMMA, (b) Água sólida e (c) Água.

Nas FIG. 37 a 41 são mostradas os valores de sensibilidade dos DTLs para feixes de elétrons utilizando os mesmos objetos simuladores, PMMA, água sólida e água. 


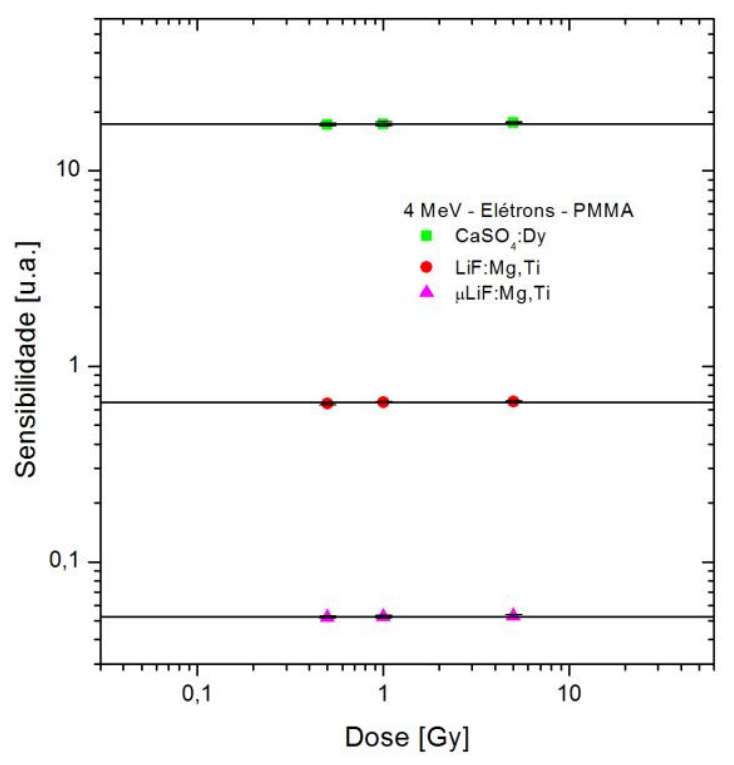

(a)

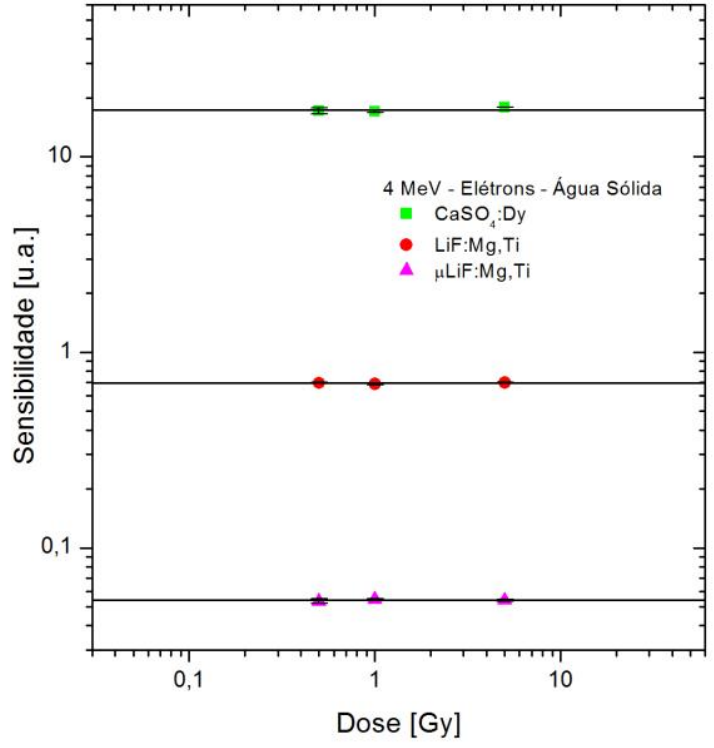

(b)

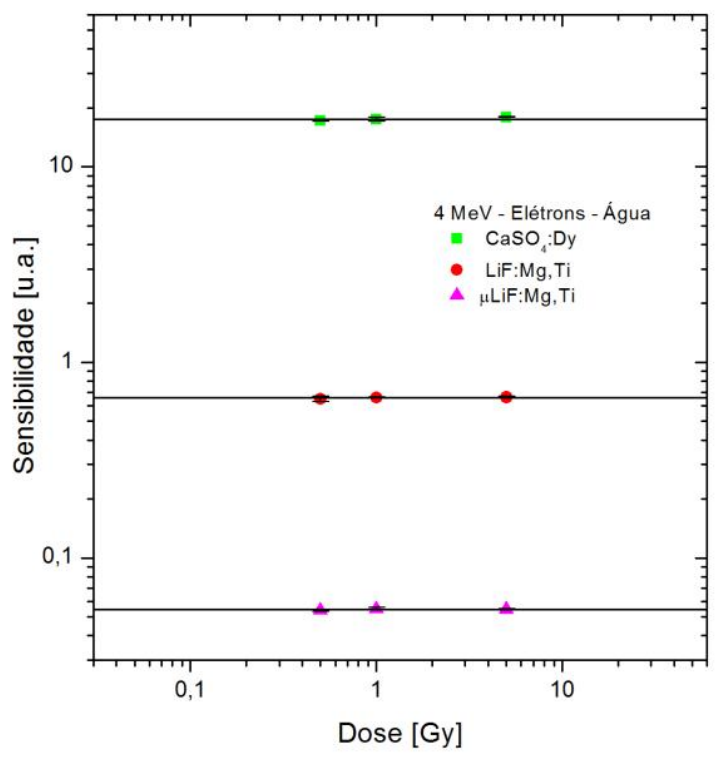

(c)

FIGURA 37 - Sensibilidade $\mathrm{TL}$ do $\mathrm{CaSO}_{4}$ :Dy, LiF: Mg,Ti e $\mu \mathrm{LiF}: \mathrm{Mg}$,Ti à radiação de elétrons de $4 \mathrm{MeV}$ para objeto simulador de (a) PMMA, (b) Água sólida e (c) Água. 


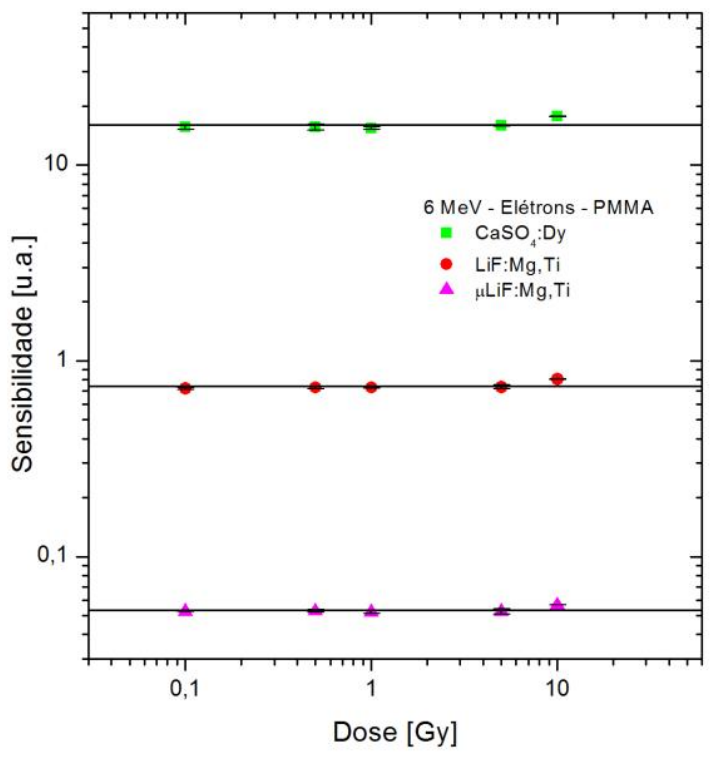

(a)

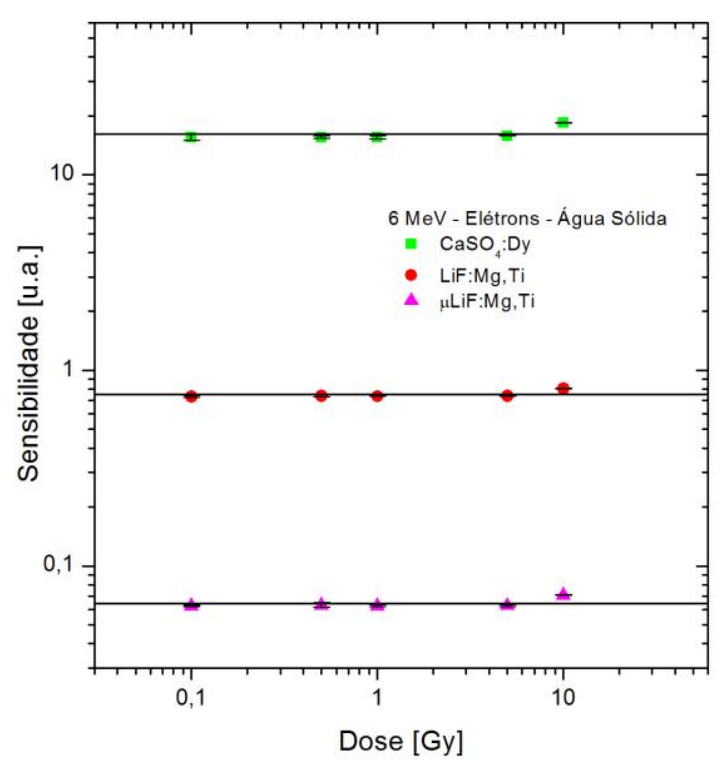

(b)

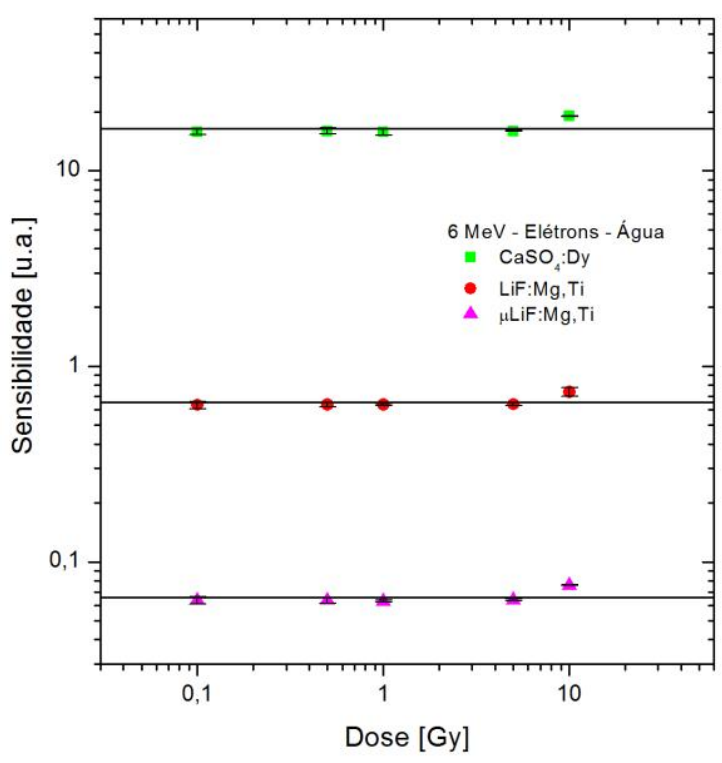

(c)

FIGURA 38 - Sensibilidade $\mathrm{TL}$ do $\mathrm{CaSO}_{4}$ :Dy, LiF: Mg,Ti e $\mu \mathrm{LiF}: \mathrm{Mg}$,Ti à radiação de elétrons de $6 \mathrm{MeV}$ para objeto simulador de (a) PMMA, (b) Água sólida e (c) Água. 


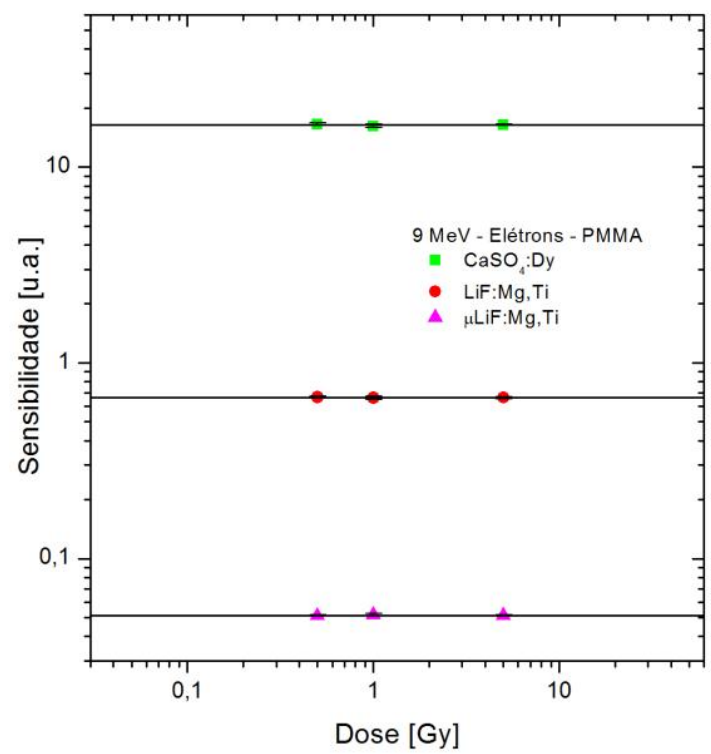

(a)

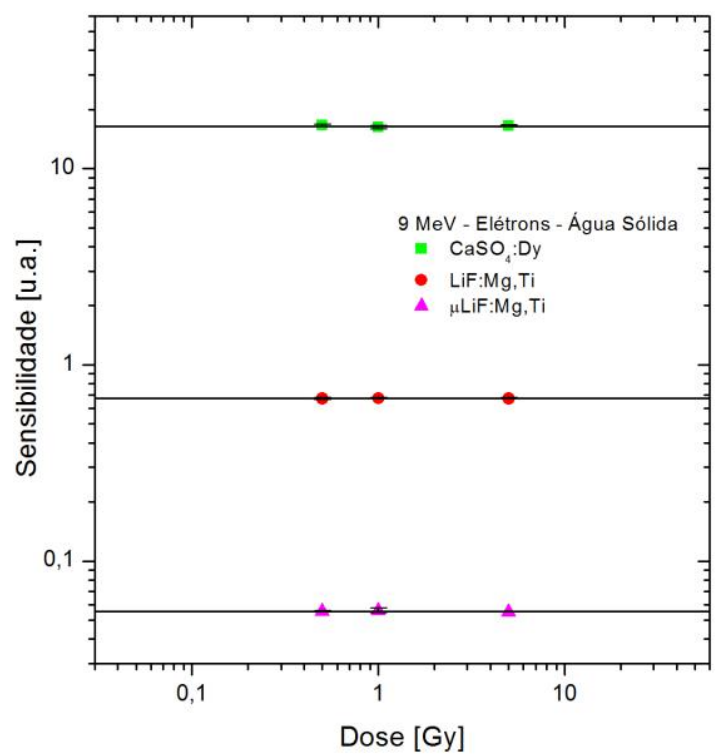

(b)

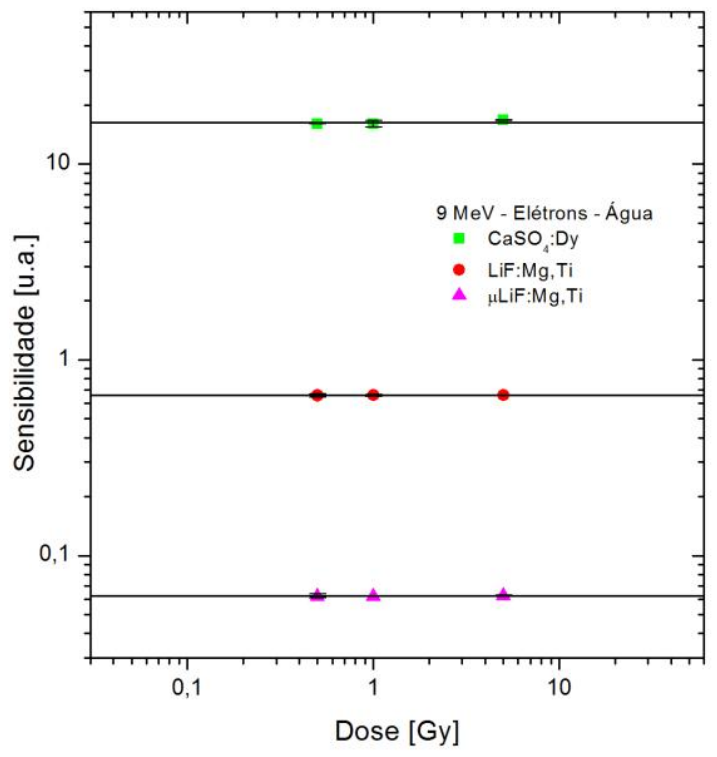

(c)

FIGURA 39 - Sensibilidade $\mathrm{TL}$ do $\mathrm{CaSO}_{4}$ :Dy, LiF: Mg,Ti e $\mu \mathrm{LiF}: \mathrm{Mg}$,Ti à radiação de elétrons de $9 \mathrm{MeV}$ para objeto simulador de (a) PMMA, (b) Água sólida e (c) Água. 


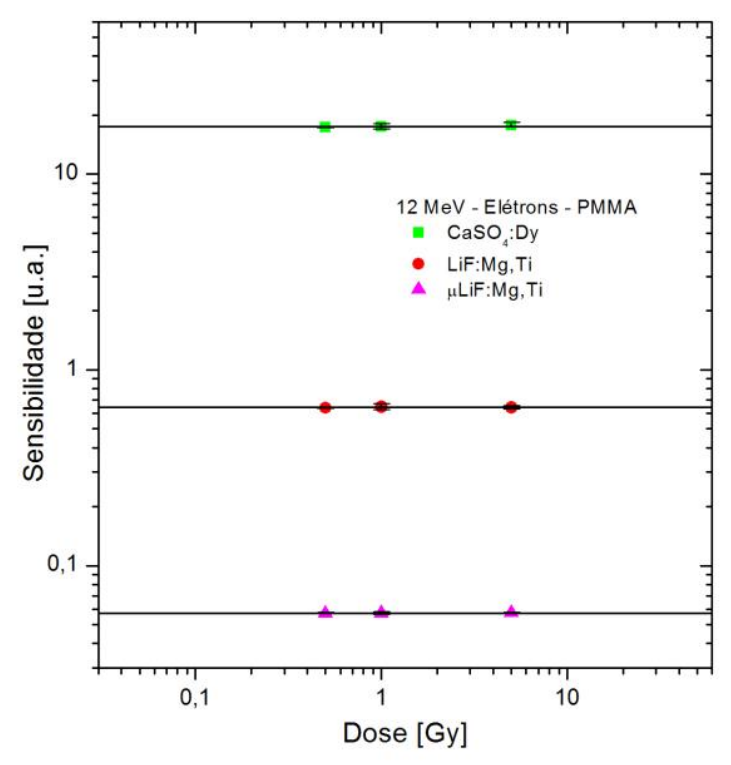

(a)

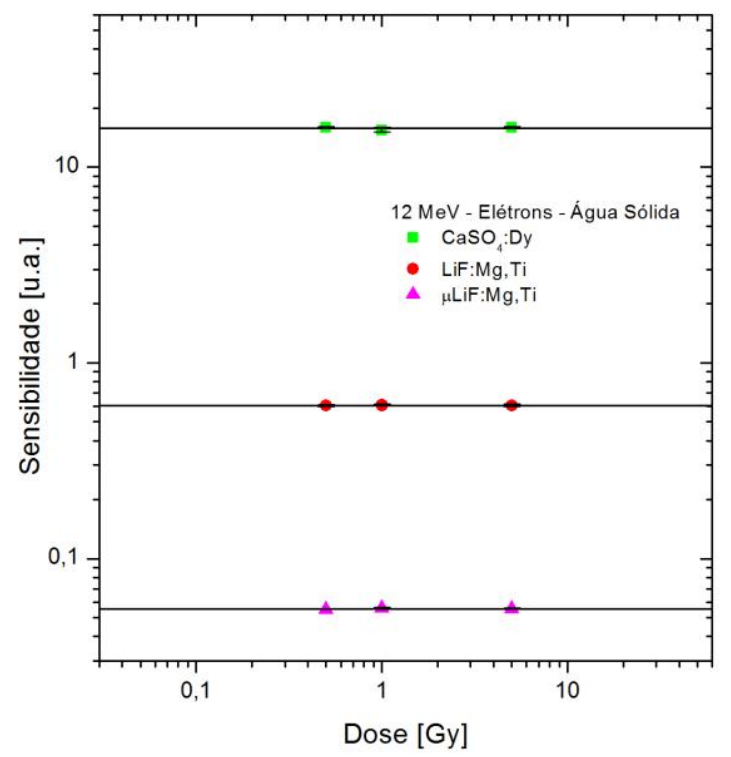

(b)

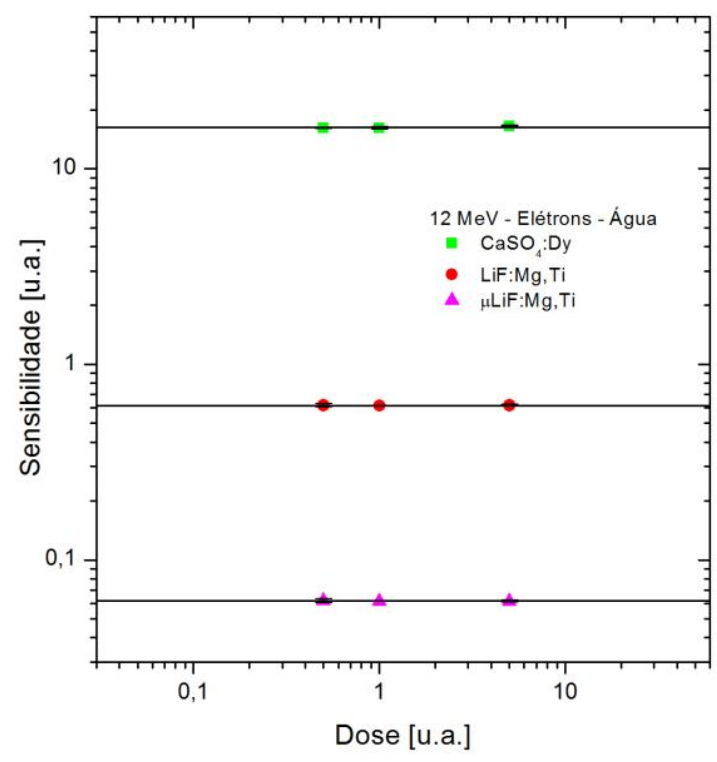

(c)

FIGURA 40 - Sensibilidade $\mathrm{TL}$ do $\mathrm{CaSO}_{4}$ :Dy, LiF: Mg,Ti e $\mu \mathrm{LiF}: \mathrm{Mg}$,Ti à radiação de elétrons de12 MeV para objeto simulador de (a) PMMA, (b) Água sólida e (c) Água. 


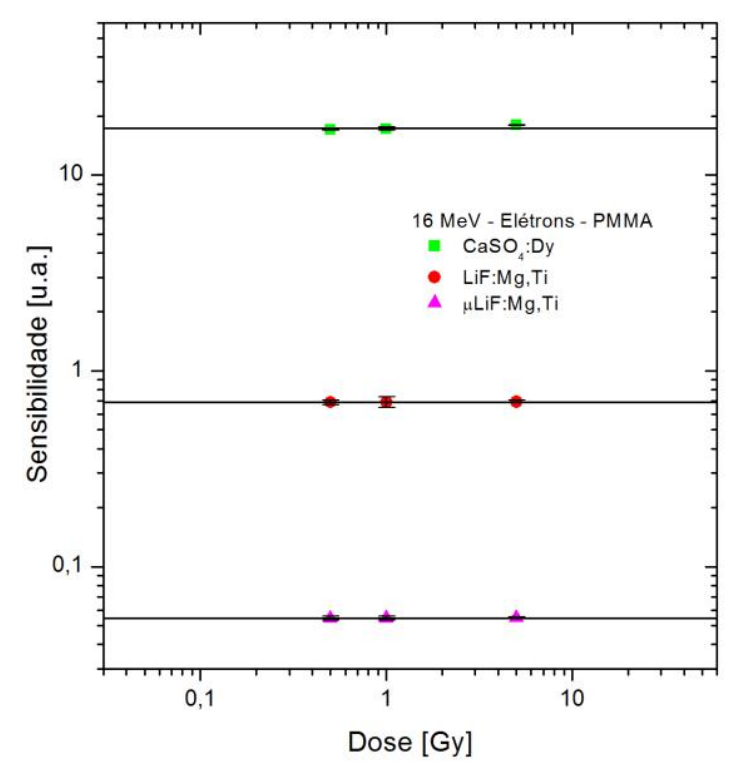

(a)

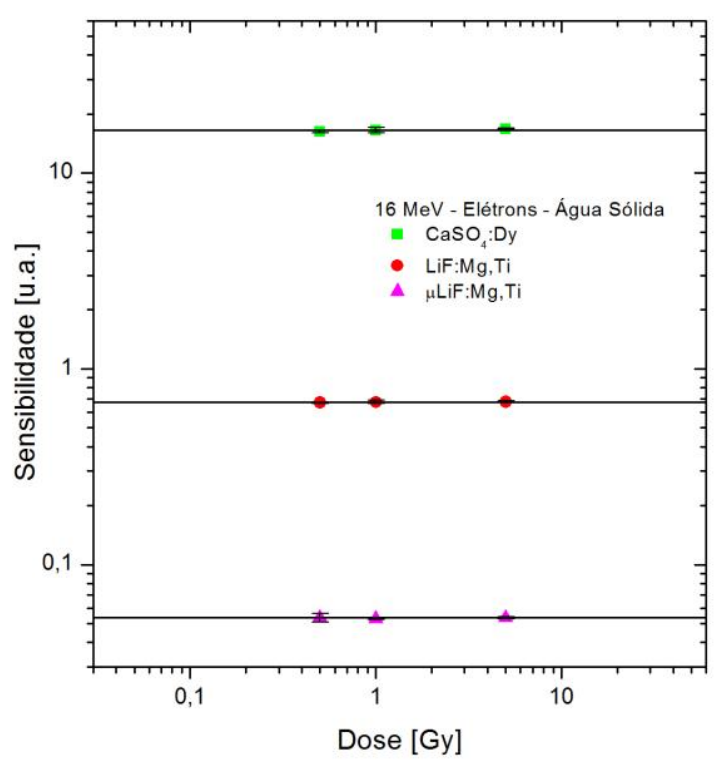

(b)

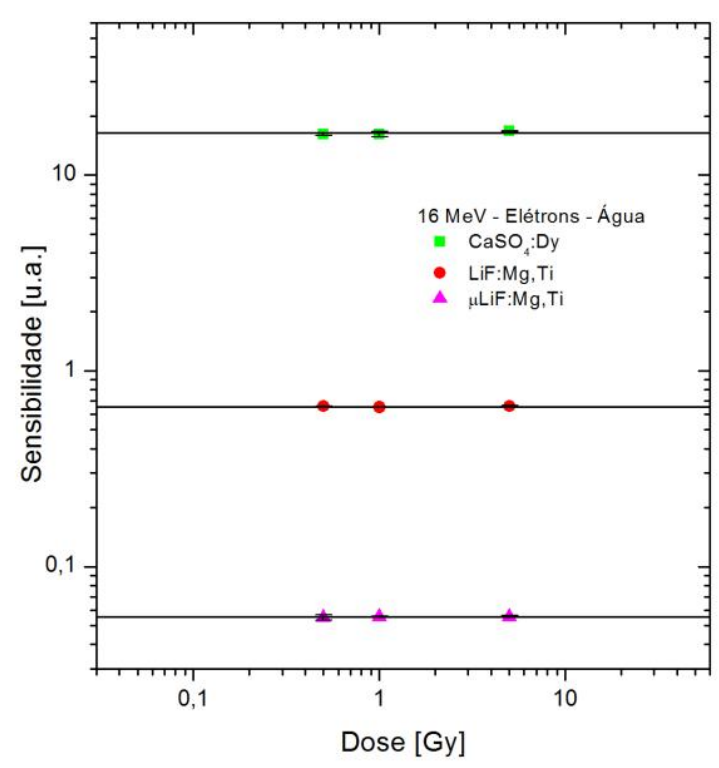

(c)

FIGURA 41 - Sensibilidade TL do $\mathrm{CaSO}_{4}: \mathrm{Dy}$, LiF: Mg,Ti e $\mu \mathrm{LiF}: \mathrm{Mg}$,Ti à radiação de elétrons de $16 \mathrm{MeV}$ para objeto simulador de (a) PMMA, (b) Água sólida e (c) Água.

Assim como já foi observado através das curvas de dose-resposta, para os três tipos de detectores nota-se que os valores permanecem praticamente constantes até a dose de 5 Gy. Nos gráficos de sensibilidade em função da dose (FIG. 34 a 41) é possível observar com mais clareza a tendência à supralinearidade quando os dosímetros são expostos a doses a partir de $10 \mathrm{~Gy}$. A sensibilidade do $\mathrm{CaSO}_{4}$ :Dy é, em média, aproximadamente 26 e 283 vezes superior à do LiF:Mg,Ti e do $\mu \mathrm{LiF}: \mathrm{Mg}, \mathrm{Ti}$, respectivamente. 


\subsection{Dependência Energética}

Nas FIG. 41 a 43 são apresentados os gráficos referentes à dependência energética da resposta TL dos dosímetros termoluminescentes de $\mathrm{CaSO}_{4}: \mathrm{Dy}$, LiF:Mg,Ti e $\mu \mathrm{LiF}: M g$,Ti para o feixe de elétrons em simuladores de água, água sólida e PMMA.

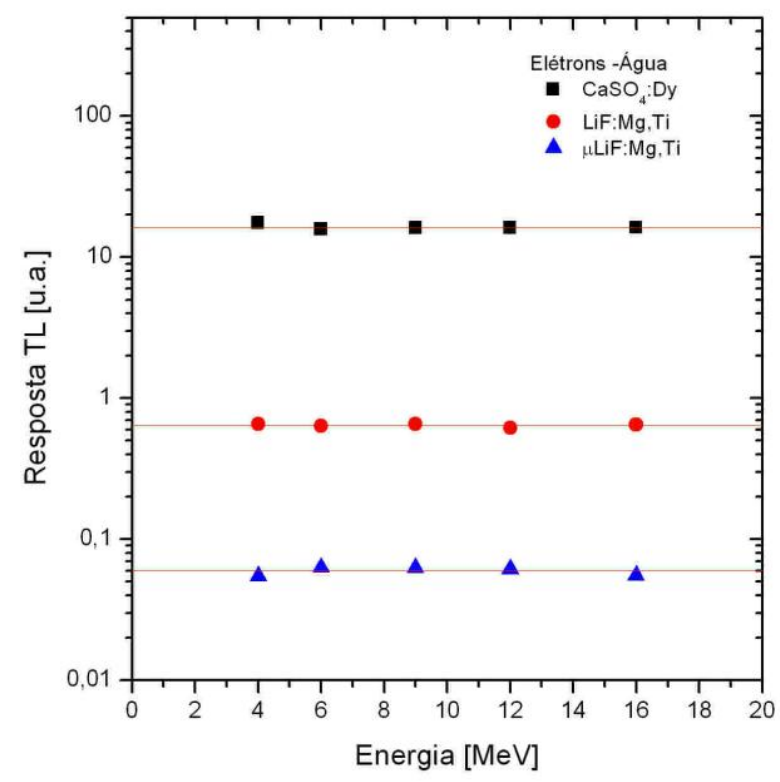

(a)

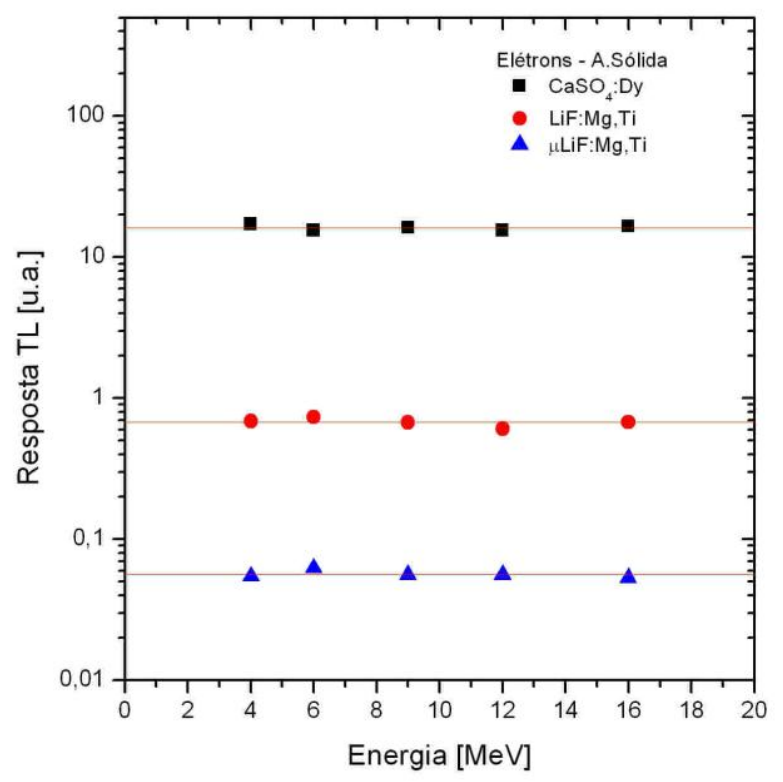

(b)

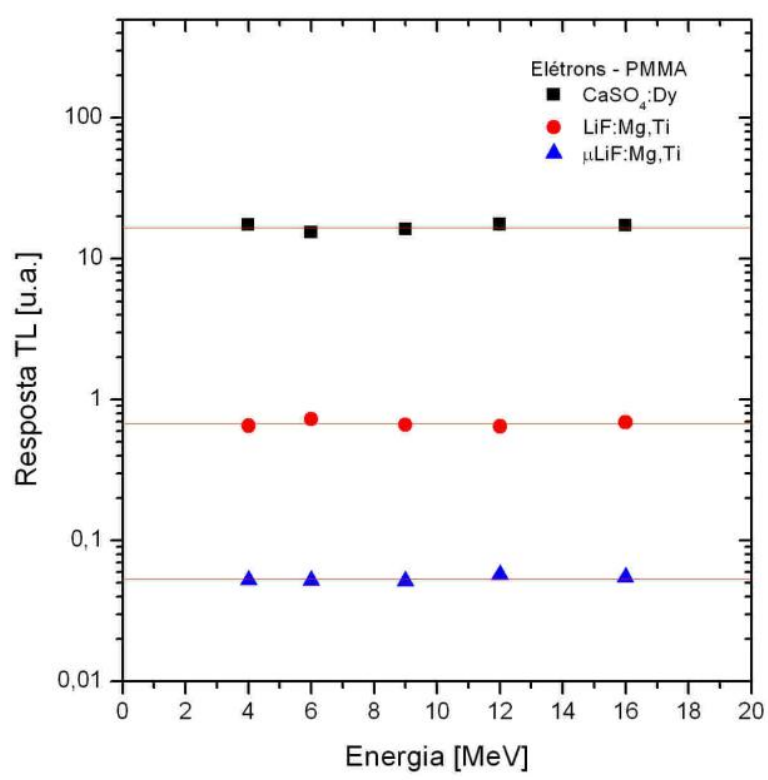

(c)

FIGURA 42 - Dependência Energética da resposta TL dos DTLs aos feixes de elétrons em objetos simuladores de (a) água; (b) água sólida; e (c) PMMA. 
Para os três objetos simuladores utilizados, o $\mathrm{CaSO}_{4}: \mathrm{Dy}$, o $\mathrm{LiF}: \mathrm{Mg}$,Ti e o $\mu \mathrm{LiF}: M g$,Ti não apresentaram diferenças significativas nas respostas TL. Sendo assim, pode-se afirmar que as respostas TL dos três tipos de detectores para o feixe de elétrons não apresentam dependência energética.

\subsection{Reprodutibilidade da resposta TL aos feixes clínicos de fótons e elétrons}

Nas TAB. 9 e 10 são apresentadas a sensibilidade relativa ao ${ }^{60}$ Co para os três tipos de dosímetros e os simuladores de PMMA, água sólida e água irradiados com feixes de fótons e elétrons, respectivamente.

TABELA 9 - Sensibilidade relativa ao ${ }^{60} \mathrm{Co}\left(\mathrm{S}_{\mathrm{DTL}} \mathrm{E} /{ }^{60} \mathrm{Co}\right)$ para os três tipos de DTLs irradiados com feixe de fótons utilizando em objeto simulador de PMMA, água sólida e água.

\begin{tabular}{|c|c|c|c|c|c|c|c|c|c|}
\hline \multirow[t]{2}{*}{ Irradiação } & \multicolumn{3}{|c|}{$\mathrm{CaSO}_{4}: \mathrm{Dy}$} & \multicolumn{3}{|c|}{ LiF:Mg,Ti } & \multicolumn{3}{|c|}{ $\mu \mathrm{LiF}: M g, T i$} \\
\hline & PMMA & AS & Água & PMMA & AS & Água & PMMA & AS & Água \\
\hline Fótons & $\mathrm{S}_{\mathrm{DTL}, \mathrm{E} /{ }^{60} \mathrm{Co}}$ & $\mathrm{S}_{\mathrm{DTL}, \mathrm{E} /{ }^{60} \mathrm{Co}}$ & $\mathrm{S}_{\mathrm{DTL}, \mathrm{E} /{ }^{60} \mathrm{Co}}$ & $\mathrm{S}_{\mathrm{DTL}} \mathrm{E} /{ }^{60} \mathrm{Co}$ & $\mathrm{S}_{\mathrm{DTL}} \mathrm{E} /{ }^{60} \mathrm{Co}$ & $\mathrm{S}_{\mathrm{DTL}, \mathrm{E} /{ }^{60} \mathrm{Co}}$ & $\mathrm{S}_{\mathrm{DTL}, \mathrm{E} /{ }^{60} \mathrm{Co}}$ & $\mathrm{S}_{\mathrm{DTL}} \mathrm{E} /{ }^{60} \mathrm{Co}$ & $\mathrm{S}_{\mathrm{DTL}}, \mathrm{E} /{ }^{60} \mathrm{Co}$ \\
\hline \multirow{5}{*}{$6 \mathrm{MV}$} & 0,88 & 0,90 & 0,95 & 0,76 & 0,74 & 0,76 & 0,78 & 0,76 & 0,83 \\
\hline & 0,95 & 0,91 & 0,95 & 0,77 & 0,76 & 0,78 & 0,76 & 0,75 & 0,81 \\
\hline & 0,95 & 0,92 & 0,96 & 0,74 & 0,75 & 0,76 & 0,78 & 0,75 & 0,76 \\
\hline & 0,92 & 0,90 & 0,90 & 0,74 & 0,75 & 0,76 & 0,70 & 0,72 & 0,76 \\
\hline & 0,96 & 0,89 & 0,96 & 0,76 & 0,74 & 0,77 & 0,84 & 0,79 & 0,78 \\
\hline \multirow[t]{3}{*}{ Média } & $0,93 \pm 0,03$ & $0,90 \pm 0,01$ & $0,94 \pm 0,02$ & $0,75 \pm 0,01$ & $0,75 \pm 0,01$ & $0,76 \pm 0,01$ & $0,77 \pm 0,05$ & $0,75 \pm 0,04$ & $0,78 \pm 0,06$ \\
\hline & 0,96 & 0,94 & 0,94 & 0,88 & 0,93 & 0,75 & 0,76 & 0,77 & 0,77 \\
\hline & 0,97 & 0,99 & 0,99 & 0,89 & 0,94 & 0,77 & 0,77 & 0,77 & 0,76 \\
\hline \multirow[t]{3}{*}{$15 \mathrm{MV}$} & 0,97 & 0,96 & 0,97 & 0,85 & 0,91 & 0,73 & 0,70 & 0,72 & 0,70 \\
\hline & 0,97 & 1,00 & 0,93 & 0,87 & 0,90 & 0,75 & 0,71 & 0,69 & 0,70 \\
\hline & 0,95 & 0,96 & 0,94 & 0,86 & 0,90 & 0,73 & 0,77 & 0,75 & 0,74 \\
\hline Média & $0,96 \pm 0,01$ & $0,97 \pm 0,03$ & $0,96 \pm 0,03$ & $0,87 \pm 0,02$ & $0,91 \pm 0,02$ & $0,74 \pm 0,01$ & $0,74 \pm 0,04$ & $0,74 \pm 0,03$ & $0,73 \pm 0,03$ \\
\hline
\end{tabular}


TABELA 10 - Sensibilidade relativa ao ${ }^{60} \mathrm{Co}\left(\mathrm{S}_{\mathrm{DTL}, \mathrm{E} /}{ }^{60} \mathrm{Co}\right)$ para os três tipos de DTLs irradiados com feixe de rons utilizando objeto simulador de PMMA, água sólida e água.

\begin{tabular}{|c|c|c|c|c|c|c|c|c|c|}
\hline \multirow[t]{2}{*}{ Irradiação } & \multicolumn{3}{|c|}{$\mathrm{CaSO}_{4}: \mathrm{Dy}$} & \multicolumn{3}{|c|}{ LiF:Mg,Ti } & \multicolumn{3}{|c|}{$\mu L i F: M g, T i$} \\
\hline & PMMA & AS & Água & PMMA & AS & Água & PMMA & AS & Água \\
\hline \multirow[t]{3}{*}{ Elétrons } & $\mathrm{S}_{\mathrm{DTL}, \mathrm{E} /{ }^{60} \mathrm{Co}}$ & $\mathrm{S}_{\mathrm{DTL}, \mathrm{E} /{ }^{60} \mathrm{Co}}$ & $\mathrm{S}_{\mathrm{DTL}, \mathrm{E} /{ }^{60} \mathrm{Co}}$ & $\mathrm{S}_{\mathrm{DTL}} \mathrm{E} /{ }^{60} \mathrm{Co}$ & $\mathrm{S}_{\mathrm{DTL}, \mathrm{E} /}{ }^{60} \mathrm{Co}$ & $\mathrm{S}_{\mathrm{DTL}, \mathrm{E} /{ }^{60} \mathrm{Co}}$ & $\mathrm{S}_{\mathrm{DTL}, \mathrm{E} /}{ }^{60} \mathrm{Co}$ & $\mathrm{S}_{\mathrm{DTL}, \mathrm{E} /{ }^{60} \mathrm{Co}}$ & $\mathrm{S}_{\mathrm{DTL}, \mathrm{E} /}{ }^{60} \mathrm{Co}$ \\
\hline & 0,95 & 0,93 & 0,97 & 0,75 & 0,79 & 0,76 & 0,65 & 0,68 & 0,70 \\
\hline & 0,96 & 0,96 & 0,98 & 0,75 & 0,78 & 0,76 & 0,65 & 0,68 & 0,66 \\
\hline \multirow[t]{3}{*}{$4 \mathrm{MeV}$} & 0,94 & 0,92 & 0,92 & 0,73 & 0,76 & 0,74 & 0,59 & 0,62 & 0,61 \\
\hline & 0,98 & 0,93 & 0,93 & 0,73 & 0,77 & 0,73 & 0,59 & 0,62 & 0,64 \\
\hline & 0,91 & 0,92 & 0,97 & 0,73 & 0,77 & 0,73 & 0,66 & 0,68 & 0,68 \\
\hline \multirow[t]{3}{*}{ Média } & $0,95 \pm 0,02$ & $0,93 \pm 0,02$ & $0,95 \pm 0,02$ & $0,74 \pm 0,01$ & $0,77 \pm 0,01$ & $0,74 \pm 0,02$ & $0,63 \pm 0,03$ & $0,65 \pm 0,03$ & $0,65 \pm 0,03$ \\
\hline & 0,85 & 0,86 & 0,88 & 0,84 & 0,84 & 0,72 & 0,64 & 0,77 & 0,79 \\
\hline & 0,84 & 0,83 & 0,88 & 0,85 & 0,85 & 0,73 & 0,65 & 0,76 & 0,78 \\
\hline \multirow[t]{3}{*}{$6 \mathrm{MeV}$} & 0,85 & 0,86 & 0,82 & 0,81 & 0,82 & 0,72 & 0,58 & 0,71 & 0,72 \\
\hline & 0,84 & 0,83 & 0,90 & 0,81 & 0,83 & 0,70 & 0,60 & 0,72 & 0,73 \\
\hline & 0,83 & 0,84 & 0,83 & 0,82 & 0,82 & 0,72 & 0,65 & 0,78 & 0,77 \\
\hline \multirow[t]{3}{*}{ Média } & $0,84 \pm 0,01$ & $0,84 \pm 0,02$ & $0,86 \pm 0,04$ & $0,82 \pm 0,02$ & $0,83 \pm 0,01$ & $0,72 \pm 0,01$ & $0,62 \pm 0,03$ & $0,75 \pm 0,03$ & $0,75 \pm 0,03$ \\
\hline & 0,87 & 0,90 & 0,90 & 0,75 & 0,77 & 0,75 & 0,64 & 0,70 & 0,77 \\
\hline & 0,91 & 0,87 & 0,87 & 0,75 & 0,78 & 0,77 & 0,64 & 0,67 & 0,77 \\
\hline \multirow[t]{3}{*}{$9 \mathrm{MeV}$} & 0,88 & 0,90 & 0,82 & 0,73 & 0,75 & 0,74 & 0,60 & 0,65 & 0,71 \\
\hline & 0,88 & 0,89 & 0,90 & 0,74 & 0,76 & 0,74 & 0,58 & 0,65 & 0,71 \\
\hline & 0,87 & 0,87 & 0,88 & 0,76 & 0,75 & 0,73 & 0,65 & 0,67 & 0,76 \\
\hline \multirow[t]{3}{*}{ Média } & $0,88 \pm 0,02$ & $0,89 \pm 0,01$ & $0,88 \pm 0,04$ & $0,75 \pm 0,01$ & $0,76 \pm 0,01$ & $0,75 \pm 0,02$ & $0,62 \pm 0,03$ & $0,66 \pm 0,02$ & $0,74 \pm 0,03$ \\
\hline & 0,96 & 0,85 & 0,90 & 0,76 & 0,70 & 0,70 & 0,72 & 0,70 & 0,77 \\
\hline & 0,98 & 0,87 & 0,87 & 0,74 & 0,70 & 0,71 & 0,70 & 0,69 & 0,76 \\
\hline \multirow[t]{3}{*}{$12 \mathrm{MeV}$} & 0,90 & 0,81 & 0,87 & 0,70 & 0,67 & 0,69 & 0,64 & 0,63 & 0,70 \\
\hline & 0,95 & 0,82 & 0,89 & 0,70 & 0,69 & 0,69 & 0,65 & 0,65 & 0,71 \\
\hline & 0,97 & 0,86 & 0,87 & 0,73 & 0,68 & 0,69 & 0,72 & 0,69 & 0,75 \\
\hline \multirow[t]{3}{*}{ Média } & $0,95 \pm 0,03$ & $0,84 \pm 0,02$ & $0,88 \pm 0,01$ & $0,72 \pm 0,03$ & $0,69 \pm 0,01$ & $0,69 \pm 0,01$ & $0,69 \pm 0,04$ & $0,67 \pm 0,03$ & $0,73 \pm 0,03$ \\
\hline & 0,92 & 0,87 & 0,92 & 0,75 & 0,77 & 0,74 & 0,69 & 0,67 & 0,69 \\
\hline & 0,97 & 0,92 & 0,85 & 0,74 & 0,75 & 0,75 & 0,65 & 0,65 & 0,69 \\
\hline \multirow[t]{3}{*}{$16 \mathrm{MeV}$} & 0,91 & 0,88 & 0,88 & 0,81 & 0,75 & 0,73 & 0,64 & 0,61 & 0,63 \\
\hline & 0,94 & 0,89 & 0,88 & 0,82 & 0,77 & 0,73 & 0,63 & 0,60 & 0,63 \\
\hline & 0,95 & 0,94 & 0,89 & 0,77 & 0,77 & 0,73 & 0,66 & 0,65 & 0,68 \\
\hline Média & $0,93 \pm 0,02$ & $0,90 \pm 0,03$ & $0,88 \pm 0,03$ & $0,77 \pm 0,04$ & $0,76 \pm 0,01$ & $0,73 \pm 0,01$ & $0,65 \pm 0,02$ & $0,64 \pm 0,03$ & $0,66 \pm 0,03$ \\
\hline
\end{tabular}


Analisando os resultados, nota-se que para todas as energias e simuladores empregados as sensibilidades relativas ao ${ }^{60} \mathrm{Co}$ de cada grupo de irradiação não ultrapassam o intervalo de $\pm 5 \%$, limite máximo.

Na TAB. 11 são apresentados os valores de reprodutibilidade dos DTLs para os feixes de fótons e elétrons utilizando os três simuladores.

TABELA 11 - Reprodutibilidade do $\mathrm{CaSO}_{4}$ :Dy, LiF:Mg,Ti e $\mu \mathrm{LiF}: M g, T i$ para cada energia dos feixes de fótons e elétrons e para os três tipos de objeto simulador.

\begin{tabular}{|c|c|c|c|c|c|}
\hline \multirow[t]{2}{*}{ Objeto Simulador } & \multirow[t]{2}{*}{ Irradiação } & \multirow[t]{2}{*}{ Energia } & \multicolumn{3}{|c|}{ Reprodutibilidade (\%) } \\
\hline & & & $\mathrm{CaSO}_{4}: \mathrm{Dy}$ & LiF:Mg,Ti & $\mu \mathrm{LiF}: \mathrm{Mg}, \mathrm{Ti}$ \\
\hline \multirow{7}{*}{ PMMA } & Fótons & 6 & 1,5 & 0,72 & 2,9 \\
\hline & [MV] & 15 & 0,45 & 0,90 & 2,2 \\
\hline & & 4 & 1,1 & 0,65 & 2,4 \\
\hline & Elétrons & 6 & 0,45 & 0,95 & 2,2 \\
\hline & {$[\mathrm{MeV}]$} & 9 & 0,85 & 0,79 & 2,0 \\
\hline & & 12 & 1,5 & 2,1 & 2,3 \\
\hline & & 16 & 1,1 & 2,1 & 1,6 \\
\hline \multirow{7}{*}{ AS } & Fótons & 6 & 0,44 & 0,57 & 2,5 \\
\hline & [MV] & 15 & 1,2 & 0,79 & 1,9 \\
\hline & & 4 & 0,88 & 0,76 & 2,3 \\
\hline & Elétrons & 6 & 0,84 & 0,53 & 2,2 \\
\hline & {$[\mathrm{MeV}]$} & 9 & 0,73 & 0,69 & 1,6 \\
\hline & & 12 & 1,3 & 0,67 & 1,8 \\
\hline & & 16 & 1,4 & 0,60 & 2,3 \\
\hline \multirow{7}{*}{ Água } & Fótons & 6 & 1,1 & 0,66 & 3,1 \\
\hline & [MV] & 15 & 1,2 & 0,81 & 2,1 \\
\hline & & 4 & 1,1 & 0,95 & 2,1 \\
\hline & Elétrons & 6 & 1,8 & 0,62 & 1,8 \\
\hline & {$[\mathrm{MeV}]$} & 9 & 1,8 & 1,0 & 1,9 \\
\hline & & 12 & 0,71 & 0,66 & 1,8 \\
\hline & & 16 & 1,3 & 0,60 & 1,9 \\
\hline
\end{tabular}

Para o DTL de $\mathrm{CaSO}_{4}: \mathrm{Dy}$, a reprodutibilidade da resposta TL é melhor que 1,8\% para feixe de elétrons de $6 \mathrm{MeV}$ e $9 \mathrm{MeV}$ e simulador de água. No caso dos 
dosímetros de LiF:Mg,Ti, a reprodutibilidade é melhor que 2,1\% para feixe de elétrons de $12 \mathrm{MeV}$ e $16 \mathrm{MeV}$ e simulador de PMMA. E para os $\mu \mathrm{LiF}: \mathrm{Mg}$,Ti, é melhor que 3,1\% para feixe de fótons de 6 MV e simulador de água. Todos os valores obtidos para reprodutibilidade dos dosímetros estão abaixo do limite máximo de aceitação em radioterapia, $5 \%$.

Pode-se observar que para os $\mu \mathrm{LiF}: \mathrm{Mg}$,Ti os valores de reprodutibilidade são maiores do que para o $\mathrm{CaSO}_{4}$ :Dy e LiF:Mg,Ti. Essa alteração está relacionada a erros no posicionamento dos dosímetros durante as irradiações. Por serem detectores de menores dimensões exigem maior cautela em suas medidas.

\subsection{Eficiência Intrínseca dos DTLs}

Nas TAB. 12, 13 e 14 são apresentados os valores dos coeficientes angulares e da eficiência intrínseca de cada detector, para todos os objetos simuladores e valores de energia utilizados. Os coeficientes angulares foram utilizados para se obter a eficiência intrínseca, como já indicado anteriormente no item 3.4.4.1.7.

TABELA 12 - Coeficientes angulares das curvas de calibração e eficiência intrínseca do $\mathrm{CaSO}_{4}$ :Dy para cada energia dos feixes de fótons e elétrons e para os três tipos de objeto simulador.

\begin{tabular}{cccccccc}
\hline & \multicolumn{3}{c}{ Coeficiente } & \multicolumn{3}{c}{ Eficiência Intrínseca (\%) } \\
\cline { 2 - 8 }$\underline{\text { CaSO }_{4}: D y}$ & & Água & AS & PMMA & Água & AS & PMMA \\
\hline \multirow{6}{*}{${ }^{60} \mathrm{Co}$} & & & 19,85 & & & $0,12 \pm 0,01$ \\
& $4 \mathrm{MeV}$ & 17,91 & 17,84 & 17,57 & $0,11 \pm 0,01$ & $0,11 \pm 0,01$ & $0,10 \pm 0,01$ \\
& $6 \mathrm{MeV}$ & 18,37 & 17,88 & 17,31 & $0,11 \pm 0,01$ & $0,11 \pm 0,01$ & $0,10 \pm 0,01$ \\
& $6 \mathrm{MeV}$ & 16,73 & 16,51 & 16,44 & $0,10 \pm 0,01$ & $0,10 \pm 0,01$ & $0,10 \pm 0,01$ \\
& $12 \mathrm{MeV}$ & 16,54 & 15,94 & 17,81 & $0,10 \pm 0,01$ & $0,10 \pm 0,01$ & $0,11 \pm 0,01$ \\
& $16 \mathrm{MeV}$ & 16,74 & 16,81 & 17,93 & $0,10 \pm 0,01$ & $0,10 \pm 0,01$ & $0,11 \pm 0,01$ \\
\cline { 2 - 8 } & $6 \mathrm{MV}$ & 17,92 & 16,74 & 17,82 & $0,10 \pm 0,02$ & $0,10 \pm 0,01$ & $0,11 \pm 0,01$ \\
& $15 \mathrm{MV}$ & 21,63 & 21,32 & 20,75 & $0,13 \pm 0,01$ & $0,13 \pm 0,01$ & $0,12 \pm 0,01$ \\
\hline
\end{tabular}


TABELA 13 - Coeficientes angulares das curvas de calibração e eficiência intrínseca do LiF:Mg,Ti para cada energia dos feixes de fótons e elétrons e para os três tipos de objeto simulador.

\begin{tabular}{cccccccc}
\hline & & \multicolumn{3}{c}{ Coeficiente } & \multicolumn{3}{c}{ Eficiência Intrínseca (\%) } \\
\cline { 2 - 8 }$\underline{\text { LiF:Mg.Ti }}$ & & Água & AS & PMMA & Água & AS & PMMA \\
\hline \multirow{6}{*}{ Elétrons } & ${ }^{60} \mathrm{Co}$ & & & 1,007 & & & $0,050 \pm 0,005$ \\
& $4 \mathrm{MeV}$ & 0,6625 & 0,6984 & 0,6579 & $0,033 \pm 0,003$ & $0,035 \pm 0,003$ & $0,033 \pm 0,003$ \\
& $6 \mathrm{MeV}$ & 0,7174 & 0,7915 & 0,7891 & $0,036 \pm 0,004$ & $0,039 \pm 0,004$ & $0,039 \pm 0,004$ \\
& $9 \mathrm{MeV}$ & 0,6584 & 0,6736 & 0,6639 & $0,033 \pm 0,003$ & $0,034 \pm 0,003$ & $0,033 \pm 0,003$ \\
& $12 \mathrm{MeV}$ & 0,6173 & 0,6066 & 0,6419 & $0,031 \pm 0,003$ & $0,030 \pm 0,003$ & $0,032 \pm 0,003$ \\
& $16 \mathrm{MeV}$ & 0,6591 & 0,6784 & 0,6945 & $0,033 \pm 0,003$ & $0,034 \pm 0,003$ & $0,035 \pm 0,003$ \\
\cline { 2 - 8 } & $6 \mathrm{MV}$ & 0,6806 & 0,6687 & 0,6666 & $0,034 \pm 0,003$ & $0,033 \pm 0,003$ & $0,033 \pm 0,003$ \\
& $15 \mathrm{MV}$ & 0,7354 & 0,9068 & 0,8335 & $0,037 \pm 0,004$ & $0,045 \pm 0,005$ & $0,042 \pm 0,004$ \\
\hline
\end{tabular}

TABELA 14 - Coeficientes angulares das curvas de calibração e eficiência intrínseca do $\mu \mathrm{LiF}: M g, T i$ para cada energia dos feixes de fótons e elétrons e para os três tipos de objeto simulador.

\begin{tabular}{|c|c|c|c|c|c|c|c|}
\hline \multirow{2}{*}{ $\mu L i F: M g, T i$} & & \multicolumn{3}{|c|}{ Coeficiente } & \multicolumn{3}{|c|}{ Eficiência Intrínseca (\%) } \\
\hline & & Água & AS & PMMA & Água & AS & PMMA \\
\hline \multirow{6}{*}{ Elétrons } & ${ }^{60} \mathrm{Co}$ & & & 0,09636 & & & $0,0096 \pm 0,0010$ \\
\hline & $4 \mathrm{MeV}$ & 0,05453 & 0,05404 & 0,05283 & $0,0055 \pm 0,0005$ & $0,0054 \pm 0,0005$ & $0,0053 \pm 0,0005$ \\
\hline & $6 \mathrm{MeV}$ & 0,07358 & 0,06902 & 0,05572 & $0,0074 \pm 0,0008$ & $0,0069 \pm 0,0007$ & $0,0056 \pm 0,0006$ \\
\hline & $9 \mathrm{MeV}$ & 0,06261 & 0,05527 & 0,05141 & $0,0063 \pm 0,0006$ & $0,0055 \pm 0,0006$ & $0,0051 \pm 0,0005$ \\
\hline & $12 \mathrm{MeV}$ & 0,06146 & 0,05555 & 0,05751 & $0,0061 \pm 0,0006$ & $0,0056 \pm 0,0006$ & $0,0058 \pm 0,0006$ \\
\hline & $16 \mathrm{MeV}$ & 0,05574 & 0,05354 & 0,05488 & $0,0056 \pm 0,0006$ & $0,0054 \pm 0,0005$ & $0,0055 \pm 0,0005$ \\
\hline \multirow{2}{*}{ Fótons } & $6 \mathrm{MV}$ & 0,06472 & 0,06232 & 0,06482 & $0,0065 \pm 0,0006$ & $0,0062 \pm 0,0006$ & $0,0065 \pm 0,0006$ \\
\hline & $15 \mathrm{MV}$ & 0,07117 & 0,07077 & 0,06902 & $0,0071 \pm 0,0008$ & $0,0071 \pm 0,0007$ & $0,0069 \pm 0,0007$ \\
\hline
\end{tabular}

As eficiências variam até $(3,45 \pm 0,25) \%,(10,13 \pm 0,24) \%$ e $(5,54 \pm 0,02) \%$ para o $\mathrm{CaSO}_{4}: \mathrm{Dy}$, $\mathrm{LiF}: \mathrm{Mg}$,Ti e $\mu \mathrm{LiF}: \mathrm{Mg}$,Ti, respectivamente, de acordo com o material simulador empregado. Em relação ao tipo de feixe, as eficiências dos DTLs de $\mathrm{CaSO}_{4}: \mathrm{Dy}, \mathrm{LiF}: \mathrm{Mg}$,Ti e $\mu \mathrm{LiF}: \mathrm{Mg}$,Ti variam até $(12,43 \pm 0,91) \%,(9,97 \pm 0,24) \%$ e $(16,06 \pm 0,06) \%$, respectivamente. Os dosímetros de $\mathrm{CaSO}_{4}: \mathrm{Dy}$, possuem eficiência intrínseca 3 e 17 vezes maior que o LiF:Mg,Ti e o $\mu \mathrm{LiF}: M g$,Ti, respectivamente. Isso já era esperado visto que a eficiência intrínseca é dependente da resposta TL e da massa 
do material. As eficiências obtidas para estão de acordo com a literatura (Meijvogel et al, 1996; Nunes, 2008).

\subsection{Limite inferior de detecção (LID)}

Na TAB. 15 são apresentados os valores das leituras TL médias dos dosímetros não irradiados $\left(\bar{R}_{T L, 0}\right)$ e nas TAB. 16, 17 e 18 os fatores de calibração $\left(f_{\text {cal }}\right.$ ) dos dosímetros de $\mathrm{CaSO}_{4}$ :Dy, LiF:Mg,Ti e $\mu \mathrm{LiF}: \mathrm{Mg}, \mathrm{Ti}$, os valores calculados para os LIDs de cada tipo de DTL para radiação gama do ${ }^{60} \mathrm{Co}$, feixe de elétrons e feixe de fótons e seus respectivos erros.

TABELA 15 - Valores de leituras TL médias dos dosímetros não-irradiados.

\begin{tabular}{cc}
\hline DTL & $\bar{R}_{\text {TL,o }}[\mathbf{n C}]$ \\
\hline $\mathrm{CaSO}_{4}: \mathrm{Dy}$ & $0,5456 \pm 0,0153$ \\
$\mathrm{LiF}: \mathrm{Mg}, \mathrm{Ti}$ & $0,4307 \pm 0,0047$ \\
$\mu \mathrm{LiF}: \mathrm{Mg}, \mathrm{Ti}$ & $0,0412 \pm 0,0013$ \\
\hline
\end{tabular}

TABELA 16 - Limite inferior de detecção (LID) do $\mathrm{CaSO}_{4}$ :Dy para radiação gama do ${ }^{60} \mathrm{Co}$, feixe de elétrons e fótons.

\begin{tabular}{cccccc}
\hline \multicolumn{3}{c}{$f_{\text {cal }}[\boldsymbol{\mu G y} / \mathbf{n C}]$} & \multicolumn{3}{c}{ LID [ $\boldsymbol{\mu G y}]$} \\
Água & AS & PMMA & Água & AS & PMMA \\
\hline & & 50,4 & & & $29,8 \pm 0,8$ \\
55,8 & 56,1 & 56,9 & $33,2 \pm 0,9$ & $33,2 \pm 0,8$ & $33,7 \pm 0,8$ \\
54,4 & 55,9 & 57,8 & $32,2 \pm 0,8$ & $33,1 \pm 0,8$ & $34,2 \pm 0,8$ \\
59,8 & 60,6 & 60,8 & $36,3 \pm 0,9$ & $35,8 \pm 0,9$ & $35,9 \pm 0,9$ \\
60,5 & 62,7 & 56,1 & $35,8 \pm 0,9$ & $37,1 \pm 0,9$ & $33,2 \pm 0,8$ \\
59,7 & 59,5 & 55,8 & $35,3 \pm 0,8$ & $35,2 \pm 0,8$ & $33,0 \pm 0,8$ \\
55,8 & 59,7 & 56,1 & $33,0 \pm 0,7$ & $35,3 \pm 0,7$ & $33,2 \pm 0,8$ \\
46,2 & 46,9 & 48,2 & $27,7 \pm 0,7$ & $27,7 \pm 0,7$ & $28,5 \pm 0,7$ \\
\hline
\end{tabular}


TABELA 17 - Limite inferior de detecção (LID) do LiF:Mg,Ti para radiação gama do ${ }^{60} \mathrm{Co}$, feixe de elétrons e fótons.

\begin{tabular}{lccccc}
\hline \multicolumn{3}{c}{$f_{\text {cal }}[\mu \mathrm{Gy} / \mathbf{n C}]$} & \multicolumn{3}{c}{ LID [ $\mu \mathrm{Gy}]$} \\
Água & AS & PMMA & Água & AS & PMMA \\
\hline & & 993 & & & $442 \pm 5$ \\
1509 & 1432 & 1520 & $673 \pm 8$ & $637 \pm 7$ & $676 \pm 8$ \\
1394 & 1263 & 1267 & $621 \pm 7$ & $562 \pm 6$ & $564 \pm 6$ \\
1519 & 1485 & 1506 & $675 \pm 9$ & $660 \pm 8$ & $670 \pm 8$ \\
1620 & 1649 & 1620 & $721 \pm 9$ & $734 \pm 10$ & $693 \pm 9$ \\
1517 & 1474 & 1440 & $675 \pm 8$ & $656 \pm 8$ & $641 \pm 7$ \\
1469 & 1495 & 1500 & $491 \pm 6$ & $665 \pm 9$ & $668 \pm 8$ \\
1360 & 1103 & 1200 & $676 \pm 8$ & $491 \pm 5$ & $534 \pm 6$ \\
\hline
\end{tabular}

TABELA 18 - Limite inferior de detecção (LID) do $\mu$ LiF:Mg,Ti para radiação gama do ${ }^{60} \mathrm{Co}$, feixe de elétrons e fótons.

$$
f_{\text {cal }}[\mu \mathrm{Gy} / \mathrm{nC}] \quad \text { LID }[\mu \mathrm{Gy}]
$$

\begin{tabular}{cccccccc}
\hline$\underline{\mu L i F: M g, T i}$ & & Água & AS & PMMA & Água & AS & PMMA \\
\hline \multirow{6}{*}{ Co-60 } & & & 10378 & & & $468 \pm 15$ \\
& $4 \mathrm{MeV}$ & 18339 & 18505 & 18929 & $839 \pm 19$ & $839 \pm 19$ & $858 \pm 20$ \\
& $6 \mathrm{MeV}$ & 13591 & 14489 & 17947 & $716 \pm 16$ & $756 \pm 17$ & $813 \pm 18$ \\
& $9 \mathrm{MeV}$ & 15972 & 18093 & 19451 & $731 \pm 17$ & $820 \pm 18$ & $881 \pm 20$ \\
& $12 \mathrm{MeV}$ & 16271 & 18002 & 17388 & $738 \pm 17$ & $816 \pm 18$ & $788 \pm 18$ \\
& $16 \mathrm{MeV}$ & 17940 & 18678 & 18222 & $813 \pm 19$ & $846 \pm 20$ & $826 \pm 18$ \\
& $6 \mathrm{MV}$ & 15451 & 16046 & 15427 & $700 \pm 16$ & $727 \pm 17$ & $699 \pm 16$ \\
& $15 \mathrm{MV}$ & 14051 & 14130 & 14489 & $641 \pm 15$ & $641 \pm 15$ & $657 \pm 16$ \\
\hline
\end{tabular}

Todos os valores de LID estão de acordo com valores encontrados na literatura (Campos e Lima, 1986; Metcalfe et al, 2007).

Para a radiação gama do ${ }^{60} \mathrm{Co}$, o $\mathrm{LID}$ do $\mathrm{CaSO}_{4}$ :Dy é 14 e 16 vezes menor do que o LID do LiF:Mg,Ti e do $\mu \mathrm{LiF}: M g$,Ti respectivamente. Já para os feixes de fótons e elétrons, o LID do $\mathrm{CaSO}_{4}$ :Dy é 18 e 22 vezes menor que o LiF:Mg,Ti e $\mu \mathrm{LiF}: \mathrm{Mg}$,Ti. 


\subsection{Incerteza nas medidas}

Como incerteza do tipo A nota-se uma dispersão de 3,0\%, 3,5\% e 3,5\% nos valores de resposta TL realizadas na leitora TL para feixe de ${ }^{60} \mathrm{Co}$, elétrons e fótons, respectivamente. Em relação às incertezas do tipo $B$, observam-se alguns erros que podem ser considerados insignificantes: erro no tempo dos tratamentos térmicos dos DTLs, erro no tempo de irradiação dos DTLs na fonte de radiação gama do ${ }^{60}$ Co do Laboratório de Materiais Dosimétricos do IPEN e erro em relação ao tempo de armazenamento dos detectores na blindagem de chumbo (até que fosse efetuada a leitura dos mesmos). 0 erro relacionado à pesagem dos DTLs também pode ser desprezada, pois a balança utilizada para essa finalidade possui precisão de $\pm 0,0001$.

Erros relacionados ao posicionamento dos dosímetros durante as irradiações nos aceleradores lineares do HIAE podem acarretar variações nos valores de reprodutibilidade, como ocorreu com os $\mu \mathrm{LiF}: \mathrm{Mg}$,Ti expostos a feixes de fótons de 6 MV utilizando simuladores de PMMA e água. Ainda em relação à irradiação com feixes clínicos de fótons e elétrons, a dose absorvida tem precisão de \pm 0,001 Gy. Avaliando todas as incertezas relacionadas e observando que quase a maioria é considerada irrelevante, a incerteza total pode ser considerada menor que $5 \%$, valor máximo recomendado para incertezas em radioterapia. 


\section{CONCLUSÕES}

Os resultados dos testes de luz padrão interna e de razão sinal/ruído realizados na leitora TL mostraram que a mesma apresentou uma boa estabilidade, auxiliando o desenvolvimento do trabalho, pois não foi necessário repetir nenhuma irradiação e leitura. 0 bom desempenho da leitora e a seleção minuciosa dos dosímetros possibilitaram a precisão dos resultados.

Para todos os tipos de radiação ( ${ }^{60} \mathrm{Co}$, fótons e elétrons) e objetos simuladores (PMMA, água sólida e água) as curvas de dose-resposta se mostraram lineares no intervalo de dose estudado, 0,1 a 10 Gy. A partir de $10 \mathrm{~Gy}$, dose máxima estudada, observa-se uma leve tendência à supralinearidade. Este comportamento é mais expressivo nos gráficos de sensibilidade em função da dose.

A sensibilidade média obtida para cada dose não apresentou uma variação significante e os dosímetros de $\mathrm{CaSO}_{4}$ :Dy são aproximadamente 26 e 283 vezes mais sensíveis do que os dosímetros de LiF:Mg,Ti e $\mu \mathrm{LiF}: \mathrm{Mg}, \mathrm{Ti}$, respectivamente. Para todos os objetos simuladores e valores de energia utilizados, as sensibilidades relativas ao ${ }^{60} \mathrm{Co}$ pertencem ao intervalo estabelecido para a seleção inicial dos dosímetros, $\pm 5 \%$, confirmando a homogeneidade dos lotes de detectores utilizados.

A reprodutibilidade da resposta TL do dosímetro de $\mathrm{CaSO}_{4}: \mathrm{Dy}$ variou de 0,44\%, para feixe de fótons de 6 MV e simulador de água sólida, a 1,8\%, para feixe de elétrons de $6 \mathrm{MeV}$ e $9 \mathrm{MeV}$ e simulador de água. Para os dosímetros de LiF:Mg,Ti, as reprodutibilidades apresentaram uma variação de 0,53\%, para feixe de elétrons de $6 \mathrm{MeV}$ e simulador de água sólida, a 2,1\%, para feixe de elétrons de 12 e $16 \mathrm{MeV}$ e simulador de PMMA. Os $\mu \mathrm{LiF}: \mathrm{Mg}, \mathrm{Ti}$ apresentaram valores maiores de reprodutibilidades e que variaram de 1,6\%, para feixe de elétrons de $9 \mathrm{MeV}$ e simulador de água sólida, a 3,1\%, para feixe de fótons de $6 \mathrm{MV}$ e simulador de água. Dentre todas as reprodutibilidades de resposta TL obtidas, todas estão de acordo com o valor máximo aceitável em radioterapia (5\%).

A eficiência intrínseca dos dosímetros de $\mathrm{CaSO}_{4}$ :Dy é aproximadamente $3 \mathrm{e}$ 17 vezes maior que o $\mathrm{LiF}: \mathrm{Mg}, \mathrm{Ti}$ e $\mu \mathrm{LiF}: \mathrm{Mg}$,Ti, respectivamente, sendo assim, os mesmos são ate 67\% mais eficientes do que o LiF:Mg,Ti e até $94 \%$ mais eficientes do que o $\mu \mathrm{LiF}: \mathrm{Mg}$,Ti. 
Os limites inferiores de detecção (LID) indicam que todos os materiais estudados estão dentro dos limites estabelecidos para a dosimetria em radioterapia.

A resposta TL dos dosímetros de $\mathrm{CaSO}_{4}: \mathrm{Dy}, \mathrm{LiF}: \mathrm{Mg}$,Ti e $\mu \mathrm{LiF}: \mathrm{Mg}$,Ti aos feixes de elétrons não apresenta dependência energética para as irradiações empregando os objetos simuladores de água, água sólida e PMMA.

A partir de todas as análises feitas e comparando os resultados obtidos, comprova-se o ótimo desempenho dos dosímetros produzidos pela Harshaw Chemical Company, o TLD-100, e apresenta os dosímetros produzidos pelo IPEN, o $\mathrm{CaSO}_{4}$ :Dy, como uma nova ferramenta para a dosimetria de feixes clínicos de elétrons e fótons aplicada à radioterapia, com vantagens em relação à sensibilidade, custo e obtenção dos detectores. 


\section{REFERÊNCIAS BIBLIOGRÁFICAS}

ALBUQUERQUE , M. P. P; CALDAS , L. V. E. Aplicação de uma câmara de ionização de placas paralelas para detecção da radiação-X entre 25 e $250 \mathrm{kV}$. In: 42 ${ }^{a}$ Reunião Anual da Sociedade Brasileira para o Progresso da Ciência, 1990, Porto Alegre, Proceedings...

AMERICAN ASSOCIATION OF PHYSICISTS IN MEDICINE. A protocol for clinical reference dosimetry of high-energy photon and electron beams. Med. Phys., v. 26, n. -9 , p. 1847-1870, 1999. (TG-51)

AMERICAN ASSOCIATION OF PHYSICISTS IN MEDICINE. A protocol for the determination of absorbed dose from high-energy photon and electron beams. Med. Phys., v. 10, n. 6, p. 741-771, 1983 (TG-21).

BARTESAGHI, G.; BURIAN, J.; GAMBARINI, G.; MAREK, M. NEGRI, A.; VIERERBL, L. Evaluation of all dose components in the LVR-15 reactor epithermal neutron beam using Fricke gel dosimeter layers. Applied Radiation and Isotopes, v. 67, p. 199-201, 2009.

BERGER, M. J., SELTER, S. M.; DOMEN, S. R.; LAMPERTI, P. J. Electron Dosimetry with Ionization Chambers. NBS SP456, Proceedings..., P. 307-312 (1976).

BOUDOU, C.; BISTON, M.C.; CORDE, S.; ADAM, J.F.; JOUBERT, A.; CHARVET, A.M.; NEMOZ, C.; FERRERO, C.; ESTÈVE, F.; ELLEAUME, H. Dosimetry for synchrotron stereotactic radiotherapy: Fricke gel and Monte Carlo calculations. Nuclear Instruments and Methods in Physics Research A, v. 548, p. 65-68, 2005.

BUTSON, M. J.; ELFERINK, R.; CHEUNG, T.; YU, P. K. N.; STOKES, M.; QUACK, K. Y.; METCALFE, P. Verification of lung dose in an anthropomorphic phantom calculated by the collapsed cone convolution method. Phys. Med. Biol. v. 45, p. N143-N149, 2000 .

CAMERON, J.R.; SUNTHARALINGAM, N.; KENNEY, G.N. Thermoluminescent dosimetry. Londres: The Colonial Press, 1968.

CAMPOS, L. L. Thermoluminescence of materials and its application on radiation dosimetry. Cerâmica, São Paulo, v. 44, n. 290, 1998.

CAMPOS, L. L. Thermoluminescence of materials and its application on radiation dosimetry. Cerâmica, São Paulo, v. 44, n. 290, 1998.

CAMPOS, L.L. Preparation of CaSO4:Dy TL Single Crystals. J. Lum. v. 28, p. 481, 1983.

CAMPOS, L.L.; LIMA, M.F. Dosimetric properties of $\mathrm{CaSO}_{4}: \mathrm{Dy}+$ Teflon pellets produced at IPEN. Radiol. Prot. Dosim. v. 14, n. 4, p. 333, 1986.

CAMPOS, L.L.; SOUZA, C.N. Aplicação dos dosímetros termoluminescentes de $\mathrm{CaSO}_{4}$ :Dy na dosimetria de elétrons de energia alta. In: $5^{\text {th }}$ LATIN AMERICAN 
CONFERENCE ON MEDICAL PHYSICS, October 7-12, 1990, Ribeirão Preto. Proceedings...

CAMPOS. L.L.; LIMA, M.F. Thermoluminescent $\mathrm{CaSO}_{4}$ :Dy + Teflon pellets for beta radiation detection. Rad. Prot. Dosim. v. 18, n. 2, p. 95, 1987.

CHATTERJEE, S.; BAKSHI, A.K.; KINHIKAR, R.A.; CHOURASIYA, G.; KHER, R.K. Response of $\mathrm{CaSO}_{4}$ :Dy phosphor based TLD badge system to high energy electron beams from medical linear accelerator and estimation of whole body dose and skin dose. Rad. Measurements. v. 44, p. 257-262, 2009.

CROSS, P., JOSEPH, D.J., CANT, J., COOPER, S.G.; DENHAM, J.W. Tangential breast irradiation: simples improvements. Int. J. Radiat. Oncol. Biol. Phys. v.23, p.433-42, 1992.

CUNNINGHAM, J.H.E. The physics of radiology. $4^{\text {th }}$ Edition Charles C, Thomas Publisher. 1983.

CURRY, T. S.; DOWDEY, J. E., MURRY, R. C. Christensen's physics of diagnostic radiology. 4.ed. London: Lea \& Febiger, 1990.

DERREUMAUX, S.; CHAVAUDRA, J.; BRIDIER, A.; ROSSETTI, V.; DUTREIX, A. A european quality assurance network for radiotherapy: dose measurement procedure. Phys. Med. Biol., v. 40, p. 1191-1208, 1995.

DEVITA, V. T. Cancer Principles e practice of oncology. Lippincott Williams e Wilkins. 2000.

DUCH, M. A.; GINJAUME, M.; CHAKKOR, H.; ORTEGA, X.; JORNET, N.; RIBAS, M. Thermoluminescence dosimetry applied to in vivo dose measurements for total body irradiation techniques. Radioth. Oncol. v. 47, n.ํㅜ p. 319-324, 1998.

EGGERMONT, G. JACOBS, R.; JANSSESNS, A.; SEGAERT, 0.; THIELENS, G. Dose relationship energy response and rate dependence of $\mathrm{LiF}-100, \mathrm{LiF}-7$ and $\mathrm{CaSO}_{4}-\mathrm{Mn}$ from $8 \mathrm{keV}$ to $30 \mathrm{MeV}$. In: $3^{\text {rd }}$ INTERNATIONAL CONFERENCE ON LUMINESCENCE DOSIMETRY, October 11-14, 1971, Riso. Proceedings...

ESSERS, M., MIJNHEER, B. J. In Vivo Dosimetry During Extrenal Beam Therapy: a Critical Review. Int. J. Radiat. Oncol. Biol. Phys. (1999) 43:245-259

FRAGOSO, M.; PILLAI, S.; SOLDBERG, T. D.; CHETTY, I. J. Experimental verification and clinical implementation of a commercial Monte Carlo electron beam dose calculcation algorithm. Med. Phys. v. 35, n.ํㅜ 3, p. 1028-1038, 2008.

FRASER, D.; PARKER, W.; SEUNTJENS, J. Characterization of cylindrical ionization chambers for patient specific IMRT QA. Journal of Applied clinical Medical Physics, v. 10, n. 4, p. 241-251, 2009. 
GOODEN, D.S.; BRICKNER, T.J. The routine use of thermoluminescence dosimetry for radiation therapy, Radiology 102: 685-9, 1972

HALL, E.J. Radiobiology for the radiologist. Lippincott. 1988. Handbooks 5, Bristol: Adam Hilger, 1981.

HUFTON, A. P. Practical Aspects of Thermoluminescence Dosimetry. London: HPA, 1984.

HUYSKENS, D.; BOGAERTS, R.; VERSTRAETE J.; LÖÖF, M.; NYSTRÖM, H.; FIORINO, C.; BROGGI, S.; JORNET, N.; RIBAS, M.; THWAITES, D. I. Practical Guide lines for the Implementation of In Vivo Dosimetry with Diodes in External Radiotherapy with Photons Beans (Entrance Dose). Physics for Clinical Radiotherapy Booklet, 5 2001; ESTRO: Brussels: Belgium.

INTERNATIONAL ATOMIC ENERGY AGENCY. Absorbed dose determination in photon and electron beams. An International Cod of Practice. Vienna, 1987 (TRS277).

INTERNATIONAL ATOMIC ENERGY AGENCY. Absorbed dose determination in external beam radiotherapy. An International Code of Practice for Dosimetry based on standards of absorbed dose to water. Vienna, Abr. 2000 (TRS-398).

INTERNATIONAL ATOMIC ENERGY AGENCY. Radiation Oncology Physics: A Handbook for teachers and students. Vienna, 2005.

INTERNATIONAL ATOMIC ENERGY AGENCY. The use of plane-parallel ionization chambers in high-energy electron and photon beams. An International Code of Practice Dosimetry. Vienna, 1997 (TRS-381).

INTERNATIONAL COMISSION ON RADIATION UNITS AND MEASUREMENTS - ICRU Report 48. Phantoms and Computational Models in Therapy, Diagnosis and Protection. Bethesda, Maryland: ICRU Publications, 1992.

INTERNATIONAL COMISSION ON RADIATION UNITS AND MEASUREMENTS - ICRU Report 44: Tissues Substitutes in Radiation Dosimetry and Measurement. Bethesda, Maryland: ICRU Publications, 1989.

INTERNATIONAL COMMISSION ON RADIATION UNITS AND MEASUREMENTS - ICRU Report 24: Determination of Absorbed Dose in a Patient Irradiated by Beams of X or Gamma Rays in Radiotherapy Procedures. Bethesd, Maryland: ICRU Publications, 1976.

INTERNATIONAL ORGANIZATION FOR STANDARDIZATION (ISO - DIS 4037): $\boldsymbol{X}$ and Gamma Reference Radiation for Calibrating Dosimeters and Dose Rate Meters and for Determining Their Response as a Function of Photon Energy - Part 3. ISO DIS 4037. Geneva, Switzerland: International Organization for Standardization, 1996. 
INTERNATIONAL ORGANIZATION FOR STANDARDIZATION. Guide to the Expression of Uncertainty in Measurement. 1aㅡ Edição, 1993, corrigido e reimpreso, 1995. Geneva, Suíça.

JOHNS, H.E., CUNNINGHAM, J.R. The Physics of Radiology. 3.ed. Illinois: Charles C. Thomas, 1974.

KALMYKOV, L.Z. Materials for thermoluminescent dose detectors and photon radiation energy detectors intendend for intercomparison procedures of radiation therapy units. Med. Phys., v. 21, n. 11, p. 1715-1719, 1994.

KEHWAR, T. S.; BHARDWAJ, A. K.; CHAKARVARTI, S. K. Evaluation of dosimetric effect of leaf position in a radiation field of an 80 leaf multileaf collimator fitted to the LINAC head as a tertiary collimator. Appl. Clin. Med. Phys., v. 7, n.ำ, p. 43-54, 2006.

KHAN, F.M. The physics of radiation therapy. 2.ed. Baltimore, Maryland: Williams \& Wilkins, 1994.

KNOLL, G.F. Radiation Detection and Measurement. 3 ed. New York, USA: John Wiley \& Sons. Inc. 2000.

KNÖÖS, T., AHLGREN, L.; NILSSON, M. Comparison of measured and calculated absorbed doses from tangential irradiation of the breast. Radiother. Oncol. v.7, p. 8188, 1986.

KRON, T. Applications of thermoluminescence dosimetry in medicine. Radiat. Prot. Dosimetry, v. 85, n. 1-4, p. 333-340, 1999.

KRON, T.; ELLIOT, A., WONG, T., SHOWELL, G., CLUBB, B.; METCALFE, P. X-ray surface dose measurements using TLD extrapolation. Medical Physics, v.20, p.703-711, 1994.

KUTCHER, G.; COIA, L; GILLIN, M.; HANSON, W.F.; LEIBEL, S.; MORTON, R.J.; PALTA, J.R.; PURDY, J.A.; REINSTEIN, L.E.; SVENSSON, G.K.; WELLER, M.; WINGFIELD, L. Comprehensive QA for Radiation Oncology: Report of AAPM. Radiation Therapy Committee Task Group 40. Med. Phys. 21:581-618, 1993.

LAKSHMANAN, A.R.; KHER, R.K.; SUPE, S.J. Estimation of effective dose equivalent using individual dosimeters. Rad. Prot. Dosimetry. v. 35, p. 247-253, 1991.

LEUNENS, G.; VAN DAM, J.; DUTREIX, A.; VAN DER SCHUEREN, E. Quality Assurance in Radiotherapy by In Vivo Dosimetry. Determination of the Target Absorbed Dose.

Radioth. Oncol. 19: 73-87, 1990.

LIVINGSTONE, J.; HOROWITZ,Y. S.; OSTER, L.; DATZ, H.; LERCH, M.; ROSENFELD, A; OROWITZ; A. Experimental investigation of the $100 \mathrm{keV}$ x-ray dose response of the high-temperature thermoluminescence in LiF:Mg,Ti (TLD-100):theoretical interpretation using the unified interaction model. Radiation Protection Dosimetry. v. 138, no. 4, p. 320-333, 2010. 
MACKINLAY, A. F. Thermoluminescence Dosimetry. Medical Physics

MAHESH, K.; WENG, P. S.; FURETTA, C. Thermoluminescence in Solids and its applications. Ashford: Nuclear Technology Publishing, 1989.

MANSFIELD, C.M.; SUNTHARALINGAM, N. Thermoluminescence dosimetry in radiation oncology. Appl. Radiol., v. 2, p. 43-48, 1976.

MATSUSHIMA, L.C. Avaliação da resposta de detectores termoluminescentes na dosimetria de feixes clínicos utilizando diferentes simuladores. 2010. Dissertação (Mestrado) - Instituto de Pesquisas Energéticas e Nucleares, São Paulo.

McKEEVER, S.W.S. Thermoluminescence of Solids. Cambridge, England: Cambridge University Press, 1985.

McKEEVER, S.W.S.; MOSCOVITCH, M.; TOWNSEND, P.D. Thermoluminescence dosimetry materials: Properties and uses. Ashford, Kent: Nuclear Technology Publishing, 1995.

MEIJVOGEL, K. VAN DER BURG, B.; BOS, A.J.J. Intrinsic efficiencies of TL materials. Radiat. Prot. Dosim. 65, 117-122.

METCALFE, P.; KRON, T.; HOBAN, P. The Physics of Radiotherapy X-rays from Linear Accelerators. Madison, WI: Med. Phys, 2007.

MOSCOVITCH, M.; HOROWITZ, Y. S. Thermoluminescent materials for medical applications: LiF:Mg,Ti and LiF:Mg,Cu,P. Radiation Measurements. v. 41, n. 1, p. S71-S77, 2007

NELSON, V. K.; McLEAN, I. D.; HOLLOWAY, L. Thermoluminescent dosimetry (TLD) for megavoltage electron beam energy determination. Radiation Measurements. v. 45 , p. $698-700,2010$.

NELSON, V. K.; McLEAN, I. D.; HOLLOWAY, L. Use of thermoluminescent dosimetry (TLD) for quality assurance of orthovoltage X-ray therapy machines. Radiation Measurements. v. 43, p. 908-911, 2008.

NUNES, M.G. Avaliação do desempenho dos detectores termoluminescentes de $\mathrm{CaSO}_{4}$ :Dy e LiF:Mg,Ti na dosimetria de feixes clínicos de elétrons. 2008. Dissertação (Mestrado) - Instituto de Pesquisas Energéticas e Nucleares, São Paulo.

OBERHOFER, M.; SCHARMANN, A. Applied Thermoluminescence dosimetry. Ispra, Itália: Adam Hilger Ltd (Commission of the European Communities), 1979.

OLKO, P.; MARCZEWSKA, B.; CZOPYK, L.; CZERMAK M. A.; KŁOSOWSKI, M.; WALIGÓRSKI, M. P. R. New 2-d dosimetric technique for radiotherapy based on planar thermoluminescent detectors. Radiation Protection Dosimetry. v. 118, no 2 , p. 213-218, 2006. 
PEREZ, C.A. Principles and practice of radiation oncology. Lippincott Williams e Wilkins. 2004.

PSZONA, S.; WINCEL, K.; ZAREBA, B. BULSKI, W.; ULKOWSKI, P; TRACZYCK, M. A windowless ionization chamber for soft X-ray dosimetry. Nuclear Instruments and Methods in Physics Research B, v. 268, p. 92-96, 2010.

QUOIRIN, N.S.R. Diagnóstico de amostras de madeira por tomografia de Raios-X. Disponível em: <http://www.oocities.com/tomografiademadeira/index.html> Acesso em: 25 nov 2010.

ROBAR, V.; ZANKOWSKI, C.; OLIVARES, M.P.; PODGORSAK, E.B. Thermoluminescence dosimetry in electron beams: Energy dependence. Med. Phys. v. 23, n. 5, p. 667-673, 1996.

RUDÉN, B. Evaluation of the clinical use of TLD. Acta Raiol. Ther. Phys. Biol., v. 15, p. 447-467, 1976.

SALVAJOLI, J.V., SOUHAMI, L., FARIA, S.L. Radioterapia em Oncologia. Rio de Janeiro, 1999. p.1-118.

SAW, C. B. Foundation of Radiological Physics. Omaha, NE: CBSaw, Inc, 2002.

SCAFF, L.A.M. Física da Radioterapia. São Paulo: Sarvier. 1997.

SPRAWLS, P. Physical Principles of Medical Imaging. 2 ed. Gaithersburg: Aspen Publishers, 1993.

TESSIER, F.; KAWRAKOW, I. Effective point of measurement of thimble ion chambers in megavoltage photon beams. Medical Physics. v. 37, n. 1, p. 96-107, 2009.

VAN DAM, J., MARINELlO, G. Methods for In Vivo Dosimetry in External Radiotherapy. Physics for Clinical Radiotherapy Booklet, 1 1994; ESTRO: Brussels: Belgium.

VENABLES, K.; MILES, E.A.; AIRD, E.G.A.; HOSKIN, P.J. START trial management group. The use of in vivo thermoluminescent dosimeters in the quality assurance programme for START breast fractionation trial. Radiother. Oncol. v. 71, n. ${ }^{\circ}$, p. 303-310, 2004.

VUOLO, J.H. Fundamentos da Teoria de erros. São Paulo: Edgard Blücher, 1992. 